Organoclorados em Toninhas, Pontoporia blainvillei (MAMMALIA:

CETACEA) da região costeira do Estado de São Paulo, Brasil

Dissertação apresentada ao Instituto

Oceanográfico da Universidade de São

Paulo, como parte dos requisitos para

obtenção do título de Mestre em Ciências, área de Oceanografia Química e Geológica.

Orientadora: Profa. Dra. Rosalinda Carmela Montone

São Paulo

2008 
Universidade de São Paulo

Instituto Oceanográfico

\section{Organoclorados em toninhas, Pontoporia blainvillei (MAMMALIA: CETACEA) da região costeira do Estado de São Paulo, Brasil}

\section{Mariana Batha Alonso}

Dissertação apresentada ao Instituto Oceanográfico da Universidade de São Paulo, como parte dos requisitos para obtenção do título de Mestre em Ciências, área de Oceanografia Química e Geológica.

Julgada em $\underline{04} \underline{08} \underline{\underline{2008}}$ por

Profa. Dra. Rosalinda Carmela Montone

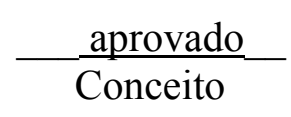

Departamento de Oceanografia Física, Química e Geológica Instituto Oceanográfico - Universidade de São Paulo

Profa. Dra. Mary Rosa Rodrigues de Marchi

aprovado

Departamento de Química Analítica

Conceito

Instituto de Química - UNESP - Araraquara

Dr. Marcos César de Oliveira Santos

aprovado

Departamento de Zoologia

Conceito

Instituto de Biociências - UNESP - Rio Claro

Projeto Atlantis, Laboratório de Biologia da Conservação de Cetáceos 
DEDICO ESSE TRABALHO A MEUS PAIS MARAVILHOSOS QUE SEMPRE ME APOIARAM EM TUDO. OBRIGADA POR ACREDITAREM EM MIM. 
“O QUE É DO HOMEM SEM OS ANIMAIS? SE OS ANIMAIS DESAPARECEREM, O HOMEM MORRERÁ DENTRO DE UMA GRANDE SOLIDÃO. A TERRA É NOSSA MÃE, E TUDO O QUE ACONTECER À TERRA ACONTECERÁ AOS FILHOS DA TERRA. A TERRA Não É do HOMEM; O HOMEM PERTENCE A TERRA. TODAS AS COISAS SÃO DEPENDENTES. NÃO FOI O HOMEM QUE TECEU A TEIA DE SUA VIDA. ELE NÃO PASSA DE UM FIO DESSA TEIA. TUDO O QUE FIZER PARA ESSA TEIA ESTARÁ FAZENDO A SI MESMO" ÍNDIO SEATTLE 


\section{AGRAdeCIMENTOS}

Agradeço a realização deste trabalho em primeiro lugar a Deus Todo-Poderoso, por me dar saúde física, mental e espiritual, e sempre me ajudar em todos os meus momentos de decisões. Agradeço muito a meus pais pelo subsídio desde os tempos de Ensino Fundamental, Médio, Cursinho Graduação, sempre me oferecendo a melhor formação e respeitando minha liberdade de escolha. Obrigada por estarem sempre a meu lado me ajudando em tudo!

Agradeço a meus familiares por acreditarem que a pesquisa com Cetáceos neste país tem futuro, e que os animais necessitam de seres humanos preocupados com sua proteção e preservação.

Agradeço a todas as Instituições que contribuíram na minha formação profissional, na Graduação à Universidade Presbiteriana Mackenzie (São Paulo, SP) e à Universidade Santa Cecília (UNISANTA - Santos, SP).

Agradeço muitíssimo ao Instituto Oceanográfico pelo excelente conteúdo das disciplinas aqui cursadas na Pós-Graduação, especialmente à minha orientadora pelo carinho, atenção, compreensão, paciência, instrução e exemplo de profissional que ela é. Além de amiga e conselheira. Em especial também o pessoal do Laboratório de Química Orgânica Marinha (LabQOM), melhor laboratório do IO, onde todo mês tem comemorações, festinhas, reuniões, almoços, jantares, lanches! O pessoal é muito unido e todos sempre foram muito carinhosos comigo, amo todos vocês! Minha querida amiga Satie Taniguchi, exemplo de profissional também e de paciência em todos os aspectos, incluindo, com os equipamentos (ai esses cromatógrafos...), meus errinhos no laboratório, nas minhas opiniões e desabafos... Márcia e Verinha, também amo vocês. Lourival, Silvio, e todos os alunos da Pós (Ana Cecília, Fernanda, Mauro, Hiléia, Vinicius, Eliete, Caios, Edgar, Josi, Diego), Prof. Rolf e estagiários.

Ao órgão financiador de minha pesquisa e minha bolsa de estudos, muito obrigada à Fundação de Amparo à Pesquisa do Estado de São Paulo (FAPESP) que proporcionou que isso fosse possível.

A todos os integrantes do Projeto BioPesca: Carolina Bertozzi (Carol, minha amigona que me introduziu no mundo dos cetáceos, sempre disposta a ajudar em tudo, inclusive necrópsias noite adentro, me ensinou a amar as toninhas mais ainda - Praia Grande), Juliana Marigo (JuMarigo - Ubatuba), Valéria Ruoppolo (Vali- SP), Fernanda Marcatto (Fe - Guarú), Janaína Ribeiro (Jana - Mongaguá), Juliana Vioto (JuVioto Itanhaém), Bárbara Henning (Babi - UBT), Lélinho (UBT).

A todos os Pescadores que viraram meus grandes amigos e os colegas também: Praia das Astúrias (Guido e toda a família, incluindo os agregados) e pessoal da Peixaria e Praia do Perequê (Xaréu e família), Guarujá; Entreposto de Santos (Nino e todos mestres e pescadores de emalhe do TPS) e a todos os outros que sempre me receberam muito bem e me ensinaram um pouquinho de sua árdua profissão e cultura caiçara. $\mathrm{O}$ Seu Rubão, da colônia Z3 (Vicente de Carvalho) que nos levou (Eu e Samuel) 2 anos em saídas de campo para vermos os Sotalia do Porto de Santos, e me fez amar o Estuário de Santos.

Ao Bill Rossiter da Cetacean Society International (CSI) e a Society for Marine Mammalogy (SMM) por financiar nosso projeto e idas às Bienais (Conferências Bianuais de Biologia de Mamíferos Marinhos) em Greensboro, NC; San Diego, CA e Cape Town, África do Sul. À PADI (Project AWARE), EUA; Fundação o Boticário, Brasil e YaquPacha, Alemanha por ajudar financeiramente o BioPesca. 
Agradeço a todos veterinários que me ensinaram a fazer as necrópsias e coletar tudo o que você imagina e não imagina (Vali e Ju Marigo), as vets da USP (Paty, Ju Savioli).

Ao Dr. Marcos César O. Santos, por ter sido meu inicio no mundo dos cetáceos com estágios e saídas de campo pelo Projeto Atlantis, por inúmeros conselhos científicos, por ter me indicado como consultora ambiental da EMBRAPORT, por ter aceitado meu convite de fazer barca da banca.

Ao Instituto Baleia Jubarte, a Márcia Engel, Milton, em especial aos meus amigos Luiza Pacheco e Marcos Rossi-Santos, que me proporcionaram os melhores embarques e as melhores avistagens de cetáceos, incluindo os oceânicos (Cruzeiros em Abrolhos, BA, no ES e Cruzeiros do Sudeste no navio oceanográfico). Ao Ignácio Moreno (Ig) e Daniel Danilewitz (Dani) do Gemars, RS, por terem me ensinado muito no cruzeiro, inclusive a fazer biópsias, e Ig por ter me emprestado o livro do Aguilar e Borrell que ganhou de presente pessoalmente.

Meus grandes amigos Samuel Farias-Junior e Fernanda Marcatto, por nos aventurarmos no mundo dos cetáceos juntos no Guarujá, como é bom ir pro campo.

Meu orientador da monografia da graduação Dr. Mario Rollo (UNESP - São Vicente, SP) por ter me ensinado também muito a respeito dos cetáceos.

Ao David Janinger (Natural History Museum of Los Angeles, EUA), por mandar tantos papers quanto forem solicitados.

Ao Dr. Peter Best (Whale Unit c/o South African Museum, Cape Town, AS) que na minha monografia de graduação me ensinou que Paciência é uma virtude"e me mandou inúmeros papers antigos de cetáceos.

Ao Dr. Peter Ross (Canadá) que me deu ótimos conselhos na minha apresentação do pôster deste trabalho na Bienal da África do Sul.

Á Unaerp e Fundação Fernando Lee, do Guarujá, que me proporcionou avistagens na Ilha dos Arvoredos, Guarujá, SP.

Aos amigos Bruno Mourato e Mauricio, que ajudaram na época de coleta dos exemplares (PROELASMO, Guarujá).

A Consultoria Paulista de Estudos Ambientais (CPEA) por terem me contratado para realização de consultoria ambiental de Monitoria dos Botos-Cinza no Estuário de Santos, pela EMBRAPORT.

Aos Professores Élio Lopes e JR Freitas-Guimarães da Pos de Gestão Ambiental da UNISANTA, que me orientaram na monografia sobre a Revisão da Contaminação do Estuário de Santos.

A Rede Record que me convidou para fazer uma consultoria cientifica no documentário Os Golfinhos (Alfredo) enquanto estava no mestrado.

A UNIMONTE (Curso de Oceanografia e Veterinária) que auxiliou no local de necrópsias e me convidaram para ministrar uma palestra.

Ao Curso de Difusão Cultural: "Noções sobre Oceanografia" - Excursão Ecológica - Local: Base do IOUSP "Dr. João de Paiva Carvalho”, Cananéia, SP.

Ao Prof Salvatore Siciliano que me convidou para participar do Workshop on Research and Conservation of the Genus Sotalia, Armação dos Búzios, RJ, Brasil, em 2006.

Ao Dr. Alexandre Zerbini que sempre me auxiliou nos trabalhos científicos.

Ao Prof. Dr. Thomas O'Shea que me enviou gentilmente um antigo artigo cientifico (1980) para este trabalho.

Ao meu querido Ricardo Thomas e família (Niterói, RJ), que me ajudaram nessa trajetória, a Isabel do Projeto Natação no Mar, de Rio das Ostras, RJ que me convidou para dar uma palestra sobre Poluição e os cetáceos. 
Ao Prof. Jose Laílson Brito JR e a Bernardete Fragoso (Berna), UERJ - MAQUA, que me deram interessantes conselhos e auxílios nesse trabalho.

As minhas queridas amigas do Litoral e de Sampa: Vivian, Vivi, Kalu, Flávia, Fefe, valeu por me agüentarem tantas horas falando desse assunto. A todos amigos biólogos, que lutam por um mundo melhor.

E como não poderia deixar de agradecer, aos magníficos cetáceos, por existirem e serem animais tão inteligentes, sociáveis, e misteriosos como os oceanos, obrigada por acrescentarem beleza, inteligência e alegria aos ambientes aquáticos!

E a todos, valeu por tudo!!! 


\section{SUMÁRIO}

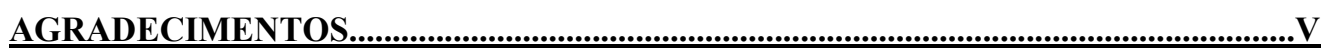

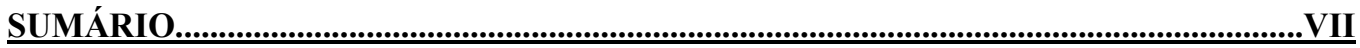

LISTA DE FIGURAS $\quad X$

\begin{tabular}{ll} 
LISTA DE TABELAS & XI \\
\hline
\end{tabular}

RESUMO

XII

ABSTRACT

XIII

1 INTRODUCÃO

\section{1}

1.1 COMPOSTOS ORGANOCLORADOS 1

1.1.1 PESTICIDAS ORGANOCLORADOS 2

$\begin{array}{ll}\text { 1.1.1.1 Diclorodifeniltricloroetanos (DDTs) } & 2\end{array}$

1.1.1.2 Hexaclorobenzeno (HCB) 4

1.1.1.3 Hexaclorociclohexanos (HCHs) 4

$\begin{array}{lll}\text { 1.1.1.4 Clordanas (CHLs) } & 4\end{array}$

1.1.1.5 Mirex 5

1.1.2 COMPOSTOS INDUSTRIAIS 6

1.1.2.1 Bifenilos Policlorados (PCBs) 6

$\begin{array}{lll}\text { 1.1.3 ALTERADORES ENDÓCRINOS } & 7\end{array}$

$\begin{array}{llr}1.2 & \text { MAMÍFEROS MARINHOS } & 8\end{array}$

$\begin{array}{ll}\text { 1.2.1 TONINHAS (Pontoporia blainvillei) } & 10\end{array}$

1.3 COMPOSTOS ORGANOCLORADOS EM MAMÍFEROS MARINHOS 13

1.3.1 EFEITOS DOS ORGANOCLORADOS NOS MAMÍFEROS MARINHOS $\quad 14$

1.4 ORGANOCLORADOS NO LITORAL DE SÃO PAULO 15

1.4.1 BAIXADA SANTISTA 16

$\begin{array}{lll}1.4 .2 & 17\end{array}$

$\begin{array}{llr}1.4 .3 & \text { LITORAL SUL } & 18\end{array}$

$\begin{array}{llr}1.5 & 19\end{array}$ 
$\begin{array}{lll}2.1 & \text { AMOSTRAGEM } & 19\end{array}$

2.2 ANÁLISE DE ORGANOCLORADOS 23

2.2.1 Cuidados Analíticos 23

2.2.1.1 Limpeza do Material 23

2.2.1.2 Tratamento dos Reagentes 23

2.2.1.3 Soluções Padrão de Organoclorados 24

2.2.1.4 Condições Cromatográficas 24

2.2.1.4.1 GC-ECD 24

2.2.1.4.2 GC-MS 24

2.2.1.5 Identificação e Quantificação dos Analitos 25

2.2.1.5.1 Curva Analítica 26

2.2.2 PROCEDIMENTO ANALÍTICO 26

2.2.2.1 Extração em Homogeneizador UltraTurrax 27

2.2.2.2 Tratamento com Ácido Sulfúrico 27

2.2.2.3 Estimativa da Quantidade de Lípídios Extraíveis 28

2.2.3 LIMITE DE DETECÇÃO DO MÉTODO (LDM) 29

2.2.4 VALIDAÇ̃̃O DA METODOLOGIA ANALÍTICA 30

2.2.4.1 Controle de Qualidade 30

3 RESULTADOS E DISCUSSÃO

3.1 ORGANOCLORADOS EM GORDURA DE TONINHAS

3.1.1 CONCENTRAÇAO DOS COMPOSTOS VERSUS DADOS BIOLÓGICOS 34

3.1.1 DIFERENÇAS ENTRE AS LOCALIDADES 48

3.2 CONCENTRACAO DE POLUENTES EM COMPARAÇÃO COM TONINHAS DE OUTRAS LOCALIDADES (INTRA-ESPECÍFICA)

3.3 CONCENTRACAO DE POLUENTES EM COMPARAÇÃO COM OUTROS

CETÁCEOS (INTER-ESPECÍFICA)

4 CONCLUSÕES $\quad 63$

5 CONSIDERAÇÕES FINAIS $\quad 64$

6 REFERÊNCIAS BIBLIOGRÁFICAS $\quad 65$ 


\section{LISTA DE FIGURAS}

Figura 1.1. Toninha (Pontoporia blainvillei). $A$ - indivíduo adulto, $B$ - filhote, encalhe vivo

Figura 1.2 Mapa de distribuição da espécie e suas áreas de manejo (FMA). (Modificado de Secchi et al., 2003)

Figura 2.1. Mapa do litoral do Estado de São Paulo, Sudeste do Brasil.

Figura 2.2 A. Toninhas ( $P$. blainvillei) capturadas acidentalmente em rede de pesca no entreposto de Santos, SP. B. Encalhe de P. blainvillei em Guarujá, SP, com evidência de emalhe em rede de pesca 20 Figura 2.3 Toninhas (P. blainvillei) A. fêmea adulta (BP 50). B. filhotes, fêmea (BP 89) e macho (BP 88), respectivamente, capturados na mesma rede de pesca. C. tecido adiposo subcutâneo blubber (seta). D. feto de fêmea (BP 152) capturada acidentalmente em rede de pesca.

Figura 3.1. Concentrações médias de DDTs (ng/g lipídios) em toninhas (P. blainvillei) machos e fêmeas em diferentes faixas etárias.

Figura 3.2. Concentrações médias de pesticidas organoclorados (em ng. $\mathrm{g}^{-1}$ de lipídios) em toninhas (P. blainvillei) machos e fêmeas em diferentes faixas etárias.

Figura 3.3. Concentrações médias de PCBs (em ng. $\mathrm{g}^{-1}$ de lipídios) em toninhas (P. blainvillei) machos e fêmeas em diferentes faixas etárias.

Figura 3.4 Porcentagem relativa dos congêneres de PCB (números IUPAC) em machos e fêmeas de toninhas de São Paulo

Figura 3.5 Porcentagem relativa dos PCBs de acordo com o número de cloros na molécula, em machos e fêmeas de toninhas de São Paulo.

Figura 3.6 Porcentagem relativa de DDT e seus metabólitos nas toninhas do litoral paulista, machos e fêmeas de acordo com suas faixas etárias.

Figura 3.7 Porcentagem relativa das clordanas nas toninhas do litoral paulista, machos e fêmeas, de acordo com suas faixas etárias.

Figura 3.8 Diferenças entre machos e fêmeas nas composições das clordanas na gordura das toninhas $(P$. blainvillei) do litoral paulista.

Figura 3.9 Porcentagem dos HCHs na gordura das toninhas (P. blainvillei) do litoral paulista, machos e fêmeas, de acordo com suas faixas etárias.

Figura 3.10 Concentração de DDTs, PCBs, HCB, Mirex, HCHs e CHLs (ng.g ${ }^{-1}$ lipídios) na gordura de $P$. blainvillei machos e fêmeas do litoral paulista relacionados com o comprimento total dos animais. 46 Figura 3.11 Médias das concentrações dos PCBs de 3 e 4 cloros, nos machos de toninha das 3 regiões do litoral paulista. 


\section{LISTA DE TABELAS}

Tabela 2.1. Dados biológicos de toninhas (P. blainvillei) machos analisados neste estudo no período de 2001 a 2007

Tabela 2.2. Dados biológicos de toninhas (P. blainvillei) fêmeas analisadas neste estudo no período de 2001 a 2007.

Tabela 2.3. Número de indivíduos de toninhas (P. blainvillei) analisados e suas porcentagens relativas por regiões do litoral do Estado de São Paulo, Brasil.

Tabela 2.4. Limite de deteç̧ão do método (LDM) para cada composto em estudo.

Tabela 2.5. Recuperação (\%) dos pesticidas organoclorados no branco e nas réplicas da matriz. 31

Tabela 2.6. Recuperação (\%) dos PCBs no branco e nas réplicas da matriz. 31

Tabela 2.7. Recuperação (\%) dos padrões internos PCB 103 e 198 nas amostras. 32

Tabela 2.8. - Validação da metodologia otimizada para os compostos (baseada nos valores de concentração certificada pelo SRM 1945).

Tabela 3.1. Concentração de pesticidas organoclorados (ng.g ${ }^{-1}$ lipídios) na gordura subcutânea de toninhas (P. blainvillei) machos do litoral paulista.

Tabela 3.2. Concentração de pesticidas organoclorados (ng.g ${ }^{-1}$ lipídios) na gordura subcutânea de toninhas (P. blainvillei) fêmeas do litoral paulista.

Tabela 3.3. Concentração de PCBs (ng.g ${ }^{-1}$ lipídios) e razão DDTs/PCBs na gordura subcutânea de toninhas (P. blainvillei) machos do litoral paulista.

Tabela 3.4. Concentração de PCBs (ng.g ${ }^{-1}$ lipídios) e razão DDTs/PCBs na gordura subcutânea de toninhas (P. blainvillei) fêmeas do litoral paulista.

Tabela 3.5. Comparação intra-específica de concentrações de compostos organoclorados em gordura de toninhas (P. blainvillei) expressos em ng. $\mathrm{g}^{-1}$ de peso lipídico.

Tabela 3.6. Médias, máximo e mínimo de concentrações de HCHs, HCB e mirex em cetáceos de diversas regiões do planeta (em ug. $\mathrm{g}^{-1}$ lipídios).

Tabela 3.7. Médias, máximo e mínimo de concentrações de PCBs e DDTs em cetáceos de diversas regiões do planeta (em ug.g ${ }^{-1}$ lipídios). 


\section{RESUMO}

Os organoclorados constituem um dos principais grupos de poluentes que afetam os ecossistemas devido a sua grande persistência no ambiente e toxicidade para os organismos. A toninha, Pontoporia blainvillei, é um cetáceo costeiro, o único golfinho brasileiro considerado ameaçado de extinção por conta das atividades antrópicas. $\mathrm{O}$ objetivo desse trabalho foi avaliar a ocorrência de organoclorados em amostras de gordura subcutânea de indivíduos de Pontoporia blainvillei coletados na região costeira do Estado de São Paulo. A metodologia de extração e purificação das amostras foi testada e otimizada conforme procedimentos descritos na literatura. Foram realizadas as análises em 53 amostras de toninha (Pontoporia blainvillei): 29 machos e 24 fêmeas. Todas as concentrações de organoclorados apresentaram valores maiores nos machos, em comparação com as fêmeas de mesma maturidade. As concentrações dos compostos organoclorados nas toninhas do litoral paulista variaram, em ng. $\mathrm{g}^{-1}$ lipídios nos PCBs de 326 a 42.185, DDTs de 107 a 7.185, HCHs n.d. a 46, CHLs n.d. a 126, HCB < 2 a 133 e Mirex $<7$ a 259. A razão DDTs/PCBs foi menor que 0,6 indicando uma maior contribuição industrial do que agrícola na área de estudo. Houve diferenças significativas dos valores dos OCs nas toninhas das localidades do litoral de São Paulo, com as maiores concentrações ocorrendo na Baixada Santista.

Palavras-chave: Poluentes, organoclorados, POPs, Toninha (Pontoporia blainvillei), Estado de São Paulo. 


\begin{abstract}
Organochlorines are one of the main pollutant groups that affect the ecosystems due to their environmental persistence and toxicity to the organisms. Franciscana dolphin, Pontoporia blainvillei, is a coastal cetacean, the only Brazilian dolphin considered threatened with extinction, due to the human activities. The aim of this work was evaluate the occurrence of organochlorines in the blubber samples of Pontoporia blainvillei collected on the coast of São Paulo State. The extraction and purification methodology was tested and optimized according to proceedings described in literature. A total of 53 individuals were analyzed: 29 males and 24 females. Organochlorine concentrations were higher in males when comparing to females with the same sexual maturity. PCBs were the predominant compounds (326 - $42185 \mathrm{ng} \mathrm{g}^{-1}$ lipid weight), followed by DDTs (107 - $7185 \mathrm{ng} \mathrm{g}^{-1}$ lipid wt), HCHs (n.d. - $46 \mathrm{ng} \mathrm{g}^{-1}$ lipid wt), CHLs (n.d. - $126 \mathrm{ng} \mathrm{g}^{-1}$ lipid wt), $\mathrm{HCB}\left(<2-133 \mathrm{ng} \mathrm{g}^{-1}\right.$ lipid wt) and Mirex $\left(<7-259 \mathrm{ng} \mathrm{g}^{-1}\right.$ lipid wt). The ratio DDTs/PCBs was lesser than 0.6 indicating a major industrial than agricultural contribution in the study area. There were significant differences between the OCs values in franciscanas from 3 localities of São Paulo State coast: with the higher concentrations occurring in Baixada Santista.
\end{abstract}

Key words: Pollutants, organochlorines, POPs, franciscana dolphin (Pontoporia blainvillei), São Paulo State. 


\section{INTRODUÇÃO}

Nas últimas décadas, tanto o ambiente terrestre quanto o marinho têm sido afetados por diversas fontes antropogênicas. $\mathrm{O}$ crescimento populacional, a grande produção de alimentos e demanda de materiais novos nas civilizações modernas têm resultado na produção de um grande número de diferentes compostos, sendo muitos deles nocivos aos organismos terrestres e aquáticos (Tanabe et al., 1994). A contaminação ambiental é um dos maiores riscos atuais e futuros ao equilíbrio dos sistemas continentais e costeiros (Windom, 1992). Até a década de 1990, na União Européia 50.000 substâncias químicas estavam em uso, sendo que 4.500 são comprovadamente tóxicas, persistentes e possivelmente bioacumulativas (Edwards, 1992).

Apesar da ampla distribuição dos contaminantes (Windom, 1992; Tanabe et al., 1994; 1998), os ambientes costeiros são os mais afetados pelas atividades industriais e humanas. Os principais problemas crônicos de poluição marinha são devido ao lançamento de grandes volumes de resíduos nas águas costeiras através de esgotos, de efluentes industriais e do defluxo terrestre (Tommasi, 1988). Muitas substâncias introduzidas nos corpos hídricos litorâneos acabam depositando-se nos sedimentos, em concentrações superiores àquelas encontradas na coluna d'água. Os efeitos dessa contaminação foram por muito tempo ignorados, porém sabe-se que os sedimentos podem ser fonte de contaminantes para os organismos bentônicos e para toda a cadeia trófica marinha (Abessa et al, 1998).

Os organoclorados são um dos principais grupos de poluentes que afetam os ecossistemas devido à sua grande persistência no ambiente e toxicidade para os organismos (Johnston, 1976; Clark, 2001; Albaigés, 1990; Tanabe et al., 1994; Marsili \& Focardi, 1996).

\subsection{COMPOSTOS ORGANOCLORADOS}

Os organoclorados (OCs) fazem parte de um grupo de compostos conhecidos mundialmente como POPs (poluentes orgânicos persistentes), que são compostos químicos resistentes a degradação fotoquímica, química e biológica. Sendo assim, estão incluídos nas listas dos poluentes prioritários ao impacto da saúde humana e do ambiente pela Agência de Proteção Ambiental dos Estados Unidos, USEPA (Jones \& Voogt, 1999). 
Entre os organoclorados incluem-se os pesticidas (DDTs, HCHs, HCB, entre outros) e os Bifenilos Policlorados (PCBs), ambos grupos de compostos altamente persistentes e que uma vez no ambiente apresentam processos de bioacumulação e biomagnificação ao longo da cadeia trófica, como conseqüência da sua afinidade a lipídios e resistência a biodegradação. Portanto podem ser encontrados em concentrações em organismos como cetáceos e outros mamíferos marinhos, dez milhões de vezes a sua concentração na água (Tanabe \& Tatsukawa, 1992).

Em 1985, os hidrocarbonetos clorados foram proibidos por lei no Brasil, entretanto seu uso para propósitos de saúde pública podem vir a ser liberados. Eles foram utilizados em grande escala durante a década de 1970 e início da década de 1980 (Brasil, 1985).

O transporte atmosférico e a circulação oceânica levam esses contaminantes até as partes mais remotas do globo, não se limitando a contaminação somente às regiões associadas ao seu uso (áreas agrícolas, industriais e portuárias). Como resultado das propriedades físico-químicas dos organoclorados e condições meteorológicas globais, existe um transporte atmosférico preferencial das regiões tropicais, onde estes contaminantes são ainda comumente empregados, para as regiões temperadas e polares. Este processo é conhecido como destilação global (Iwata et al., 1993).

\subsubsection{PESTICIDAS ORGANOCLORADOS}

Os pesticidas, também denominados defensivos agrícolas ou agrotóxicos, possuem formulações químicas diversificadas, sendo classificados de acordo com seu uso (inseticida, herbicida, fungicida, algicida, acaricida, etc.) ou por sua natureza química. Dentre os orgânicos, os que têm maior significado ambiental são os organoclorados, organofosforados e carbamatos, todos substâncias tóxicas (Lamparelli et al, 2001).

Os organoclorados (OCs) estão entre os grupos principais de praguicidas, juntamente com os compostos organofosforados e carbamatos, que apesar de serem muito úteis no controle de vetores de doenças transmissíveis, na redução de plantas aquáticas em reservatórios, e na agricultura, também causam sérios danos ao ambiente. Alguns apresentam efeitos persistentes no ambiente, e se acumulam nos tecidos gordurosos dos organismos, outros são metabolizados (CETESB, 1978).

As maiores fontes de praguicidas na água são a drenagem de terras tratadas, as descargas de indústrias, o despejo doméstico, e neste caso, a manipulação e transporte destas substâncias na área portuária (CETESB, 1978). 


\subsubsection{Diclorodifeniltricloroetanos (DDTs)}

O grupo dos DDTs é o mais conhecido dentre os pesticidas organoclorados, incluem os derivados clorados do difenil etano (entre eles o DDT, e seus metabólitos DDD e DDE e o metoxicloro). O DDT é considerado uma das substâncias sintéticas mais utilizadas e estudadas no século XX (D’Amato et al., 2002).

A mistura técnica de DDT é formada por 75\% de p,p'-DDT, 15\% de o,p'-DDT, $5 \%$ de $p, p^{\prime}$-DDE, $<0,5 \%$ de $o, p^{\prime}-\mathrm{DDE},<0,5 \%$ de $p, p^{\prime}$-DDD e $<0,5 \%$ de $o, p^{\prime}$-DDD (WHO, 1979). Uma vez no ambiente ou nos organismos, o DDT pode sofrer transformações por duas vias: uma oxidativa e uma redutiva. Na via oxidativa, o p,p'DDT perde um átomo de cloro e outro de hidrogênio, transformando-se em $p, p$ '-DDE. $\mathrm{Na}$ via redutora há a perda de apenas um átomo de cloro da molécula de $p, p$ 'DDT e a adição de um átomo de hidrogênio, formando-se o $p, p$ '-DDD. Porém, apesar de existirem duas vias de degradação, a maior parte dos DDTs encontrados no mar e $80 \%$ dos presentes nos organismos marinhos estão na forma de $p, p^{\prime}$-DDE e provavelmente quase a totalidade é derivada da degradação de p,p’-DDT (Clark, 2001). O DDT tem demonstrado ter uma atividade próxima a do estrogênio e possível atividade carcinogênica em humanos (UNEP, 2002).

A produção em grande escala iniciou-se em 1945, e foi muito utilizado na agricultura como pesticida por cerca de 30 anos. Outra função de seu uso foi em programas de controle de doenças tropicais, inclusive no Brasil, como a malária e a leishmaniose visceral. A descoberta do DDT revolucionou a luta contra a malária. Sua eficiência contra a forma adulta dos mosquitos e seu prolongado efeito residual fez com que no período de 1946-1970 todos os programas de controle de vetores se apoiassem no seu emprego (D'Amato et al., 2002).

No Brasil, as primeiras medidas restritivas ocorreram em 1971, que proibiu a fabricação e comercialização do DDT e o uso de inseticidas organoclorados no controle de pragas em pastagens (Brasil, 1971a; 1971b). Em 1985 foi proibida a comercialização, o uso e a distribuição de organoclorados destinados à agropecuária em todo território nacional. Mas continuaram a ser permitidos em campanhas de saúde publica no combate aos vetores da malária e leishmaniose, bem como em uso emergencial na agricultura, a critério do Ministério da Agricultura (Brasil, 1985). Seu uso em saúde publica ficou sob responsabilidade da Fundação Nacional de Saúde (FUNASA), e a última compra foi um 
lote de 3 mil toneladas em 1991 para controle do mosquito vetor de malária (Anopheles darlingi) na Amazônia (D‘Amato, 2002).

\subsubsection{Hexaclorobenzeno (HCB)}

Foi primeiramente introduzido em 1945 como fungicida no tratamento de sementes nas colheitas de grãos, e utilizado na fabricação de fogos de artifício, munição e borracha sintética. Hoje é principalmente um subproduto na produção de inúmeros compostos clorados, particularmente benzeno com poucos cloros como substituintes, solventes e vários pesticidas. O HCB é emitido para a atmosfera na forma de vapor gerado pela incineração de lixo e em indústrias metalúrgicas. O HCB é conhecido por causar doenças no fígado em humanos e vem sendo classificado com possível potencial carcinogênico para os mesmos pela Agência Internacional para a Pesquisa do Câncer (IARC) (UNEP, 2002).

\subsubsection{Hexaclorociclohexanos (HCHs)}

$\mathrm{O} \mathrm{HCH}$ foi um inseticida utilizado na agricultura e no ambiente doméstico, bastante difundido nos anos 1960 e 1970 em todo o mundo. Por ser um composto de alta persistência no ambiente, encontra-se presente nos estuários e oceanos, mesmo tendo sido interrompida sua fabricação na maioria dos países produtores no início ou meados da década de 1980. Existem diversos isômeros de $\mathrm{HCH}$, identificados por letras gregas (alfa, beta, gama, delta). O composto de maior ação inseticida é o gama-HCH, cujo produto comercial, de nome técnico lindano, contém pequenas quantidades de outros isômeros. Por ter sido o mais utilizado, é o que tem maior expressão ambiental. Os demais produtos comerciais são uma mistura de dois ou mais isômeros (Lamparelli et al., 2001). O lindano não demonstrou ter potencial carcinogênico em inúmeros estudos, mas apresentou atividade de alteração endócrina (UNEP, 2002).

\subsubsection{Clordanas (CHLs)}

Entre as clordanas encontram-se o endosulfan (isômeros $\alpha$ e $\beta$ ), o metoxicloro, o heptacloro, heptacloro epóxido, clordana e oxiclordana. Neste estudo serão enfatizados a clordana (isômero $\gamma$ ), a oxiclordana e o heptacloro.

A clordana foi formulada em 1945 e foi usada primariamente como inseticida 
para o controle de baratas, formigas, cupins, e outras pragas. A clordana técnica é uma mistura de pelo menos 120 compostos. Destes, 60-75\% são isômeros da clordana, o restante está relacionado a endo-compostos compreendendo heptacloro, nonacloro, ciclopentadieno e penta/hexa/octaclorociclopentadienos. A clordana foi classificada como uma substância para a qual há evidência da alteração endócrina em organismos e carcinogenicidade possível aos seres humanos (UNEP, 2002). A oxiclordana é um metabólito persistente da clordana técnica em mamíferos marinhos (Dearth \& Hites, 1991).

O heptacloro foi usado principalmente na década de 1960 e 1970 para o controle de cupins e formigas. É o maior componente das formulações técnicas das clordanas (Vorkamp et al., 2004). É degradado no ambiente para heptacloro epóxido que possui maior persistência e toxicidade. No Brasil, o heptacloro tem seu uso autorizado na agricultura, especialmente em plantações de cana-de-açúcar. De 1996 a 2002, aproximadamente 210 toneladas dessa substância foi importada pelo Brasil (UNEP, 2002). É considerado moderadamente tóxico pela classificação da USEPA e tem meiavida de dias a semanas no ambiente. A toxicidade aguda do heptacloro aos mamíferos é moderada e aos organismos aquáticos é mais elevada. A informação disponível está limitada aos efeitos em humanos e os estudos são inconclusivos a respeito do heptacloro e câncer (UNEP, 2002).

\subsubsection{Mirex}

O uso de formulações de Mirex começou em meados dos anos 1950 na maior parte para o controle das formigas. É também utilizado como retardante de chamas para plásticos, borracha, pintura, papel e bens elétricos. As preparações técnicas de mirex contêm $95,19 \%$ de mirex, $2,58 \%$ de clordecone e o restante não é especificado. A toxicidade aguda de Mirex para mamíferos é moderada. O mirex é igualmente tóxico para peixes e pode afetar seu comportamento. Há evidência de seu potencial para a alteração endócrina e possivelmente do risco carcinogênico aos seres humanos (UNEP, 2002).

É considerado um dos pesticidas mais estáveis e persistentes no ambiente, com uma meia-vida no solo de até 10 anos. Altamente lipofílico, agudamente tóxico para organismos aquáticos e pode levar à imunossupressão e a deficiências reprodutivas (de 
Marche et al., 1998; Vorkamp et al., 2004). Foi banido nos EUA e Canadá em 1978, onde foi usado principalmente como inseticida e retardante de chamas (Vorkamp et al., 2004).

\subsubsection{COMPOSTOS INDUSTRIAIS}

\subsubsection{Bifenilos Policlorados (PCBs)}

Dentre os mais importantes poluentes organoclorados nos ambientes marinhos, destacam-se os bifenilos policlorados (PCBs), um grupo de compostos sintéticos de hidrocarbonetos halogenados que apresentam um número variável de átomos de cloro ligados aos anéis aromáticos. Existem 209 congêneres formados pela ligação de um ou mais átomos de cloro aos átomos de carbono. As propriedades únicas que estas substâncias apresentam, ou seja, estabilidade química, miscibilidade com compostos orgânicos, alta constante dielétrica, não inflamabilidade e baixo custo, fizeram com que estes compostos fossem amplamente utilizados como fluidos dielétricos de transformadores e capacitores, trocadores de calor, fluidos hidráulicos, lubrificantes, retardantes de fogo, plásticos e outros materiais (Lamparelli et al., 2001).

Os produtos comerciais contendo PCBs, tais como o Ascarel e o Aroclor, são uma complexa mistura contendo de 18 a $79 \%$ de cloro. Nos Estados Unidos, as misturas complexas destes compostos são comercializadas com o nome técnico de Arocloros. O tipo de Arocloro é identificado pela porcentagem de cloro presente nas misturas. Assim, por exemplo Aroclor 1221 e 1268 são manufaturados pela cloração de bifenilos, tendo uma porcentagem variando de 21 e $68 \%$ de cloro, respectivamente (Lamparelli et al., 2001).

Os PCBs co-planares têm uma configuração molecular plana que lhe confere grande toxicidade. Os efeitos tóxicos das formulações técnicas dos PCBs geralmente são devido a presença de traços dos 20 possíveis congêneres co-planares (Rejinders, 1996).

Borlakoglu e Dills (1990) notaram que mais de 100 congêneres podem ser formados em qualquer mistura técnica de PCBs e os maiores efeitos tóxicos são associados aos não-orto-substitutos PCBs co-planares (PCB 77, 81, 126, 169). Eles têm a capacidade de se ligar aos receptores protéicos e isto envolve metabolismos hormonais (Hansen, 1994).

Estima-se que entre os PCBs co-planares, os congêneres mono-orto podem contribuir com grande impacto tóxico em mamíferos marinhos, enquanto os congêneres 
não-orto foram preponderantes em mamíferos terrestres, sugerindo diferentes ações tóxicas de PCBs entre animais marinhos e terrestres (Tanabe et al., 1994).

Tanabe et al. (1994) notaram que os cetáceos têm uma pequena capacidade para degradar hidrocarbonetos clorados através do sistema enzimático citocromo P450 comparado a muitos outros mamíferos, e que os PCBs co-planares representam um problema particular, pois estes isômeros são pobremente degradados por baleias e golfinhos.

A produção e comercialização de PCBs no Brasil está proibida desde 1981 mas capacitores e transformadores contendo PCBs ainda estão em uso, contribuindo para o aporte destes contaminantes para o ambiente aquático (Taniguchi, 1995). Parte dos PCBs retirados de equipamentos elétricos existentes na área industrial de Cubatão foram destinados para incineração no exterior e parte foi encaminhada para depósitos de resíduos e esperam destinação final adequada. Não existem fontes naturais de PCBs, consequentemente, todas as fontes de PCBs estão relacionadas a atividades humanas. Além dos produtos industriais, os PCBs podem estar presentes em emissões atmosféricas resultantes da queima de plásticos e de outros resíduos, sendo freqüentes em incineradores onde o processo de queima é incompleta e na queima de combustíveis e florestas (Lamparelli et al., 2001).

Os PCBs vêm contaminando o ambiente marinho em todo mundo por mais de 50 anos. Neste período esses compostos tornaram-se universalmente distribuídos em ambientes marinhos e estuarinos e ocorrem em quase todas as espécies de plantas e animais marinhos. Estes compostos entram nos ambientes aquáticos por diferentes vias: lixiviação dos depósitos de resíduos e de solos contaminados; lançamentos indevidos de produtos e resíduos nos esgotos domésticos e em despejos industriais; deposição atmosférica na superfície dos corpos d'água; e deposição atmosférica nos solos e vegetação com posterior transporte pelas águas de chuva, atingindo as drenagens superficiais, os rios, estuários e o mar (Lamparelli et al., 2001).

\subsubsection{ALTERADORES ENDÓCRINOS}

Recentemente a atenção tem sido focada para o papel dos OCs como disruptores do sistema endócrino em humanos e animais. A existência de compostos com capacidade de disrupção-endócrina é bem conhecida, como exemplificada pela droga denominada dietilstilbestrol (DES) usado para prevenir abortos em mulheres na década de 50 e 60 . Animais de laboratório e humanos expostos ao DES no pré-natal exibiram numerosas 
anomalias no sistema reprodutivo quando adultos. Mudanças similares vêm ocorrendo em espécies da fauna selvagem em áreas com altas concentrações de OCs, incluindo alterações nos níveis hormonais e manifestações disfuncionais de comportamento reprodutivo (Colborn et al., 1993; 1996).

Até a década de 1990, foram identificados pelo menos 51 químicos sintéticos espalhados por todo meio ambiente que alteram o sistema endócrino. Esse inventário de alteradores hormonais inclui numerosas famílias químicas como a dos PCBs, com 209 compostos, dos DDTs e das dioxinas e furanos (Colborn et al., 1996).

Alteradores endócrinos podem incluir qualquer xenobiótico que interfira na função normal do receptor protéico hormonal. Estes compostos podem mimetizar o hormônio por se ligar ao receptor e ativar a resposta hormonal, ou pode agir como um antagonista por se ligar ao receptor protéico, tornando esse receptor indisponível para ser ativado pelo hormônio natural. No caso do receptor do estrógeno, a ação é denominada estrogênica e já a inversa é a anti-estrogênica (O’Shea, 1999).

OCs exibem uma ampla gama de atividades estrogênicas em estudos de animais de laboratório. Por exemplo, o DDT é considerado um mimetizador clássico de estrógeno, ele eleva os níveis do hormônio, tem ação estrogênica. Já o DDE, que é o metabólito mais persistente, tem o efeito contrário. Ele exaure os hormônios por meio da aceleração de sua decomposição e eliminação, deixando os organismos com deficiência não apenas de estrógeno, mas também de testosterona e de outros hormônios esteróides, ele é anti-estrogênico e anti-androgênico. Isso pode levar à diferenças nos níveis hormonais tanto em organismos adultos quanto nos fetos ainda em desenvolvimento (Colborn et al., 1996).

\subsection{MAMÍFEROS MARINHOS}

Os mamíferos marinhos constituem um grupo com aproximadamente 120 espécies que dependem primariamente dos oceanos para se alimentar. São separados em 3 grandes ordens: Cetáceos (Subordem Odontoceti: botos e golfinhos e Mysticeti: baleias), Carnívora (Superfamília Pinipedia - Família Focídae: focas e elefantesmarinhos, Família Otariidae: leões e lobos-marinhos e Família Odobenidae: morsas; Família Mustelidae: lontras e ariranhas e Família Ursidae: urso-polar) e Sirênios (Família Trichechidae: peixes-boi e Dugongidae: dugongos) (Hoelzel, 2002).

Os cetáceos são mamíferos exclusivamente aquáticos que habitam oceanos e rios há milhões de anos. A ordem Cetacea compreende as baleias, os botos e os golfinhos e 
está dividida em 2 subordens: Mysticeti e Odontoceti. A Subordem Mysticeti compreende as grandes baleias, distinguidas das espécies incluídas na subordem Odontoceti pela presença de estruturas córneas denominadas barbatanas, crânio simétrico, um par de orifícios respiratórios, os machos são ligeiramente menores que as fêmeas, alimentam-se de krill (Euphasia superba), copépodos (pequenos crustáceos) e pequenos peixes; apresentam comportamento solitário de modo geral e podem realizar grandes migrações (Carwardine et al., 1999).

A Subordem Odontoceti engloba todos os cetáceos possuidores de dentes ao invés de barbatanas. Este grupo corresponde à maioria dos cetáceos, incluindo a toninha (Pontoporia blainvillei) que constitui a espécie-alvo deste trabalho (Figura 1.1). Podemos encontrar dentro deste grupo espécie marinhas e fluviais. Algumas características distintas dos misticetos são observadas nesta subordem: crânio assimétrico; presença de apenas um orifício respiratório no alto da cabeça; machos geralmente maiores que as fêmeas; capacidade de ecolocalização por estrutura denominada melão localizada à frente do crânio, alimentação baseada principalmente em peixes, lulas, crustáceos e ocasionalmente outros mamíferos; comportamento gregário, isto é, capacidade de reunir-se em grupos (Carwardine et al., 1999).

Os cetáceos respiram ar através de seus orifícios respiratórios, localizados no topo do crânio e possuem grande capacidade de apnéia (mais de 1 hora em algumas espécies). Possuem uma espessa camada de gordura que serve como isolante térmico e reserva de energia e que auxilia na flutuabilidade. Alguns cetáceos atingem grandes tamanhos e isto é possível graças ao fato destes não terem que suportar seu próprio peso. A pele fina, lisa, corpos rígidos, órgãos genitais internos e a ausência de membros posteriores reduzem o atrito, facilitando a natação. A nadadeira caudal, horizontal, possui uma forte musculatura a qual é responsável pela força e propulsão na água. A nadadeira dorsal provê a estabilidade rotacional para a maior parte das espécies. Os odontocetos possuem sofisticado sistema de processamento de som, permitindo a eles interpretar sons recebidos e propagar seus sinais por ecolocalização. A maioria dos cetáceos utiliza o som, não a luz, como principal senso para obter informações do meio. Os cetáceos contribuem na ciclagem de nutrientes e, por ocuparem os níveis tróficos mais elevados na cadeia alimentar, atuam como indicadores potenciais da saúde e da produtividade dos ecossistemas. Outrossim, algumas espécies de aves, peixes e parasitas são beneficiadas por associações alimentares com os cetáceos (Carwardine, 1995, Carwardine et al., 1999). 
Foi reportada a ocorrência de 45 espécies de cetáceos em águas brasileiras - o que corresponde a $51,1 \%$ das conhecidas em âmbito mundial - sendo possível, no futuro, o registro da ocorrência de algumas outras espécies no litoral. A fauna de mamíferos marinhos em águas juridiscionais brasileiras é proporcionalmente rica em cetáceos e sirênios (duas espécies ocorrem no Brasil) mas escassa em espécies de pinípedes (sete espécies possuem registros em águas brasileiras) (IBAMA, 2003).

\subsubsection{TONINHA (Pontoporia blainvillei)}

A toninha, ou franciscana, Pontoporia blainvillei, (Figura 1.1) é um pequeno cetáceo, endêmico da região oeste do oceano Atlântico Sul, cuja distribuição estende-se ao longo de águas costeiras desde o Golfo Nuevo ( $41^{\circ}$ 09'S), Argentina (Crespo \& Harris, 1992), até Itaúnas (18²5’S), Espírito Santo, Brasil (Moreira \& Siciliano, 1991). P. blainvillei se distribui em faixas de profundidade que variam até a isóbata de $30 \mathrm{~m}$, em geral a até cerca de 30 milhas náuticas da costa (Praderi et al., 1989).


Figura 1.1. Toninha (Pontoporia blainvillei). $A$ - indivíduo adulto, $B$ - filhote, encalhe vivo.

A distribuição parece estar fragmentada ao longo da costa brasileira, ocorrendo dois hiatos, um entre Ubatuba, SP $\left(23^{\circ} 20^{\prime} \mathrm{S}\right)$ e Macaé, RJ $\left(22^{\circ} 25^{\prime} \mathrm{S}\right)$ e o outro entre Barra de Itabapoana, ES $\left(21^{\circ} 18^{\prime} \mathrm{S}\right)$ e Regência, ES $\left(19^{\circ} 40^{\prime} \mathrm{S}\right)$. Esta distribuição fragmentada pode ser devida a fatores limitantes, como a descarga de água doce dos rios Paraíba e Doce, à estreita plataforma continental ou a presença freqüente de predadores (Siciliano et al., 2002), como grandes tubarões e Orcas (Orcinus orca).

Dois estoques populacionais de toninhas são reconhecidos baseados em diferenças morfológicas, genéticas e de marcadores parasitários: uma forma menor (norte) distribuída entre o Espírito Santo e Santa Catarina $\left(22^{\circ} \mathrm{S}-27^{\circ} \mathrm{S}\right)$ e uma maior (sul) entre o Rio Grande do Sul e Argentina $\left(32^{\circ} \mathrm{S}-38^{\circ} \mathrm{S}\right)$. A existência desses dois 
estoques demonstra a importância de tratá-los como distintos em programas de conservação e manejo (Pinedo, 1991; Secchi et al., 1998).

$\mathrm{O}$ estoque sul vem sendo estudado há mais de 20 anos, levando a um maior acúmulo de conhecimento sobre a espécie e chegando a conclusão que as capturas acidentais estão causando um impacto muito sério e que os níveis de mortalidade podem não ser sustentáveis ao longo do tempo (Secchi et al., 1997). Já o estoque norte de toninhas é relativamente pouco estudado e os estudos são mais recentes (Lodi e Capistrano, 1990; Capistrano et al. 1992; Lodi et al., 1987; Zanelatto, 1997; Di Beneditto et.al., 1998; Bertozzi e Zerbini, 2002).

Uma das principais lacunas onde faltam informações consistentes sobre a toninha é representada pelos cerca de 600 km do litoral do estado de São Paulo (Santos, 1997). Devido à distribuição costeira, essa espécie está sujeita a diversos tipos de ameaças, como a captura acidental em aparelhos de pesca principalmente da frota artesanal, a degradação do ambiente costeiro oriunda de esgotos domésticos e industriais, tornando esta espécie altamente vulnerável e ameaçada pela ação humana desordenada.

Capturas acidentais em redes de pesca são a principal fonte de mortalidade induzida por humanos ao longo da maior parte da ocorrência da espécie (e.g. Pinedo et al., 1986, 1989; Praderi et al., 1989; Ott et al., 2002). Evidências sugerem que as taxas de mortalidade sejam excessivas e insustentáveis (Crespo et al, 1998; Secchi et al., 2002; Secchi e Wang, 2003). A toninha é o cetáceo mais impactado da costa leste da América do Sul (e.g. Secchi et al., 1997) e, dessa forma está incluída na lista de espécies da fauna brasileira ameaçadas de extinção (IBAMA, 2003) e é ainda listada como "dados deficientes - DD" no Livro Vermelho da União Mundial para a Conservação ("Red Data Book") (IUCN, 2007). A toninha encontra-se, ainda, listada no Apêndice II da Convenção sobre o Comércio Internacional de Espécies da Fauna e Flora Silvestres Ameaçadas de Extinção (CITES), da qual a Argentina, Uruguai e Brasil são signatários.

Durante o último Plano de Ação para Cetáceos da IUCN/ Species Survival Commission Cetacean Specialist Group (2004-2010), a toninha foi considerada como uma espécie que necessita de medidas particulares de conservação devido à sua distribuição costeira restrita e à sua alta vulnerabilidade à captura acidental em redes de pesca (Reeves et al., 2003).

A distribuição da toninha foi dividida em 4 áreas para propósitos de manejo denominadas de Franciscana Management Areas - FMA - I a IV (Secchi et al., 2003, 
Figura 1.2). Inúmeros dados sobre história de vida e mortalidade por pesca estão disponíveis para as áreas I, III e IV (e.g. Perez-Macri \& Crespo, 1989; Praderi et al., 1989; Corcuera, 1994; Secchi et al., 1997; Di Beneditto et. al., 1998; Kinas \& Secchi, 1998; Danilewicz et al., 2000). A população da FMA III já se encontra listada na categoria "Vulnerável - VU" no Livro Vermelho da União Mundial para a Conservação (Secchi \& Wang, 2003). Entretanto os dados são muito limitados para a area II (e.g. Zanellato, 1997; Rosas, 2000; Bertozzi \& Zerbini, 2002). Esta área corresponde a costa dos estados de São Paulo, Paraná e Santa Catarina (Sudeste e Sul do Brasil). Nesta região, a pesca costeira de emalhe é conduzida principalmente por pescadores artesanais trabalhando em pequenas comunidades de pesca distribuídos ao longo da linha de costa e a captura acidental é uma importante fonte de mortalidade para as toninhas (e.g. Carvalho, 1961; Simões-Lopes \& Ximenez, 1993; Siciliano, 1994).

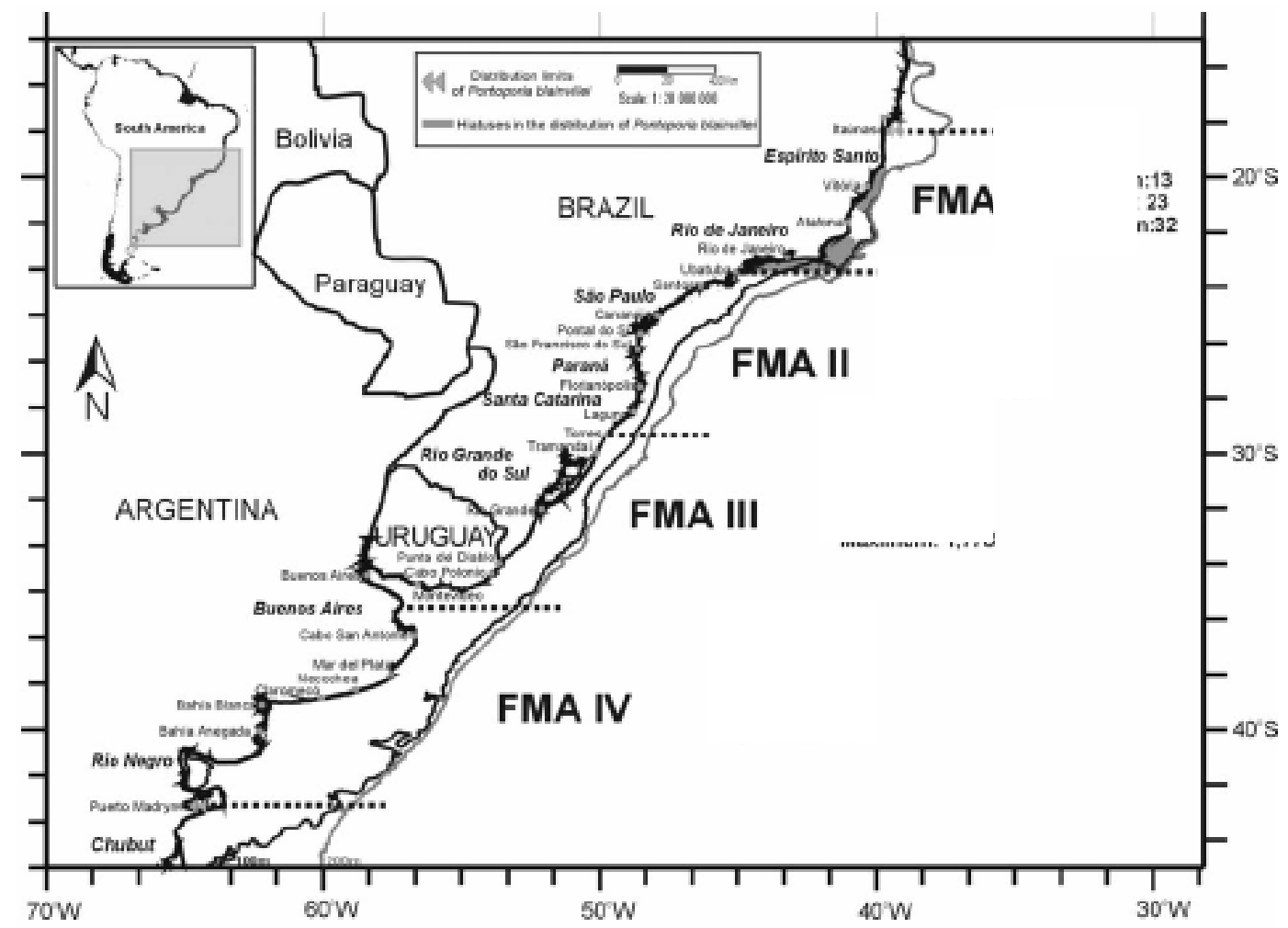

Figura 1.2 Mapa de distribuição da espécie e suas áreas de manejo (Franciscana Management Areas - FMAs) (Modificado de Secchi et al., 2003).

O status da toninha foi também revisado durante a International Whaling Commission (IWC) Scientific Committee (SC) (IWC, no prelo) e o Comitê Científico aponta para a geral falta de informações, especificamente para a população da área de manejo II (São Paulo, Santa Catarina e Paraná), e recomenda que a coleta de dados para 
avaliação dos aspectos do ciclo de vida (e.g. níveis de contaminação, idade, crescimento, reprodução) sejam obtidos.

Estas evidências apontam para a necessidade de um número maior de estudos de contaminantes em toninhas. Não obstante, as informações disponíveis acerca dos níveis de contaminação relatados para essa espécie são escassas. Para a costa brasileira, os estudos restringem-se a algumas análises pontuais (Castello et al., 2000; Yogui, 2002; Kajiwara et al., 2004; Leonel, 2007).

\subsection{COMPOSTOS ORGANOCLORADOS EM MAMÍFEROS MARINHOS}

Baseado em sua natureza lipofílica, persistência ambiental e potencial de bioacumulação, os compostos organoclorados representam uma ameaça aos organismos marinhos em geral, mas especialmente aqueles que ocupam o topo da cadeia alimentar, incluindo os mamíferos marinhos (Tanabe et al., 1994; Jarman et al., 1996). A presença desses compostos xenobióticos está ligada a muitos problemas de saúde, incluindo disfunções no sistema reprodutivo e imune em mamíferos marinhos (Rejinders, 1986; de Swart, 1994). Os mamíferos marinhos possuem baixa capacidade metabólica e/ou de excreção para esses poluentes, podendo exibir efeitos comportamentais e físiológicos adversos como resultado de uma exposição prolongada (Brooks, 1974; Hutzinger et al., 1974; Tanabe et al., 1988).

Grandes diferenças na concentração de contaminantes em cetáceos podem ser observadas entre machos e fêmeas e organismos com idades distintas, graças a processos de detoxificação/excreção e bioacumulação dos contaminantes (Tanabe et al., 1994) e à transferência destes compostos das fêmeas para seus filhotes via placenta e lactação (Rejinders, 1996).

Tanabe et al. (1988) encontraram que não apenas diferentes espécies de cetáceos e pinípedes mostram diferentes níveis de atividades, como também que os cetáceos não possuem certos tipos de enzimas, tornando-se assim mais vulneráveis aos efeitos dos PCBs do que os pinípedes. Os cetáceos possuem atividade enzimática muito baixa comparada aos mamíferos terrestres (Tanabe et al., 1994). Essas observações sugerem que alguns animais possuem função fisiológica especifica a qual é aparentemente diferente dos humanos. Isto pode acarretar aos animais uma alta acumulação e alta sensibilidade aos poluentes, bem como resultar em alto risco proveniente de tal exposição aos disruptores endócrinos (Tanabe et al., 2002). 
Mamíferos marinhos recebem contaminantes primariamente via presas ingeridas, ou seja, sua exposição a poluentes está relacionada à área onde se alimentam. Em geral, são maiores os índices em animais que ocorrem em ambientes próximos a águas costeiras poluídas, mas existem exceções (Ártico e Antártica). No caso dos mamíferos marinhos, a espessa camada de gordura subcutânea (blubber) pode conter mais de 90\% dos compostos acumulados em um único indivíduo (Tanabe et al., 1981).

As concentrações de poluentes encontradas nas baleias são menores do que nos pequenos cetáceos, pois estas se alimentam principalmente de crustáceos planctônicos e há uma maior diluição dos contaminantes lipofílicos em seus tecidos, por serem maiores. Já os golfinhos tendem a acumular concentrações maiores de organoclorados (Rejinders, 1996).

Apesar do grande número de trabalhos publicados sobre a contaminação em mamíferos marinhos, a grande maioria das informações refere-se quase que exclusivamente ao hemisfério norte (DeLong et al., 1973; Tanabe \& Tatsukawa, 1991, 1992; Kemper et al., 1994; Watanabe et al., 1996; Iwata et al., 1997; Tanabe et al., 1998; Borrel \& Aguilar, 2006). No hemisfério sul apenas algumas publicações foram encontradas referentes à contaminação de mamíferos marinhos por organoclorados. Altas concentrações de alguns praguicidas foram observados em pinípedes da colônia de Mar del Plata (Fossi et al., 1997; Jimenez et al., 1999) e na área da Punta Bermeja, Argentina (Jimenez et al., 1999). Resíduos de organoclorados foram também encontrados em tecidos de lobo-marinho-sul-americano (Arctocephalus australis) da costa do Rio Grande do Sul (Fillmann et al., 2002) e toninhas (Pontoporia blainvillei) (Leonel, 2007), bem como em cetáceos da costa de São Paulo (Yogui et al., 2003), cachalotes na Austrália (Evans et al, 2004), alguns cetáceos da África do Sul (de Kock et al., 1994) e em focasde-Weddel (Leptonychotes weddellii) na Antártica (Montone et al., 1998).

Estudos sobre a contaminação por organoclorados em cetáceos no Brasil são recentes (Junin et al., 1994; Yogui et al., 2003; Kajiwara et al., 2004; Leonel, 2007), mas são de vital importância para se ter conhecimento da saúde do ambiente e como estes compostos se comportam em mamíferos marinhos de ecossistemas tropicais.

\subsubsection{EFEITOS DOS ORGANOCLORADOS NOS MAMÍFEROS MARINHOS}

Alguns dos principais efeitos toxicológicos reportados para mamíferos marinhos são anormalidades reprodutivas (Reijnders, 1986, Subramanian et al., 1987), 
imunodepressão (Ross, 2002; Swart et al., 1994), lesões cranianas e deformidades ósseas (Bergman, et al., 1992), alterações no nível de vitamina A (Jenssen, 1996) e impactos populacionais (Martineau et al., 1987). Nestes casos, mesmo exposições a concentrações sub-letais podem, a longo prazo, tornar estes indivíduos mais susceptíveis a predação, reduzindo suas habilidades de sobrevivência e reprodução (Reijnders, 1996).

São exemplos de estudos de caso de problemas imunológicos e reprodutivos relacionados aos organoclorados em mamíferos marinhos: focas-cinza (Halichoerus grypus) no Mar Báltico foram reportadas oclusões e estenoses uterinas, tumores benignos, hiperplasia adrenocortical, hiperqueratose, mudanças na simetria do crânio e lesões ósseas (Bergman et al., 1992). Nos leões-marinhos-da-Califórnia (Zalophus californianus) houve nascimentos prematuros e carcinomas (DeLong et al., 1973; Gulland et al., 1996). Nas focas-do-Porto (Phoca vitulina) do Mar Wadden houve falhas reprodutivas (Reijnders 1980, 1986; de Swart et al., 1994) e no Mar Báltico aberrações cromossômicas e lesões cranianas (Hongell, 1996; Mortensen et al., 1992). No golfinholistrado (Stenella coeruleoalba) no Mediterrâneo houve imunossupressão com efeito no timo e suscetibilidade ao morbillivirus, além de lesões no fígado (Kannan et al., 1993). Nas belugas (Delphinapterus leucas) no Rio St. Lawrence houve tumores, lesões no trato digestivo e nas glândulas mamárias, hermafroditismo verdadeiro e anomalias reprodutivas (Martineau et al., 1994). Nos golfinhos-de-Dalli (Phocoenoides dalli) houve supressão de níveis de testosterona em machos (Subramanian et al., 1987). Estes efeitos foram relacionadas principalmente a altos índices de PCBs, DDTs e metabólitos em seus tecidos.

Eventos epizoóticos severos em golfinhos-listrados (S. coeruleoalba) no Mediterrâneo foram associados a altos níveis de PCBs em suas gorduras, quando comparados a animais sadios amostrados antes e depois do evento. Além disso, a concentração de PCBs co-planares nestes animais foi a maior já reportada em cetáceos (Kannan et al., 1993).

Disfunções fisiológicas por exposição a contaminantes tóxicos vem sendo sugeridas em mamíferos marinhos baseados na análise/exame de alguns biomarcadores como as enzimas do citocromo P (CYP) e hormônios (Tanabe et al., 2002). Desde 1960, esterilidade, abortos, nascimentos pré-maturos, etc. vêm sendo observados em pinípedes e cetáceos de áreas costeiras de países desenvolvidos (De Long, 1973; Helle et al., 1976a,b; Rejinder, 1986; Beland et al., 1993). 


\subsection{ORGANOCLORADOS NO LITORAL DE SÃO PAULO}

As informações a respeito da poluição por compostos organoclorados na região costeira do Estado de São Paulo são apresentadas em 3 áreas de acordo com suas características morfogeográficas e populacionais: Baixada Santista, Litoral Norte e Litoral Sul (Figura 2.1).

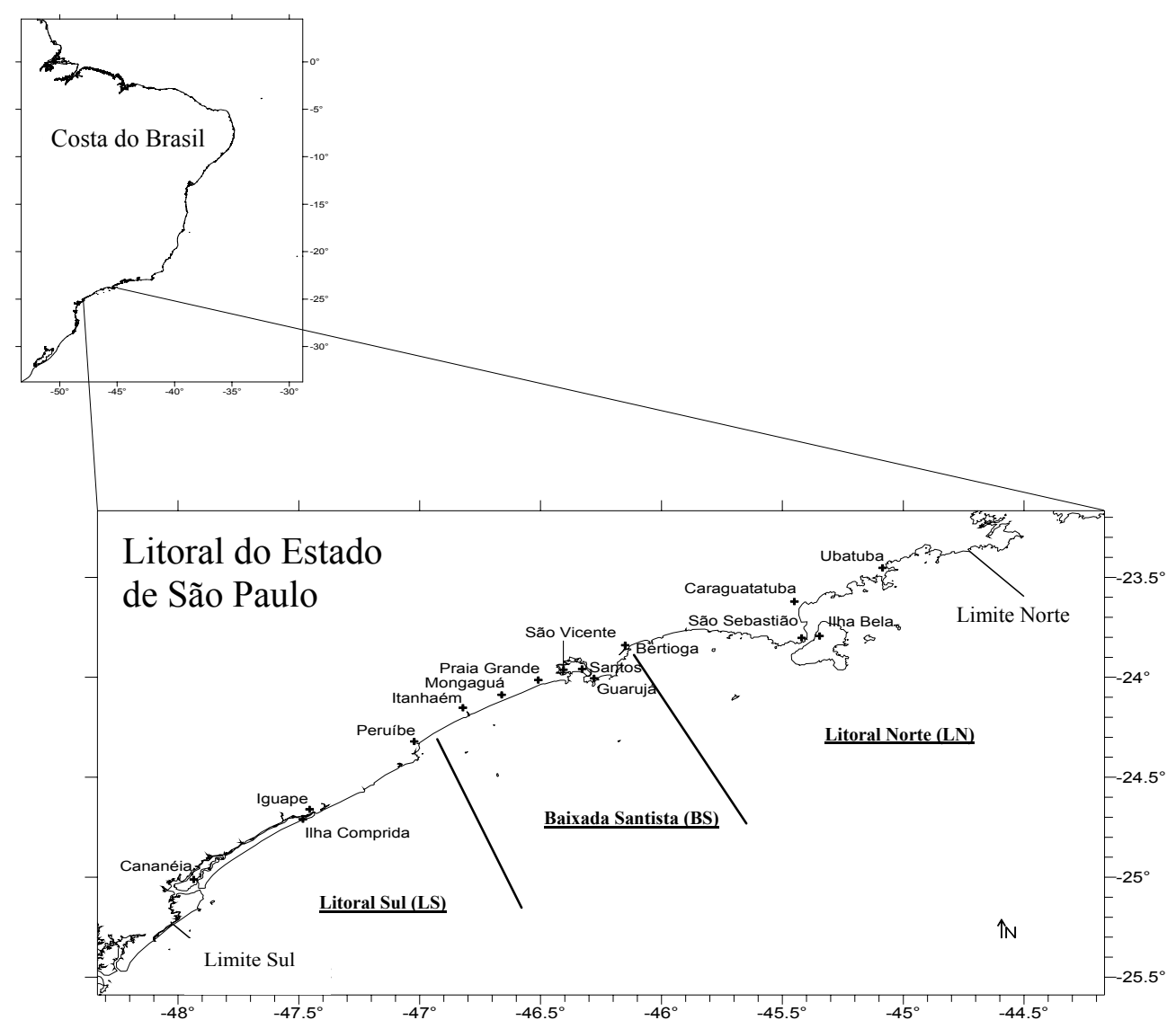

Figura 2.1. Mapa do litoral do Estado de São Paulo, Sudeste do Brasil.

\subsubsection{BAIXADA SANTISTA}

A Baixada Santista é composta por 8 municípios: Bertioga, Guarujá, Santos, São Vicente, Cubatão, Praia Grande, Mongaguá e Itanhaém, com uma população de

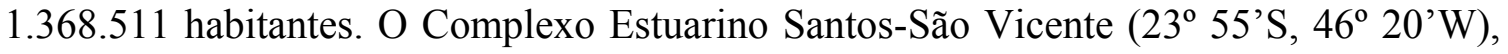
inserido na Região Metropolitana da Baixada Santista, Estado de São Paulo representa o mais importante exemplo brasileiro de degradação ambiental por poluição hídrica e atmosférica de origem industrial em ambientes costeiros, por abrigar o maior Porto da América Latina, o Porto de Santos, e o maior pólo industrial do país, em Cubatão (Lamparelli et al., 2001). 
A atividade industrial na região teve início na década de 1950, com a implantação de diversas indústrias de base (siderúrgica, petroquímica e fertilizantes), com alto potencial poluidor e fazendo dos estuários de Santos e São Vicente grandes receptores de resíduos tóxicos e efluentes líquidos contaminados (Lamparelli et al., 2001).

Durante décadas as indústrias do Pólo de Cubatão emitiram diferentes tipos de poluentes e resíduos tóxicos para o ser humano, tanto no ar, solo como nos corpos d'água, que se constituíram em óxidos de enxofre, óxidos de nitrogênio, monóxido e dióxido de carbono, metano, hidrocarbonetos diversos, organoclorados, fenóis clorados, fluoretos, aldeídos, ácidos, metais pesados e poeiras (Freitas Guimarães, 2005).

Desde o ano de 1978 foi verificado que várias indústrias lançavam resíduos sólidos em áreas de manguezal, ocasionando a poluição do solo e das águas dessa região (CETESB apud Tommasi, 1987). Atualmente, segundo os mais recentes relatórios da CETESB sobre a região $(2001,2003,2004)$, os resíduos encontrados no solo e no sedimento do estuário são classificados como Classe 1, ou seja, perigosos (ABNT, 2003).

Embora a região não seja de vocação agrícola, os produtos investigados podem estar presentes pelo uso doméstico, pela aplicação nas antigas plantações de banana que existiam em toda Baixada Santista, ou trazidos de outras regiões pelos cursos d'água (Lamparelli et al., 2001).

Em 1985, os hidrocarbonetos clorados foram proibidos por lei no Brasil (Brasil, 1985), entretanto eles foram utilizados em grande escala durante a década de 1970 e início da década de 1980 (D’Amato et al., 2002). Considerando a importância da região metropolitana de Santos num contexto de impactos antrópicos, seu ecossistema marinho adjacente possui poucas informações referentes aos organoclorados. Conforme sugere Tanabe et al (1994), o clima favorece a volatilização dos compostos mais leves, como os HCHs e o HCB. De fato, parece que ambos não são biomagnificados no ecossistema marinho da Baixada Santista, visto que as concentrações em moluscos (Taniguchi, 1995) e cetáceos estiveram praticamente todas na mesma ordem de grandeza; em contrapartida, o mesmo não ocorreu com DDTs e PCBs, que foram detectados em níveis muito superiores nos cetáceos desta região (Yogui, 2002).

\subsubsection{LITORAL NORTE}

O litoral Norte do estado de São Paulo possui uma área com 1.977 km², abrange os municípios de São Sebastião, Ilha Bela, Caraguatatuba e Ubatuba, com uma população de 224.656 habitantes. Diferente da costa central (Baixada Santista), o litoral norte do 
estado não abriga uma grande população humana, por ser uma área extremamente acidentada inserida entre a Serra do Mar e o oceano Atlântico. Caracteriza-se pela diversidade de recursos naturais e pela intensa especulação imobiliária. Sua economia é marcada pela sazonalidade decorrente da predominância do turismo veranista, que é o seu principal fator de desenvolvimento (SMA/CPLEA, 2005).

Constitui-se numa região caracterizada pela potencialidade turística e pela existência de problemas ambientais relacionados com a especulação imobiliária, parcelamento irregular do solo, pesca predatória, estruturas náuticas e atividades portuárias em desconformidade com a conservação dos recursos marinhos (SMA/CPLEA, 2005).

Entre os problemas ambientais existentes nesta região, está o fato de sediar o Porto de São Sebastião e o Terminal de Petróleo Almirante Barroso (TEBAR), ambos localizados no município de São Sebastião, mas que interferem nos demais municípios da região por provocarem a intensificação do tráfego de veículos pesados e por conta dos derramamentos de óleo resultantes dos acidentes nas operações do terminal petrolífero. Tais problemas são agravados pela perspectiva de se implantar na região grandes projetos vinculados ao transporte e ao armazenamento de cargas. Outra linha de problemas ambientais bastante comum na região decorre do desequilíbrio entre o crescimento da população fixa e flutuante e a capacidade de abastecimento público e da infra-estrutura de saneamento básico instalada (SMA/CPLEA, 2005).

Nessa região não são encontradas grandes indústrias, e não foi relatado o uso de agrotóxicos organoclorados na literatura. Não é considerada uma área nem industrial nem agrícola, cuja principal atividade econômica é o turismo. Pode ser considerada então uma região onde suas principais fontes poluidoras são o esgoto doméstico e eventuais acidentes petrolíferos.

\subsubsection{LITORAL SUL}

O litoral Sul do estado de São Paulo inclui os municípios de Peruíbe, Iguape, Ilha Comprida e Cananéia, com uma população de 46.429 habitantes. Essa região está dentro de uma área de preservação ambiental de Cananéia-Iguape-Peruíbe (APA) cuja responsabilidade de fiscalização está a cargo do governo federal. Essa região possui o aporte de grandes rios e um grande complexo estuarino-lagunar, Cananéia-Iguape. Como todos os ambientes estuarinos, destaca-se por ser berçário de diversas espécies marinhas 
e fluviais, sendo sua manutenção íntegra de grande valor, como já enfatizado por Besnard (1950).

Esse litoral possui características rurais e ausência de grandes indústrias, onde são raras as informações sobre PCBs no ambiente (Yogui, 2002).

Os pesticidas clorados DDT, HCH, aldrin, endrin, heptacloro, mirex e endosulfan foram citados por Ferreira et al. (1980) como os mais utilizados nas plantações da região em 1975. A maior parte desses compostos atingiu o complexo estuarino provavelmente lixiviados pelo rio Ribeira de Iguape. A construção da barragem no canal do Valo Grande, que impediu o aporte desse rio no complexo estuarino-lagunar, provavelmente diminuiu a entrada de pesticidas nesse ambiente (Yogui, 2002).

Os pesticidas organoclorados mais persistentes como o DDT e Mirex não foram encontrados nos sedimentos dessa região, mas foram reportadas altas concentrações em cetáceos residentes desse ambiente. Para os DDTs, por exemplo, foram obtidas concentrações nos botos-cinza (Sotalia guianensis) de 3 a 5 ordens de grandeza superiores do que no sedimento, tanto no estuário quanto a montante de rios que compõem a bacia do Ribeira de Iguape. Esse OC foi completamente banido do Vale do Ribeira em 1997, quando seu uso foi interrompido em campanhas de saúde publica, mas a completa detoxificação desses animais ainda deverá levar muitas gerações (Yogui, 2002).

A região costeira do Estado de São Paulo apresenta áreas impactadas por poluentes orgânicos persitentes tanto quanto áreas menos poluídas. Os dados desses poluentes em toninhas ( $P$. blainvillei) contribuem para o estudo e monitoramento dos compostos organoclorados nessa região. Numa escala global, a geração desses dados diminuiu a lacuna de estudos existente no hemisfério sul com respeito aos mamíferos marinhos, auxilia na compreensão da distribuição global desses poluentes persistentes e pode levar ao favorecimento de manejo ambiental e preservação dessa espécie em risco. 


\subsection{OBJETIVO}

Avaliar a presença de poluentes organoclorados no litoral de São Paulo, usando como bioindicador o mamífero marinho Pontoporia blainvillei, toninha.

\subsubsection{OBJETIVOS ESPECÍFICOS}

Os objetivos específicos deste trabalho são:

a) determinar as concentrações de bifenilos policlorados e pesticidas organoclorados em tecido adiposo subcutâneo de toninhas (Pontoporia blainvillei) coletadas ao longo do litoral de São Paulo;

b) verificar as possíveis relações entre a ocorrência de organoclorados o sexo e a maturidade sexual dos organismos.

\section{MATERIAIS E MÉTODOS}

\subsection{AMOSTRAGEM}

As amostras biológicas foram provenientes do banco de tecidos de mamíferos marinhos do Laboratório de Patologia Comparada de Animais Silvestres (LAPCOM) do Departamento de Patologia (VPT) da Faculdade de Medicina Veterinária da Universidade de São Paulo (USP), tombadas pela ONG Projeto BioPesca. As toninhas (Pontoporia blainvillei) foram mortas acidentalmente capturadas em redes de pesca, ou encalhadas no litoral do Estado de São Paulo.

Essas amostras vêm sendo coletadas através de monitoramento das comunidades pesqueiras do litoral de São Paulo desde 1998 pela ONG Projeto BioPesca (Bertozzi \& Zerbini, 2002; Bertozzi et al., 2003; Alonso et al., 2005; Marigo et al., 2005).

Os animais da região da Baixada Santista (Fig. 2.2-A) compreendem a maior parte das amostras e foram provenientes de capturas acidentais em importantes pontos pesqueiros como ao redor da Ilha da Moela, Guarujá, local de descarte de sedimento contaminado proveniente da dragagem do canal do Porto de Santos; e nas proximidades da Baía de Santos e do município de Praia Grande (Alonso et al., 2004; 2005; Bertozzi \& Zerbini, 2002). Alguns espécimes coletados provêm de encalhes em praias do Estado (Fig. 2.2-B). 
Fotos: Projeto BioPesca/ Alonso e Bertozzi

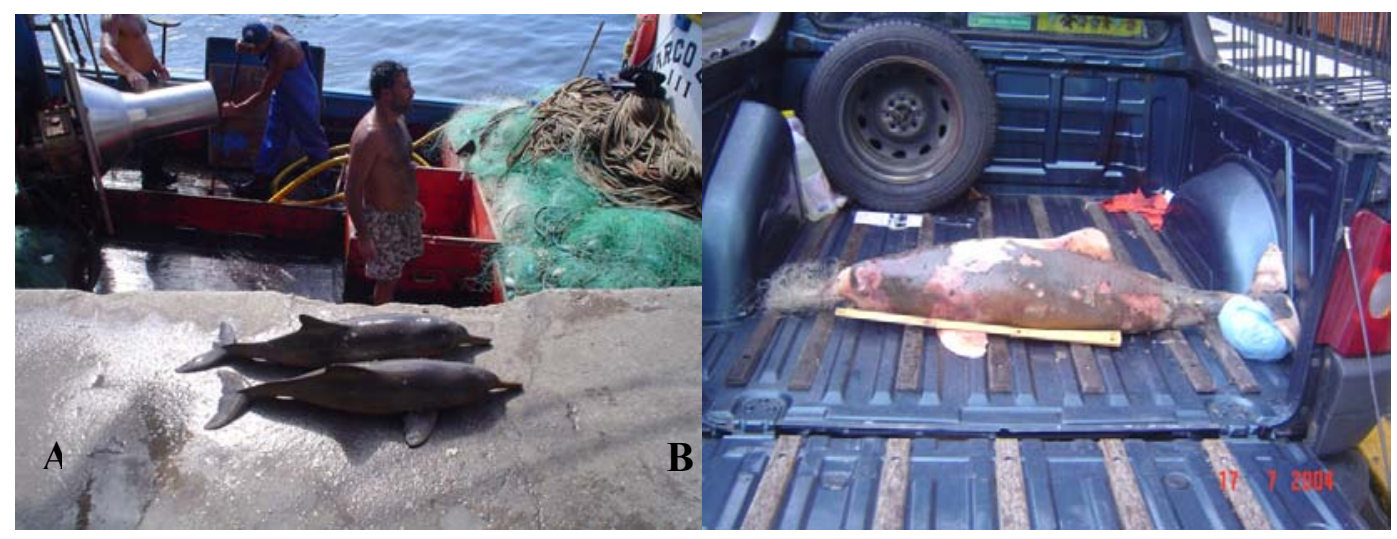

Fig. 2.2 A. Toninhas (P. blainvillei) capturadas acidentalmente em rede de pesca no entreposto de Santos, SP. B. Encalhe de P. blainvillei em Guarujá, SP, com evidência de emalhe em rede de pesca.

As análises de organoclorados foram executadas em amostras de gordura subcutânea (blubber) de 53 toninhas (P. blainvillei) (Fig. 2.3). Os dados biológicos e demais informações sobre os espécimes estão nas Tabelas 2.1 e 2.2, separados por sexo, 29 machos e 24 fêmeas. Devido à ausência de dados de maturidade sexual através de análises histológicas de gônadas nesses animais, foi utilizada a classificação de acordo com Rosas \& Monteiro-Filho (2002) onde, indivíduos machos são considerados maduros sexualmente com comprimento total a partir de $112 \mathrm{~cm}$ e fêmeas a partir de $122 \mathrm{~cm}$.



Fig. 2.3 Toninhas (P. blainvillei) A. fêmea adulta (BP 50). B. filhotes, fêmea (BP 89) e macho (BP 88), respectivamente, capturados na mesma rede de pesca. $C$. tecido adiposo subcutâneo blubber (seta). D. feto de fêmea (BP 152) capturada acidentalmente em rede de pesca. 
Tabela 2.1 - Dados biológicos de toninhas (P. blainvillei) machos analisados neste estudo no período de 2001 a 2007.

\begin{tabular}{|c|c|c|c|c|c|c|}
\hline No. Tombo & Origem & Data & $\mathrm{CT}(\mathrm{cm})$ & Local & Maturidade Sexual & Observações \\
\hline \multicolumn{7}{|l|}{ Adultos } \\
\hline BP 13 & Captura & mar-01 & 117 & Praia Grande, Baixada Santista, SP & maduro & \\
\hline BP 21 & Captura & set-02 & 113 & Praia Grande, Baixada Santista, SP & maduro & \\
\hline BP 64 & Captura & jun-04 & 123 & Ubatuba, Litoral Norte, SP & maduro & cisto no fígado \\
\hline BP 91 & Captura & jan-05 & 118 & Peruíbe, Litoral Sul, SP & maduro & \\
\hline BP 103 & Captura & mar-05 & 119 & Peruíbe, Litoral Sul, SP & maduro & \\
\hline BP 104 & Captura & mai-05 & 116 & Iguape, Litoral Sul, SP & maduro & \\
\hline BP 110 & Captura & jul-05 & 124 & Praia Grande, Baixada Santista, SP & maduro & \\
\hline BP 133 & Captura & mar-06 & 112 & Peruíbe, Litoral Sul, SP & maduro & \\
\hline BP 136 & Captura & jun-06 & 114 & Praia Grande, Baixada Santista, SP & maduro & \\
\hline BP 157 & Captura & jul-07 & 117 & Peruíbe, Litoral Sul, SP & maduro & presença de cicatriz no fígado \\
\hline \multicolumn{7}{|l|}{ Subadultos } \\
\hline BP 19 & Captura & ago-02 & 110 & Praia Grande, Baixada Santista, SP & imaturo & \\
\hline BP 56 & Captura & fev-04 & 110 & Guarujá, Baixada Santista, SP & imaturo & \\
\hline BP 63 & Captura & jun-04 & 108 & Praia Grande, Baixada Santista, SP & imaturo & \\
\hline BP 72 & Captura & jul-04 & 110 & Praia Grande, Baixada Santista, SP & imaturo & \\
\hline BP 75 & Captura & jul-04 & 105 & Guarujá, Baixada Santista, SP & imaturo & \\
\hline BP 82 & Captura & out-04 & 104 & Praia Grande, Baixada Santista, SP & imaturo & \\
\hline BP 84 & Captura & nov-04 & 108 & Peruíbe, Litoral Sul, SP & imaturo & \\
\hline BP 85 & Captura & nov-04 & 111 & Praia Grande, Baixada Santista, SP & imaturo & \\
\hline BP 120 & Captura & nov-05 & 103 & Peruíbe, Litoral Sul, SP & imaturo & \\
\hline BP 125 & Captura & dez-05 & 100 & Bertioga, Baixada Santista, SP & imaturo & \\
\hline \multicolumn{7}{|l|}{ Filhotes } \\
\hline BP 46 & Encalhe & nov-03 & 69 & Ubatuba, Litoral Norte, SP & imaturo & encalhe vivo \\
\hline BP 59 & Captura & jun-04 & 93 & Guarujá, Baixada Santista, SP & imaturo & \\
\hline BP 66 & Captura & jun-04 & 99 & Praia Grande, Baixada Santista, SP & imaturo & \\
\hline BP 70 & Captura & jul-04 & 96 & Praia Grande, Baixada Santista, SP & imaturo & \\
\hline BP 88 & Captura & jan-05 & 83 & Bertioga, Baixada Santista, SP & imaturo & \\
\hline BP 94 & Captura & fev-05 & 82 & Praia Grande, Baixada Santista, SP & imaturo & \\
\hline BP 107 & Captura & jul-05 & 91 & Praia Grande, Baixada Santista, SP & imaturo & \\
\hline BP 112 & Captura & out -05 & 98 & Guarujá, Baixada Santista, SP & imaturo & \\
\hline BP 116 & Captura & nov-05 & 94 & Guarujá, Baixada Santista, SP & imaturo & \\
\hline
\end{tabular}

Tabela 2.2 - Dados biológicos de toninhas (P. blainvillei) fêmeas analisadas neste estudo no período de 2001 a 2007.

\begin{tabular}{|c|c|c|c|c|c|c|}
\hline No. Tombo & Origem & Data & $\mathrm{CT}^{*}(\mathrm{~cm})$ & Local & Maturidade Sexual & Observações \\
\hline \multicolumn{7}{|l|}{ Adultos } \\
\hline BP 16 & Captura & dez-01 & 130 & Praia Grande, Baixada Santista, SP & maduro & \\
\hline BP 43 & Captura & jul-03 & 126 & Mongaguá, Baixada Santista, SP & maduro & \\
\hline BP 44 & Captura & jul-03 & - & Praia Grande, Baixada Santista, SP & - & \\
\hline BP 48 & Captura & dez-03 & 122 & Mongaguá, Baixada Santista, SP & maduro & \\
\hline BP 50 & Captura & jan-04 & 132 & Guarujá, Baixada Santista, SP & maduro & com feto \\
\hline BP 62 & Encalhe & jun-04 & 143 & Cananéia, Litoral Sul, SP & maduro & com feto \\
\hline BP 93 & Captura & jan-05 & 137 & Guarujá, Baixada Santista, SP & maduro & com feto \\
\hline BP 132 & Captura & fev-06 & 141 & Ubatuba, Litoral Norte, SP & maduro & lactante \\
\hline BP 137 & Captura & jun-06 & 137 & Praia Grande, Baixada Santista, SP & maduro & \\
\hline BP 152 & Captura & mai-07 & 132 & Itanhaém, Baixada Santista, SP & maduro & com feto e lactante \\
\hline BP 153 & Captura & mai-07 & 129 & Itanhaém, Baixada Santista, SP & maduro & com feto e lactante \\
\hline \multicolumn{7}{|l|}{ Subadultos } \\
\hline BP 83 & Encalhe & out-04 & 106 & Praia Grande, Baixada Santista, SP & imaturo & \\
\hline BP 90 & Captura & dez-04 & 120 & São Sebastião, Litoral Norte, SP & imaturo & \\
\hline BP 101 & Captura & fev-05 & 102 & Praia Grande, Baixada Santista, SP & imaturo & \\
\hline BP 102 & Captura & fev-05 & 114 & Peruíbe, Litoral Sul, SP & imaturo & \\
\hline BP 109 & Captura & jul-05 & 108 & Praia Grande, Baixada Santista, SP & imaturo & \\
\hline BP 113 & Captura & out-05 & 110 & Guarujá, Baixada Santista, SP & imaturo & \\
\hline BP 124 & Captura & dez-05 & 113 & Guarujá, Baixada Santista, SP & imaturo & \\
\hline BP 126 & Captura & jan-06 & 121 & Guarujá, Baixada Santista, SP & imaturo & \\
\hline \multicolumn{7}{|l|}{ Filhotes } \\
\hline BP 45 & Encalhe & nov-03 & 64 & Mongaguá, Baixada Santista, SP & imaturo & encalhe vivo \\
\hline BP 89 & Captura & jan-05 & 82 & Bertioga, Baixada Santista, SP & imaturo & \\
\hline BP 100 & Captura & fev-05 & 81 & Guarujá, Baixada Santista, SP & imaturo & \\
\hline BP 108 & Captura & jul-05 & 94 & Praia Grande, Baixada Santista, SP & imaturo & \\
\hline BP 146 & Encalhe & jan-07 & 90 & Guarujá, Baixada Santista, SP & imaturo & marcas de rede \\
\hline
\end{tabular}


O Litoral de São Paulo foi dividido em 3 regiões: Litoral Norte com animais provenientes dos municípios de São Sebastião e Ubatuba; Baixada Santista que incluiu Bertioga, Guarujá, Praia Grande, Mongaguá e Itanhaém; e Litoral Sul com indivíduos coletados em Peruíbe, Cananéia, e Iguape (Tabela 2.3).

Tabela 2.3 - Número de indivíduos de Toninhas (P. blainvillei) analisados e suas porcentagens relativas por regiões do litoral do Estado de São Paulo, Brasil.

\begin{tabular}{cccc}
\hline Baixada Santista & Litoral Norte & Litoral Sul & Total \\
\hline 41 & 4 & 8 & $\mathbf{5 3}$ \\
$77 \%$ & $8 \%$ & $15 \%$ & $\mathbf{1 0 0} \%$ \\
\hline
\end{tabular}

\subsection{ANÁLISE DE ORGANOCLORADOS}

\subsubsection{CUIDADOS ANALÍTICOS}

Para a análise de contaminantes orgânicos traço é necessária a eliminação de contaminação externa, tanto nas vidrarias quanto em todo material utilizado na análise.

\subsubsection{Limpeza do Material}

Toda a vidraria e os utensílios utilizados como pinça, bisturi, etc. foram previamente lavados a fim de eliminar qualquer resíduo orgânico. Para tanto, todo o material foi deixado imerso em solução detergente Extran alcalino (Merck) durante pelo menos 8 horas. Após esse período, o material foi abundantemente enxaguado em água corrente e por fim, em água destilada e deionizada (Milli-Q Water System).

A secagem da vidraria foi feita em estufa a aproximadamente $150{ }^{\circ} \mathrm{C}$ e em seguida calcinada em mufla $\left(400^{\circ} \mathrm{C}\right)$, exceto para a vidraria volumétrica que secou a temperatura ambiente e que foi lavada duas vezes com uma mistura de n-hexano e diclorometano $(1: 1)(\mathrm{v} / \mathrm{v})$ e duas com n-hexano antes do uso.

\subsubsection{Tratamento dos Reagentes}

No estudo dos traços os solventes orgânicos devem ter elevado grau de pureza, de modo que interfira o mínimo possível nas análises, sendo usados solventes para análise de resíduos: n-hexano e diclorometano da J.T. Baker. O sulfato de sódio da J.T. Baker foi calcinado em forno mufla a temperatura de $400{ }^{\circ} \mathrm{C}$ durante 4 horas. Este processo 
garantiu a eliminação de interferentes orgânicos, bem como tornou o sulfato de sódio anidro. Esse reagente foi mantido em recipiente de vidro e estocado em dessecador.

\subsubsection{Soluções Padrão de Organoclorados}

Foram adquiridas soluções padrão de organoclorados do laboratório internacional AccuStandard (EUA).

1). Mix de Pesticidas (Pesticide Mix 1), com 31 compostos: Aldrin, a-HCH, b-HCH, g$\mathrm{HCH}, \mathrm{d}-\mathrm{HCH}$, a-clordana, g-clordana, o,p'-DDD, p,p'-DDD, o,p'-DDE, $p, p^{\prime}$-DDE, $o, p^{\prime}$ DDT, $p, p$ '-DDT, Dieldrin, Endosulfan I, Endosulfan II, Endrin, Heptacloro, Heptacloro epóxido A, Heptacloro epóxido B, Hexaclorobenzeno, Isodrin, Metoxicloro, Mirex, Oxicloradana, PCB 28, 52, 101, 153, 138, 180 com 95,5 a 100\% de pureza e concentrações de $10 \mu \mathrm{g} \mathrm{ml}^{-1}$ cada pesticida e $1 \mu \mathrm{g} \mathrm{ml}^{-1}$ cada PCB em tolueno;

2). Mix de PCBs (WHO/ NIST/ NOAA Congener List), com 28 compostos: PCB 8, 18, $28,44,52,66,77,81,101,105,114,118,123,126,128,138,153,156,157,167,169$, $170,180,187,189,195,206,209$ com 99 a 100\% de pureza e concentração de $10 \mu \mathrm{g} \mathrm{ml}^{-}$ 1 cada em isoctano;

3). Mix de PCBs (PCB Congener Mix for West Coast Fish Studies), com 24 compostos: PCB 31, 33, 49, 56, 60, 70, 87, 95, 97, 99, 110, 132, 141, 149, 151, 156, 158, 174, 177 , 194, 201, 203, 183, 74 com 99 a $100 \%$ de pureza e concentração de $25 \mu \mathrm{g} \mathrm{ml}^{-1}$ cada em isoctano;

4). PCB 198 (2,2',3,3',4,5,5',6-Octachlorobiphenyl), 100\% de pureza, $5 \mathrm{mg}$;

5). PCB 103 (Individual Congener), 100\% de pureza $10 \mathrm{mg}$;

6). TCMX (Surrogate Standard Mix) $96 \%$ de pureza, $1000 \mu \mathrm{g} \mathrm{ml}^{-1} \mathrm{em}$ hexano.

A partir destes padrões certificados, preparou-se três tipos de solução: mistura de organoclorados (mistura de $\mathrm{OCs}$ ), padrão interno ou surrogate (PI) e padrão interno cromatográfico ou internal standard (PI-CG).

A solução de PI continha 2 compostos: PCB 103 e PCB 198, e a solução de PICG continha o composto TCMX (2,3,5,6-tetracloro-m-xileno), todos em concentração de $1,0 \mathrm{ng} \mu \mathrm{l}^{-1}$. A mistura de OCs continha 25 pesticidas e 51 PCBs, com concentração de 1,0 $\operatorname{ng} \mu 1^{-1}$. 


\subsubsection{Condições Cromatográficas}

\subsection{GC-ECD}

As análises dos pesticidas organoclorados foram feitas em um cromatógrafo a gás Agilent Technologies (modelo 6890N), equipado com detector de captura eletrônica (GC-ECD). A coluna de sílica fundida utilizada tinha $25 \mathrm{~m}$ de comprimento por $0,25 \mathrm{~mm}$ de diâmetro interno, com $5 \%$ de fenilmetilsilicona e $0,52 \mu \mathrm{m}$ de espessura do filme.

O gás de arraste usado foi o hidrogênio (pureza > 99,999\%), com pressão constante de 13,00 psi na coluna. O nitrogênio foi utilizado como gás auxiliar (makeup) com um vazão de $60 \mathrm{ml} \mathrm{min}{ }^{1}$.

A rampa utilizada na separação dos compostos permaneceu em $70^{\circ} \mathrm{C}$ por $1 \mathrm{~min}$, elevou-se a $170^{\circ} \mathrm{C}\left(40^{\circ} \mathrm{C} \min ^{-1}\right), 240^{\circ} \mathrm{C}\left(1,5^{\circ} \mathrm{C} \min ^{-1}\right)$ e então subiu até $300^{\circ} \mathrm{C}$, a $15^{\circ} \mathrm{C}$ $\min ^{-1}$, mantendo-se estável nessa temperatura por $5 \mathrm{~min}$, totalizando $61,16 \mathrm{~min}$. As temperaturas do injetor e do detector foram de $280^{\circ} \mathrm{C}$ e $320^{\circ} \mathrm{C}$, respectivamente. $\mathrm{O}$ volume injetado foi de $2 \mu \mathrm{L}$ no modo sem divisão de fluxo (splitless).

\subsection{GC-MS}

Para a análise de PCBs as amostras foram injetadas em um cromatógrafo a gás acoplado a um espectrômetro de massas (GC-MS), da Agilent Technologies (modelo $5973 \mathrm{~N}$ ) com impacto de elétrons (EI). O equipamento operou no modo de monitoramento seletivo de íons (SIM) $(70 \mathrm{eV})$. A coluna utilizada foi a HP 5 da Agilent com $30 \mathrm{~m}$ de comprimento, $0,25 \mathrm{~mm}$ de diâmetro interno e 0,25 $\mu \mathrm{m}$ de espessura de filme de $5 \%$ fenil metilsiloxana.

Para PCBs a rampa de temperatura utilizada na separação dos compostos teve início em $75^{\circ} \mathrm{C}$, permanecendo por $3 \mathrm{~min}$, quando começou a subir a uma taxa de $15^{\circ} \mathrm{C}$ $\min ^{-1}$ até atingir $150{ }^{\circ} \mathrm{C}$, depois subiu até $260^{\circ} \mathrm{C}$ a uma taxa de $2^{\circ} \mathrm{C} \min ^{-1}$ e então subiu até $300{ }^{\circ} \mathrm{C}$ a uma taxa de $20^{\circ} \mathrm{C} \mathrm{min}^{-1}$, mantendo-se estável nessa temperatura por $10 \mathrm{~min}$, totalizando 66 min. O gás de arraste utilizado foi o hélio com vazão constante de 1,1 ml $\min ^{-1}$. A temperatura do injetor foi de $270^{\circ} \mathrm{C}$.

A temperatura da interface foi $280^{\circ} \mathrm{C}$, a temperatura da fonte foi $300^{\circ} \mathrm{C}$ e a temperatura do quadrupolo foi $200^{\circ} \mathrm{C}$. O volume injetado era de $1 \mu \mathrm{L}$ no modo sem divisão de fluxo (splitless). 


\subsubsection{Identificação e Quantificação dos Analitos}

A identificação dos pesticidas foi baseada em seus respectivos tempos de retenção, enquanto a quantificação foi feita com base nas áreas dos picos no cromatograma. Para a identificação dos PCBs, além dos tempos de retenção, também foram utilizados os espectros de massa e a quantificação também foi feita em relação à área dos picos.

\subsection{Curva Analítica}

Depois da aquisição das soluções de padrões de organoclorados, construiu-se as curvas analíticas. Para isso, foram injetadas soluções padrão da mistura de pesticidas no GC-ECD e da mistura de PCBs no GC-MS. Para a construção da curva de cada analito, foram utilizados as seguintes concentrações dentro da faixa de linearidade do detector e faixa estimada para os níveis de concentração das amostras, totalizando nove pontos: 1 , $5,10,20,50,80,100,150$ e 200 pg. $\mu \mathrm{L}^{-1}$. Todos os padrões injetados continham o padrão interno (PI) e cromatográfico (PI-CG) na concentração final de $100 \mathrm{pg} \cdot \mu \mathrm{L}^{-1}$.

Para todas as curvas foi considerado um coeficiente de correlação maior ou igual a 99,5\% $(r=0,995)$, conforme proposto em Sericano (1998). As curvas foram verificadas recalculando-se seus próprios pontos. A curva estava boa para o uso caso apresentasse um fator de resposta com menos de $25 \%$ de variação.

\subsubsection{PROCEDIMENTO ANALÍTICO}

O procedimento analítico para extração, purificação e análise cromatográfica das amostras foi baseada em publicações do National Oceanographic and Atmospheric Administration; Sericano (1998); Mcleod et al. (1986) e Yogui et al. (2003). Os experimentos foram divididos em 2 etapas: 1) Extração; 2) Purificação dos extratos.

Aproximadamente 0,5 g de tecido adiposo subcutâneo de um espécime de toninha (Pontoporia blainvillei), armazenadas previamente no freezer em papel alumínio foram utilizadas em cada uma das amostras. As porções de amostras utilizadas foram cortadas da parte interna da amostra original para evitar contaminações que poderiam ter ocorrido na superfície. As amostras foram pesadas em papel alumínio utilizando-se uma balança analítica. 
Considerando que as matrizes gordurosas contêm pouca quantidade de água, não foi necessário liofilizar as amostras. Logo, foi usado o sulfato de sódio anidro $\left(\mathrm{Na}_{2} \mathrm{SO}_{4}\right)$ para evitar o surgimento de duas fases nesta etapa.

\subsubsection{Extração em homogeneizador UltraTurrax}

Antes da utilização do homogenizador é necessária a lavagem do aparelho que foi feita da seguinte forma: primeiramente agita-se por 1 minuto $200 \mathrm{ml}$ de água destilada em um balão de fundo chato grande $(250 \mathrm{ml})$, depois por mais um minuto $100 \mathrm{ml} \mathrm{de}$ metanol em um balão de fundo chato pequeno $(125 \mathrm{ml})$ e por último agita-se mais um minuto $100 \mathrm{ml}$ da mistura $\mathrm{n}$-hexano/diclorometano em um balão pequeno. No final da extração de cada amostra foi realizada uma nova lavagem.

A amostra foi misturada com $10 \mathrm{~g}$ de $\mathrm{Na}_{2} \mathrm{SO}_{4}$ e extraída em homogenizador UltraTurrax com $30 \mathrm{ml}$ da mistura de n-hexano e diclorometano na proporção (1:1) (v/v) durante 3 minutos. $\mathrm{O}$ extrato é transferido para outro recipiente e são adicionados mais $15 \mathrm{ml}$ da mistura onde é homogenizado durante 3 minutos por mais 2 vezes. O extrato foi concentrado em evaporador rotativo a vácuo a $2 \mathrm{ml}$; reservou-se $0,1 \mathrm{ml}$ para determinação de lipídios, 0,9 $\mathrm{ml}$ para a purificação e 1,0 $\mathrm{ml}$ para armazenamento. Antes da extração, $100 \mu \mathrm{L}$ de cada um dos PIs (PCB 103 e 198) foram adicionados em cada uma das amostras e brancos.

\subsubsection{Tratamento com Ácido Sulfúrico}

A purificação da amostra foi realizada por tratamento ácido. Este tratamento foi adaptado de UNEP/FAO/IOC/IAEA (1986). O tratamento ácido é utilizado para a purificação dos extratos gordurosos, entretanto, alguns compostos sofrem transformações e não podem ser quantificados. Diversos grupos de compostos organoclorados são estáveis sob tratamento ácido, como PCBs, DDTs, HCHs, entre outros. Em contrapartida, analitos como dieldrin, endrin e heptacloro epóxido são destruídos, assim como os lipídios que são interferentes na análise.

A reação ocorreu entre $0,9 \mathrm{~mL}$ do extrato e 2,0 $\mathrm{mL}$ de ácido sulfúrico concentrado (96\%) e agitados durante 1 minuto para garantir a hidrólise completa dos lipídios. Após esse período, os tubos de reação foram colocados em centrífuga Excelsa II (modelo 206 $\mathrm{BL}$ ) por 60 minutos, com $2500 \mathrm{rpm}$, no formato de 16 X $15 \mathrm{ml}$. Para balancear os pesos 
na centrifuga, onde haviam frascos vazios foram colocados frascos com água contendo o mesmo peso dos frascos com amostras.

A fase hexânica foi separada e lavada com $10 \mathrm{~mL}$ de água livre de orgânicos 2 vezes agitando-se essa mistura heterogênea por 1 minuto. Essa etapa é importante para remover resíduos de ácido dissolvidos no n-hexano (que podem danificar a coluna capilar do cromatógrafo), bem como compostos polares resultantes do tratamento ácido. Filtrouse a fase hexânica em sulfato de sódio e concentrou-se o filtrado em nitrogênio a $0,5 \mathrm{~mL}$ onde foi adicionado $50 \mu 1$ de PI-CG (TCMX).

As análises dos pesticidas organoclorados foram feitas em cromatógrafo a gás com detector de captura de elétrons (GC-ECD), enquanto que dos PCBs (bifenilas policloradas) foram feitas em um cromatógrafo a gás com detector de espectrômetro de massa (GC-MS), descritas nos itens 2.2.1.4.1 e 2.2.1.4.2.

\subsubsection{Estimativa da quantidade de lipídios extraíveis}

A análise de lipídios foi feita através de método gravimétrico, baseado em UNEP/FAO/IOC/IAEA (1986). O peso lipídico foi calculado separando-se uma alíquota de $0,1 \mathrm{ml}$ do extrato concentrado. Este volume foi colocado em pequenos frascos de vidro, previamente pesados. Após a total evaporação, cada frasco foi novamente pesado e a diferença entre a pesagem inicial e a pesagem após a adição e evaporação da alíquota foi utilizada no cálculo da percentagem de lipídios. A equação utilizada foi:

$$
\text { \%lipídios }=\frac{\text { massa resíduo }(\mathrm{g}) \text { x volume total do extrato }(\mathrm{ml})}{\text { massa amostra }(\mathrm{g}) \times \text { vol. da alíquota }(\mathrm{ml})} \times 100
$$

\subsubsection{LIMITE DE DETECÇÃO DO MÉTODO (LDM)}

O LDM é definido como a concentração mínima de uma substância que pode ser medida com $99 \%$ de confiança de que essa concentração é maior do que zero e pode ser determinada em uma matriz contendo o analito (Wade \& Cantillo, 1994). Assim, uma das maneiras de se calcular o LDM é através da quantificação de uma pequena quantidade de analitos adicionados a uma matriz que não contenha os compostos em estudo. A determinação do LDM com o uso de matrizes, possibilita avaliar a influência das matrizes durante a análise. Porém, uma grande dificuldade em determinar LDM desta forma é a obtenção de amostras reais das matrizes que sejam "limpas", ou seja, que apresentem baixas concentrações dos analitos. 
No caso dos mamíferos marinhos, por se tratar de organismos que pertencem ao topo de suas cadeias tróficas, é muito difícil de encontrar um indivíduo livre da contaminação por organoclorados. Desta forma, alternativamente, para a determinação do LDM foi utilizado como amostra o fígado de uma raia-morcego (Rhinoptera sp.) fêmea capturada em Ubatuba, SP, por ser uma matriz gordurosa e de um local com baixas concentrações de poluentes.

Foram feitas 7 réplicas de aproximadamente $0,2 \mathrm{~g}$ cada e analisadas segundo o Método 3 (Item 2.1.2.3), fortificadas com $100 \mu \mathrm{l}$ de mistura padrão de OCs com uma concentração 20 pg. $\mu 1^{-1}$ e $100 \mu 1$ de PIs (PCB 103 e 198) em um volume final de 1,0 mL. Foi retirada uma alíquota de $0,1 \mathrm{~mL}$ para a determinação dos lipídios. Antes da injeção nos cromatógrafos, foi adicionado $90 \mu \mathrm{l}$ de PI-CG (TCMX), em um volume final de 0,9 $\mathrm{ml}$.

O LDM foi determinado a partir do desvio padrão dessas réplicas com os valores mais próximos, e estes desvios foram multiplicados por 3 (Wade \& Cantillo, 1994).

Para a discussão deste trabalho, foram utilizados os dados que se encontravam acima do Limite de Detecção do Método (LDM), ao invés do Limite de Quantificação (LQM). A aplicação do LQM não permitiria discutir a presença de compostos detectados acima do LDM mas abaixo do LQM, o que poderia prejudicar a avaliação da presença de alguns compostos nas amostras.

A Tabela 2.4 apresenta os valores do LDM calculados para cada pesticida organoclorado e para cada congênere de PCB analisados neste estudo, respectivamente.

Tabela 2.4 - Limite de detecção do método (LDM) para cada composto em estudo.

\begin{tabular}{lc}
\hline Composto & $\begin{array}{c}\text { LDM } \\
\left(\mathrm{ng} . \mathrm{g}^{-1}\right)\end{array}$ \\
\hline$o, p^{\prime}$-DDT & 9,7 \\
$p, p^{\prime}$-DDT & 7,6 \\
$o, p^{\prime}$-DDD & 9,7 \\
$p, p^{\prime}$-DDD & 10,2 \\
$o, p^{\prime}-\mathrm{DDE}$ & 2,8 \\
$p, p^{\prime}$-DDE & 3,3 \\
& \\
a-HCH & 2,1 \\
$\beta$-HCH & 6,9 \\
g-HCH & 3,4 \\
$\delta$-HCH & 4,4 \\
& \\
heptacloro & 3,1 \\
g-clordana & 2,3 \\
oxiclordana & 6,3 \\
HCB & \\
& 2,0 \\
mirex & 7,4 \\
\hline
\end{tabular}

\begin{tabular}{lccc}
\hline Composto & $\begin{array}{c}\text { LDM } \\
(\text { ng.g }\end{array}$ & Composto & $\begin{array}{c}\text { LDM } \\
\left(\mathrm{ng} . \mathrm{g}^{-1}\right)\end{array}$ \\
\hline PCB8 & 1,7 & PCB153 & 6,0 \\
PCB18 & 3,0 & PCB132 & 3,7 \\
PCB31 & 3,2 & PCB105 & 3,4 \\
PCB28 & 2,9 & PCB141 & 3,3 \\
PCB33 & 3,0 & PCB138 & 5,5 \\
PCB52 & 2,9 & PCB158 & 1,6 \\
PCB49 & 2,5 & PCB126 & 3,0 \\
PCB44 & 2,6 & PCB187 & 2,0 \\
PCB74 & 1,8 & PCB183 & 2,5 \\
PCB70 & 3,3 & PCB128 & 2,5 \\
PCB66 & 2,6 & PCB167 & 2,5 \\
PCB95 & 3,2 & PCB174 & 1,7 \\
PCB56/60 & 2,8 & PCB177 & 2,6 \\
PCB101 & 3,2 & PCB156 & 3,2 \\
PCB99 & 1,9 & PCB157 & 3,9 \\
PCB97 & 2,1 & PCB180 & 3,9 \\
PCB81 & 1,8 & PCB169 & 3,4 \\
PCB87 & 1,8 & PCB170 & 2,6 \\
BCP77 & 2,8 & PCB199 & 2,4 \\
PCB110 & 4,2 & PCB203 & 2,3 \\
PCB151 & 2,1 & PCB189 & 2,2 \\
PCB123 & 2,1 & PCB195 & 4,1 \\
PCB149 & 1,5 & PCB194 & 3,4 \\
PCB118 & 2,6 & PCB206 & 3,7 \\
PCB114 & 1,7 & PCB209 & 2,4 \\
\hline
\end{tabular}




\subsubsection{VALIDAÇÃO DA METODOLOGIA ANALÍTICA}

\subsubsection{Controle de Qualidade}

A metodologia deve ter seu desempenho avaliado a fim de verificar a confiabilidade dos resultados, os interferentes na matriz e a recuperação dos compostos adicionados. Com esse intuito, o controle de qualidade do método foi obtido com a seguinte bateria de amostras: (1) branco, (2) branco fortificado, (3) matriz, (4) duplicata e (5) matriz fortificada. As amostras (1) e (2) são brancos de análise, ou seja, incluem todos os reagentes e etapas a que a amostra foi submetida.

Um branco aceitável não deve apresentar mais do que 3 picos referentes aos analitos e seu nível de concentração não pode ser maior do que 3 vezes o limite de detecção do método, a não ser que a concentração do analito na amostra seja 10 vezes o limite de detecção do método. O branco foi usado para determinar se as amostras foram contaminadas durante todo o processo analítico, sendo que os valores encontrados no branco foram descontados de todo o restante das amostras (Sericano, 1998).

A análise de uma amostra em duplicata demonstra a heterogeneidade da amostra $\mathrm{e}$ precisão analítica na presença de uma matriz representativa, sendo que a diferença entre a amostra original e a duplicata não deve ultrapassar 25 \% (Sericano, 1998).

O branco fortificado e a matriz fortificada são usados para estimar a exatidão e precisão do método, quando se trabalha com matrizes complexas. Uma recuperação aceitável deve conter $80 \%$ dos analitos no limite entre $50 \%$ e $150 \%$ de recuperação e recuperação do padrão interno (PI) entre 40\% e 120\% em cada amostra analisada (Sericano, 1998). Para o cálculo da recuperação do PI utilizou-se a relação de área entre o PI e o PICG.

Os resultados foram analisados em termos de recuperação dos analitos adicionados, assim, obteve-se resultados de recuperação do branco (subtraindo os resultados de branco adicionado e branco) e das duas réplicas da matriz (subtraindo os resultados de matriz adicionada e média da matriz réplica $\mathrm{A}$ e $\mathrm{B}$ ). Todos eles foram expressos em termos de porcentagem.

De acordo com os resultados obtidos neste controle, mostrou-se que esta metodologia encontra-se adequada para as amostras de P. blainvillei, pois apresentou valores de recuperação dentro dos critérios propostos por Sericano (1998), tanto para os padrões internos quanto para os padrões externos (adicionados). Os resultados dos 
pesticidas organoclorados adicionados podem ser observados na Tabela 2.5 e os PCBs adicionados e seus resultados constam na Tabela 2.6.

Tabela 2.5 - Recuperação (\%) dos pesticidas organoclorados no branco e nas réplicas da matriz.

\begin{tabular}{lcc}
\hline Composto & $\begin{array}{c}\text { Branco } \\
\text { Rec. (\%) }\end{array}$ & $\begin{array}{c}\text { Amostra } \\
\text { Rec. (\%) }\end{array}$ \\
\hline$o, p^{\prime}$-DDT & 81 & 78 \\
$p, p^{\prime}-\mathrm{DDT}$ & 85 & 78 \\
$o, p^{\prime}$-DDD & 91 & 79 \\
$p, p^{\prime}$-DDD & 102 & 106 \\
$o, p^{\prime}$-DDE & 96 & 88 \\
$p, p^{\prime}$-DDE & 98 & 58 \\
a-HCH & 99 & 95 \\
3-HCH & 85 & 65 \\
g-HCH & 85 & 71 \\
$\delta$-HCH & 59 & 57 \\
heptacloro & 84 & 63 \\
g-clordana & 88 & 82 \\
oxiclordana & 81 & 81 \\
HCB & 81 & 75 \\
mirex & 81 & 101 \\
\hline
\end{tabular}

Tabela 2.6 - Recuperação (\%) dos PCBs no branco e nas réplicas da matriz.

\begin{tabular}{lcclcc}
\hline Composto & $\begin{array}{c}\text { Branco } \\
\text { Rec. (\%) }\end{array}$ & $\begin{array}{c}\text { Amostra } \\
\text { Rec. (\%) }\end{array}$ & Composto & $\begin{array}{c}\text { Branco } \\
\text { Rec. (\%) }\end{array}$ & $\begin{array}{c}\text { Amostra } \\
\text { Rec. (\%) }\end{array}$ \\
\hline PCB8 & 93 & 92 & PCB153 & 114 & 185 \\
PCB18 & 88 & 84 & PCB132 & 85 & 57 \\
PCB31 & 111 & 92 & PCB105 & 109 & 89 \\
PCB28 & 96 & 80 & PCB141 & 114 & 123 \\
PCB33 & 92 & 83 & PCB138 & 123 & 162 \\
PCB52 & 101 & 108 & PCB158 & 107 & 86 \\
PCB49 & 91 & 86 & PCB126 & 119 & 125 \\
PCB44 & 92 & 84 & PCB187 & 104 & 108 \\
PCB74 & 98 & 96 & PCB183 & 122 & 104 \\
PCB70 & 96 & 89 & PCB128 & 128 & 107 \\
PCB66 & 96 & 90 & PCB167 & 140 & 125 \\
PCB95 & 89 & 68 & PCB174 & 114 & 98 \\
PCB56/60 & 100 & 88 & PCB177 & 118 & 107 \\
PCB101 & 107 & 125 & PCB156 & 126 & 129 \\
PCB99 & 96 & 102 & PCB157 & 123 & 119 \\
PCB97 & 96 & 93 & PCB180 & 137 & 150 \\
PCB81 & 105 & 104 & PCB169 & 132 & 152 \\
PCB87 & 95 & 83 & PCB170 & 126 & 132 \\
BCP77 & 122 & 119 & PCB199 & 114 & 102 \\
PCB110 & 113 & 117 & PCB203 & 124 & 132 \\
PCB151 & 114 & 103 & PCB189 & 154 & 168 \\
PCB123 & 107 & 107 & PCB195 & 125 & 116 \\
PCB149 & 99 & 87 & PCB194 & 150 & 147 \\
PCB118 & 106 & 106 & PCB206 & 136 & 138 \\
PCB114 & 118 & 122 & PCB209 & 122 & 111 \\
\hline & & & & &
\end{tabular}


Estes resultados mostraram que os seguintes pesticidas não foram recuperados através do tratamento ácido: Isodrin, Heptacloro Epóxido A e B, $\alpha$-clordana, Dieldrin, Endrin, Endosulfan I e II, Metoxicloro.

Nas amostras analisadas foram utilizados os PCBs 103 e 198 como padrões internos. O PCB 103 foi utilizado para calcular a concentração dos compostos estudados. Os resultados das recuperações dos padrões internos no controle de qualidade estão na Tabela 2.7 .

Tabela 2.7 Recuperação (\%) dos padrões internos PCB 103 e 198 nas amostras.

\begin{tabular}{lcc}
\hline Amostra & \multicolumn{2}{c}{ Rec. (\%) } \\
& PCB 103 & PCB 198 \\
\hline branco & 96 & 110 \\
branco fortificado & 96 & 98 \\
matriz réplica A & 71 & 91 \\
matriz réplica B & 40 & 105 \\
matriz adicionada & 77 & 102 \\
\hline
\end{tabular}

A etapa de validação é a mais importante no desenvolvimento de uma metodologia analítica, pois todas as análises provenientes de uma metodologia podem ser colocadas em xeque quanto à confiabilidade de seus resultados. Assim, antes de empregar um procedimento analítico de forma regular é essencial checar o desempenho do método frente a materiais de referência certificados, para assegurar a produção de dados exatos e precisos (UNEP/IOC/IAEA/FAO, 1989).

Com o intuito de validar a metodologia otimizada para analisar organoclorados em gordura de cetáceos, foi utilizado um material de referência padrão do National Institute of Standards and Technology (NIST), sediado nos Estados Unidos. Este órgão comercializa gordura de baleia (SRM 1945), que é ideal para validar a metodologia analítica em questão e contém concentrações certificadas de orgânicos (congêneres de PCB, pesticidas organoclorados e analitos adicionais) (NIST, 1998).

A análise de organoclorados no SRM 1945 (orgânicos em gordura de baleia) foi procedida de acordo com o procedimento analítico adotado para as amostras. A comparação entre a metodologia e o certificado de análise do SRM 1945 foi feita utilizando-se o critério para validação baseado em Wade \& Cantillo (1994), que leva em consideração um intervalo de $\pm 35 \%$ em torno dos limites do intervalo de confiança 
(95\%) estabelecido no certificado de análise. De acordo com a Tabela 2.8, o método desenvolvido foi válido para todos os analitos certificados.

Tabela 2.8 - Validação da metodologia otimizada para os compostos (baseada nos valores de concentração certificada pelo SRM 1945).

\begin{tabular}{|c|c|c|c|c|c|c|}
\hline \multicolumn{2}{|c|}{ Resultados obtidos } & \multicolumn{5}{|c|}{ Resultados aceitáveis } \\
\hline \multirow[t]{2}{*}{ Compostos } & \multirow[t]{2}{*}{$\left(\operatorname{ng~g}^{-1}\right)$} & \multirow{2}{*}{$\begin{array}{c}\text { Valor certificado (95\%) } \\
\left(\mathrm{ng} \mathrm{g}^{-1}\right)\end{array}$} & \multirow[t]{2}{*}{ Desvio padrão } & \multicolumn{2}{|c|}{ Faixa aceitável } & \multirow[b]{2}{*}{ Avaliação } \\
\hline & & & & inferior & superior & \\
\hline$\overline{\mathrm{PCB} 18}$ & 3,51 & 4,5 & 0,9 & 2,3 & 7,2 & OK \\
\hline PCB52 & 28,1 & 43,6 & 2,5 & 26,7 & 62,2 & OK \\
\hline PCB49 & 11,2 & 20,8 & 2,8 & 11,7 & 31,9 & OK \\
\hline РCB44 & 7,2 & 12,2 & 1,4 & 7,0 & 18,4 & OK \\
\hline PCB66 & 15,3 & 23,6 & 1,6 & 14,3 & 34,0 & OK \\
\hline PCB95 & 21,7 & 33,8 & 1,7 & 20,9 & 47,9 & OK \\
\hline PCB101 & 49,6 & 65,2 & 5,6 & 38,7 & 95,6 & OK \\
\hline PCB99 & 30,3 & 45,4 & 5,4 & 26,0 & 68,6 & OK \\
\hline PCB87 & 15,6 & 16,7 & 1,4 & 9,9 & 24,5 & OK \\
\hline PCB110 & 21,8 & 23,3 & 4,0 & 12,5 & 36,9 & OK \\
\hline PCB151 & 16,6 & 28,7 & 5,2 & 15,3 & 45,8 & OK \\
\hline PCB149 & 66,0 & 107 & 8,4 & 63,8 & 155 & OK \\
\hline PCB118 & 51,2 & 74,6 & 5,1 & 45,2 & 107 & OK \\
\hline PCB153 & 201 & 213 & 19,0 & 126 & 313 & OK \\
\hline PCB138 & 135 & 132 & 7,4 & 80,7 & 187 & OK \\
\hline PCB187 & 84,6 & 105 & 9,1 & 62,4 & 154 & OK \\
\hline PCB183 & 22,5 & 36,6 & 4,1 & 21,1 & 54,9 & OK \\
\hline PCB128 & 16,4 & 23,7 & 1,7 & 14,3 & 34,3 & OK \\
\hline PCB156 & 6,9 & 10,3 & 1,1 & 6,0 & 15,4 & OK \\
\hline PCB180 & 109 & 107 & 5,3 & 65,9 & 151 & OK \\
\hline PCB170 & 37,1 & 40,6 & 2,6 & 24,7 & 58,3 & OK \\
\hline PCB195 & 9,2 & 17,7 & 4,3 & 8,7 & 29,7 & OK \\
\hline PCB194 & 46,0 & 39,6 & 2,5 & 24,1 & 56,8 & OK \\
\hline PCB206 & 44,0 & 31,1 & 2,7 & 18,5 & 45,6 & OK \\
\hline PCB209 & 12,2 & 10,6 & 1,1 & 6,2 & 15,8 & OK \\
\hline $\mathrm{HCB}$ & 21,2 & 32,9 & 1,7 & 20,3 & 46,7 & OK \\
\hline$\alpha-\mathrm{HCH}$ & 9,4 & 16,2 & 3,4 & 6,1 & 21,9 & OK \\
\hline$\gamma-\mathrm{HCH}$ & 5,3 & 3,3 & 0,8 & 3,4 & 4,5 & OK \\
\hline Oxiclordana & 17,4 & 19,8 & 1,9 & 11,3 & 26,7 & OK \\
\hline Mirex & 31,1 & 28,9 & 2,8 & 20,2 & 39,0 & OK \\
\hline op'-DDE & 17,3 & 12,3 & 0,9 & 11,2 & 16,6 & OK \\
\hline pp'-DDE & 330 & 445 & 37,0 & 215 & 601 & $\mathrm{OK}$ \\
\hline op'-DDD & 23,0 & 18,1 & 2,8 & 14,9 & 24,4 & OK \\
\hline pp'-DDD & 153 & 133 & 10,0 & 99,2 & 180 & OK \\
\hline op'-DDT & 69,1 & 106 & 14,0 & 44,9 & 143 & OK \\
\hline pp'-DDT & 154 & 245 & 15,0 & 100 & 331 & OK \\
\hline
\end{tabular}




\section{RESULTADOS E DISCUSSÃO}

\subsection{ORGANOCLORADOS EM GORDURA DE TONINHAS}

Os resultados das análises de compostos organoclorados na gordura subcutânea de Pontoporia blainvillei foram expressos com base em peso lipídico. Segundo Aguilar (1987), os níveis de organoclorados expressos em relação ao peso úmido são inapropriados para estabelecer comparações entre diferentes órgãos de um mesmo indivíduo e/ou diferentes indivíduos em uma mesma população ou espécies diferentes. Isso porque ocorrem variações no conteúdo de lipídios dos tecidos que afetam substancialmente a carga do contaminante. Os resultados expressos em peso úmido estão no anexo.

Os DDTs compreendem a soma de o,p'-DDT, $p, p^{\prime}$-DDT, $o, p^{\prime}$-DDD, $p, p^{\prime}-\mathrm{DDD}, o, p$ 'DDE, $p, p^{\prime}$-DDE, as clordanas (CHLs) referem-se a soma de heptacloro, $\gamma$-clordana (gama-clordana ou g-clordana) e oxiclordana e os HCHs compreendem a soma dos isômeros $\alpha-\mathrm{HCH}, \beta-\mathrm{HCH}, \gamma-\mathrm{HCH}$ (lindano) e $\delta-\mathrm{HCH}$. Os PCBs compreendem a soma dos 51 PCBs descritos no item 2.1.1.3.

As concentrações dos compostos organoclorados nas toninhas do litoral paulista variaram, em ng.g $\mathrm{g}^{-1}$ lipídios nos PCBs de 326 a 42185, DDTs de 107 a 7185, HCHs n.d. a 46, CHLs n.d. a 126, HCB < 2 a 133 e Mirex $<7$ a 259. Os comprimentos totais (CT) dos animais variaram de 64 a $143 \mathrm{~cm}$ e as porcentagens de lipídios nas amostras de tecido adiposo subcutâneo variaram de 62 a $89 \%$.

\subsubsection{CONCENTRAÇÃO DOS COMPOSTOS VERSUS DADOS BIOLÓGICOS}

As análises estatísticas foram realizadas com o auxílio do programa Statistica (Statsoft, 1999). Foram realizados Testes W de Shapiro-Wilk para a verificação da normalidade dos dados, que se mostraram em aproximadamente $80 \%$ como não-normais $(\mathrm{p}>0,05)$. Sendo assim, foram realizados testes não-paramétricos para as análises estatísticas dos dados. Foram aplicados Testes de Spearman $(\mathrm{p}<0,05)$ para as análises de correlação entre as variáveis, Teste U de Mann-Whitney $(\mathrm{p}<0,05)$ para verificação de diferenças significativas comparando 2 grupos independentes de variáveis e Teste ANOVA e Mediana de Kruskal-Wallis comparando amostras independentes múltiplas.

Por não haver dados referentes à idade destes animais, foram utilizados os comprimentos totais para serem correlacionados com as concentrações dos compostos. 
Para se estimar a maturidade sexual, foram utilizados dados de comprimento total, uma vez que as análises histológicas das gônadas destes espécimes estão em andamento e integram os dados de uma tese do Programa de Oceanografia Biológica do Instituto Oceanográfico da Universidade de São Paulo (IOUSP).

As concentrações dos principais grupos de compostos organoclorados em cada espécime analisado contendo suas médias e amplitudes de acordo com as faixas etárias, constam nas Tabelas 3.1 a 3.4 .

Tabela 3.1- Concentração de pesticidas organoclorados (ng. $\mathrm{g}^{-1}$ lipídios) na gordura subcutânea de toninhas (P. blainvillei) machos do litoral paulista.

\begin{tabular}{|c|c|c|c|c|c|c|c|}
\hline Sexo e Maturidade & Num. Tombo & Lipidios (\%) & $\sum$ DDTs & $\begin{array}{c}\sum \mathrm{HCHs} \\
\text { (ng.g }{ }^{-1} \text { lipídios) }\end{array}$ & $\sum \mathrm{CHLs}$ & $\mathrm{HCB}$ & Mirex \\
\hline \multicolumn{8}{|l|}{ Machos Maduros } \\
\hline & BP 13 & 65,3 & 3883 & 12,9 & 67,4 & 65,7 & 62,0 \\
\hline & BP 21 & 77,3 & 1664 & n.d. & 14,5 & 29,0 & 65,0 \\
\hline & BP 64 & 74,8 & 7114 & n.d. & 35,5 & 21,4 & 258,7 \\
\hline & BP 91 & 68,3 & 1589 & n.d. & n.d. & 14,0 & 77,4 \\
\hline & BP 103 & 77,4 & 1069 & n.d. & 10,7 & 18,6 & 19,4 \\
\hline & BP 104 & 80,7 & 1193 & n.d. & 11,9 & 12,7 & 33,6 \\
\hline & BP 110 & 76,0 & 3640 & n.d. & 49,4 & 19,5 & 167,0 \\
\hline & BP 133 & 74,3 & 1223 & n.d. & 26,7 & 29,4 & $<7.4$ \\
\hline & BP 136 & 65,2 & 7186 & 5,0 & 98,1 & 51,5 & 250,1 \\
\hline & BP 157 & 80,4 & 3461 & n.d. & 16,0 & 11,1 & 131,1 \\
\hline Média $(n=10)$ & & $\mathbf{7 4 , 0}$ & 3202 & 1,8 & 33,0 & 27,3 & 106,4 \\
\hline Amplitude & & $65,2-80,7$ & $1069-7186$ & n.d.-12,9 & n.d.-98,1 & $11,1-65,7$ & $<7,4-258,7$ \\
\hline \multicolumn{8}{|l|}{ Machos Imaturos } \\
\hline Subadultos & BP 19 & 78,9 & 3189 & n.d. & 48,3 & 56,6 & 64,6 \\
\hline & BP 56 & 61,7 & 1120 & 21,4 & 24,5 & 16,7 & 28,4 \\
\hline & BP 63 & 75,3 & 1203 & n.d. & 16,1 & 11,9 & 45,9 \\
\hline & BP 72 & 79,9 & 1372 & n.d. & 10,7 & 21,7 & 14,1 \\
\hline & BP 75 & 70,7 & 1673 & n.d. & 32,1 & 30,7 & 25,4 \\
\hline & BP 82 & 78,5 & 1362 & n.d. & 8,4 & 19,3 & 12,7 \\
\hline & BP 84 & 76,0 & 1082 & n.d. & 23,2 & 18,8 & 24,2 \\
\hline & BP 85 & 69,9 & 1199 & n.d. & 20,0 & 14,1 & 21,6 \\
\hline & BP 120 & 78,1 & 1248 & n.d. & 8,1 & 11,2 & 31,1 \\
\hline & BP 125 & 79,0 & 1035 & n.d. & 15,9 & 19,8 & 20,5 \\
\hline Média (n=10) & & $\mathbf{7 4 , 8}$ & 1448 & 2,1 & 20,7 & 22,1 & 28,9 \\
\hline Amplitude & & $61,7-79,9$ & 1035-3189 & n.d.-21,4 & $8,1-48,3$ & $11,9-56,6$ & $12,7-64,6$ \\
\hline Filhotes & BP 46 & 81,5 & 276 & n.d. & n.d. & 6,3 & $<7.4$ \\
\hline & BP 59 & 85,6 & 481 & 16,3 & 31,8 & 21,7 & 36,9 \\
\hline & BP 66 & 71,0 & 1583 & n.d. & 20,8 & 21,8 & 16,5 \\
\hline & BP 70 & 87,8 & 522 & n.d. & 14,7 & 10,4 & 17,5 \\
\hline & BP 88 & 88,6 & 281 & 7,8 & n.d. & 13,9 & $<7.4$ \\
\hline & BP 94 & 84,6 & 1273 & n.d. & 20,8 & 14,9 & 21,3 \\
\hline & BP 107 & 87,9 & 428 & n.d. & n.d. & 7,6 & 10,6 \\
\hline & BP 112 & 84,2 & 609 & n.d. & 8,4 & 16,5 & 15,4 \\
\hline & BP 116 & 86,5 & 2142 & n.d. & 42,9 & 38,9 & 23,3 \\
\hline Média $(n=9)$ & & 84,2 & 844 & 2,4 & 15,0 & 16,9 & 17,8 \\
\hline Amplitude & & $71-88,6$ & 281-2142 & n.d.-16,3 & n.d. $-42,9$ & $6,3-38,9$ & $<7,4-36,9$ \\
\hline
\end{tabular}


Os níveis residuais de compostos organoclorados nos machos, em ng. $\mathrm{g}^{-1}$ de lipídios, variaram de 1100 a 42185 de PCBs; 281 a 7186 de DDTs; de n.d. a 21 de HCHs; n.d. a 98 de CHLs; 6 a 66 de HCB e $<7$ a 259 de Mirex. Em todos os casos os maduros tiveram maiores concentrações que os imaturos (Tabela 3.1 e 3.3 e Figuras 3.1 a 3.3), pois nestes há uma tendência de aumento na concentração dos OCs de acordo com a idade (Borrel et al., 1995).

Nas fêmeas, em ng.g ${ }^{-1}$ de lipídios, abrangeram de 326 a 22181 de PCBs; 107 a 2405 de DDTs; n.d. a 46 de HCHs; n.d. a 123 de CHLs; $<2$ a 133 de HCB e $<7$ a 70 de Mirex. As concentrações variaram com as maturidades, com as juvenis apresentando as maiores concentrações, com exceção do Mirex e HCHs (Tabela 3.2 e Figuras 3.1 a 3.3).

Tabela 3.2 - Concentração de pesticidas organoclorados (ng.g ${ }^{-1}$ lipídios) na gordura subcutânea de toninhas ( $P$. blainvillei) fêmeas do litoral paulista.

\begin{tabular}{|c|c|c|c|c|c|c|c|}
\hline Sexo e Maturidade & \multicolumn{7}{|c|}{ (ng.g ${ }^{-1}$ lipídios) } \\
\hline \multicolumn{8}{|l|}{ Fêmeas Maduras } \\
\hline & BP 16 & 77,2 & 1211 & n.d. & 10,8 & 17,7 & 66,6 \\
\hline & BP 43 & 83,5 & 547 & n.d. & n.d. & 13,0 & 23,1 \\
\hline & BP 44 & 80,8 & 637 & n.d. & n.d. & 14,8 & 26,9 \\
\hline & BP 48 & 85,1 & 520 & 5,4 & n.d. & 3,5 & 69,1 \\
\hline & BP 50 & 63,2 & 2405 & n.d. & 27,1 & 21,0 & 59,4 \\
\hline & BP 62 & 61,8 & 107 & 8,8 & n.d. & $<2.0$ & 69,9 \\
\hline & BP 93 & 67,7 & 701 & n.d. & 10,7 & 12,4 & 22,7 \\
\hline & BP 132 & 73,4 & 509 & n.d. & n.d. & 7,4 & 14,8 \\
\hline & BP 137 & 86,9 & 150 & n.d. & n.d. & $<2.0$ & 28,5 \\
\hline & BP 152 & 75,6 & 424 & 45,7 & 6,2 & 4,4 & 33,6 \\
\hline & BP 153 & 81,2 & 573 & n.d. & n.d. & 3,3 & 36,3 \\
\hline Média $(n=11)$ & & 76,0 & 707 & 5,4 & 5,0 & 8,9 & 41,0 \\
\hline Amplitude & & $61,8-86,9$ & $107-2405$ & n.d.-45,7 & n.d.-27,1 & $<2,0-21$ & $14,8-69,9$ \\
\hline \multicolumn{8}{|l|}{ Fêmeas Imaturas } \\
\hline Subadultos & BP 83 & 76,6 & 372 & n.d. & 32,3 & 10,6 & 26,4 \\
\hline & BP 90 & 77,7 & 670 & n.d. & 19,2 & 13,0 & 19,3 \\
\hline & BP 101 & 71,3 & 1349 & 10,9 & 122,8 & 133,5 & 49,2 \\
\hline & BP 102 & 75,4 & 429 & n.d. & 37,2 & 18,2 & 36,2 \\
\hline & BP 109 & 81,6 & 255 & n.d. & 15,7 & 9,1 & 39,2 \\
\hline & BP 113 & 77,9 & 1517 & n.d. & 20,7 & 23,0 & 25,4 \\
\hline & BP 124 & 74,1 & 568 & n.d. & 30,4 & 28,1 & 23,8 \\
\hline & BP 126 & 80,7 & 638 & n.d. & 12,0 & 12,5 & 21,2 \\
\hline Média $(n=8)$ & & 76,9 & 725 & 1,2 & 32,3 & 32,3 & 30,1 \\
\hline Amplitude & & $71,3-81,6$ & $255-1517$ & n.d.-10,9 & n.d.-122,8 & $9,1-133,5$ & $19,3-49,2$ \\
\hline \multirow[t]{5}{*}{ Filhotes } & BP 45 & 70,3 & 755 & n.d. & 11,8 & 15,5 & 12,2 \\
\hline & BP 89 & 68,5 & 312 & n.d. & n.d. & 8,9 & 12,0 \\
\hline & BP 100 & 73,8 & 1395 & n.d. & 40,4 & 42,0 & 23,2 \\
\hline & BP 108 & 63,8 & 197 & n.d. & n.d. & 11,6 & 31,6 \\
\hline & BP 146 & 80,4 & 441 & n.d. & 8,3 & 15,3 & $<7.4$ \\
\hline Média $(n=5)$ & & 71,4 & 620 & n.d. & 8,3 & 18,7 & 15,8 \\
\hline Amplitude & & $63,8-80,4$ & $197-1395$ & n.d. & n.d.-40,4 & $8,9-42$ & $<7,4-31,6$ \\
\hline
\end{tabular}


Os grupos de OCs apresentaram-se na seguinte ordem decrescente de concentração média nos indivíduos machos e fêmeas adultos: PCBs $>$ DDTs $>$ Mirex $>$ $\mathrm{HCB}>\mathrm{CHLs}=\mathrm{HCHs}($ Figuras 3.1 a 3.3).

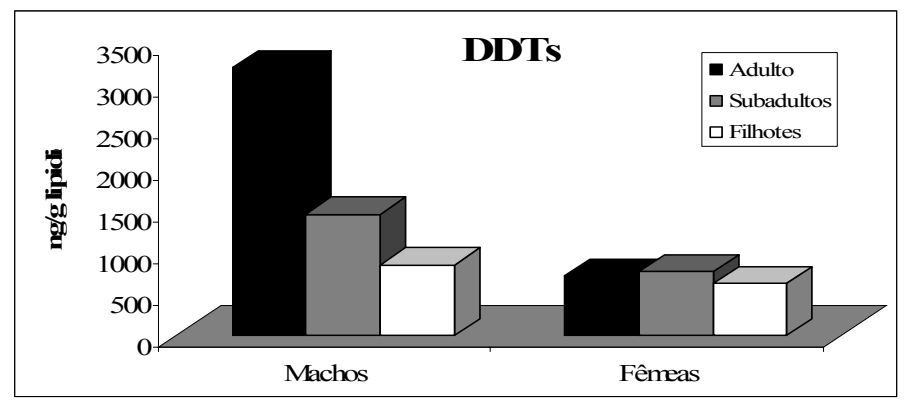

Figura 3.1 Concentrações médias de DDTs (ng/g lipídios) em toninhas ( $P$. blainvillei) machos e fêmeas em diferentes faixas etárias.
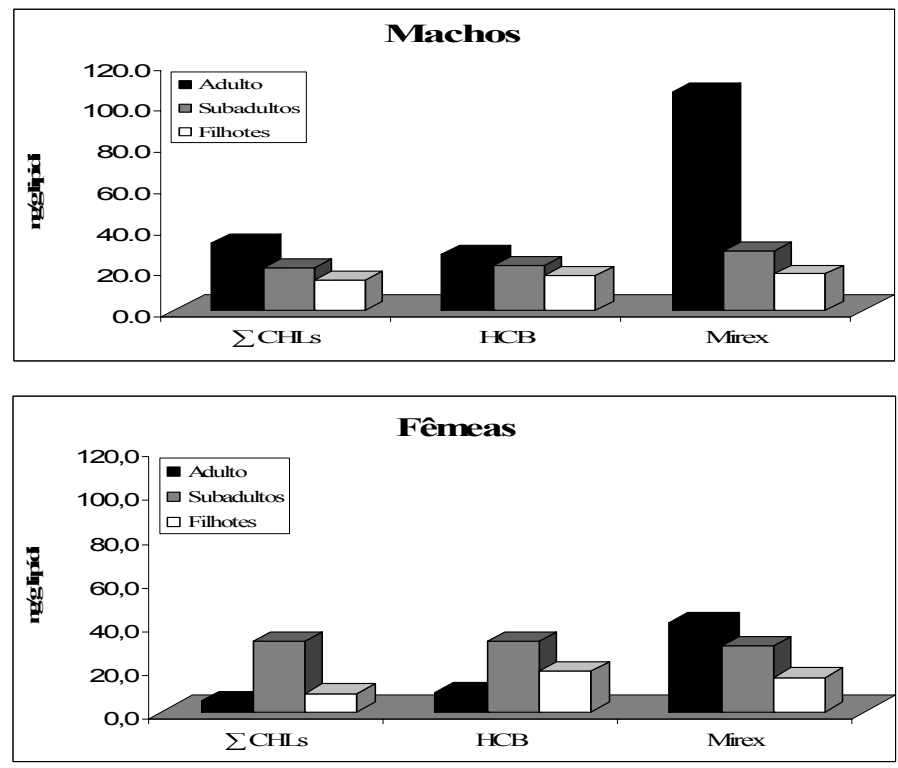

Figura 3.2 Concentrações médias de pesticidas organoclorados (em ng. $\mathrm{g}^{-1}$ de lipídios) em toninhas (P. blainvillei) machos e fêmeas em diferentes faixas etárias.

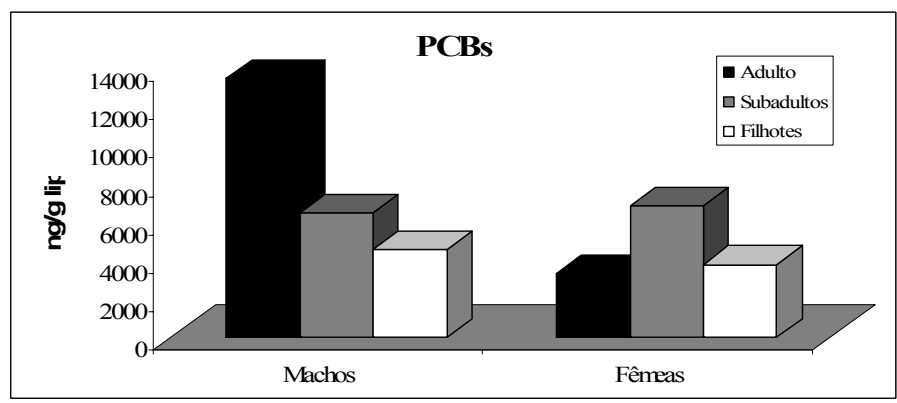

Figura 3.3 Concentrações médias de PCBs (em ng.g ${ }^{-1}$ de lipídios) em toninhas (P. blainvillei) machos e fêmeas em diferentes faixas etárias. 
Tabela 3.3- Concentração de PCBs (ng. g $^{-1}$ lipídios) e razão DDTs/PCBs na gordura subcutânea de toninhas ( $P$. blainvillei) machos do litoral paulista.

\begin{tabular}{|c|c|c|c|c|}
\hline Sexo e Maturidade & Num. Tombo & Lipidios (\%) & $\begin{array}{c}\sum \text { PCBs } \\
\text { (ng.g }{ }^{-1} \text { lipídios) }\end{array}$ & DDTs/PCBs \\
\hline \multicolumn{5}{|l|}{ Machos Maduros } \\
\hline & BP 13 & 65,3 & 19537 & 0,20 \\
\hline & BP 21 & 77,3 & 8156 & 0,20 \\
\hline & BP 64 & 74,8 & 18903 & 0,38 \\
\hline & BP 91 & 68,3 & 4057 & 0,39 \\
\hline & BP 103 & 77,4 & 4946 & 0,22 \\
\hline & BP 104 & 80,7 & 3099 & 0,39 \\
\hline & BP 110 & 76,0 & 19177 & 0,19 \\
\hline & BP 133 & 74,3 & 6155 & 0,20 \\
\hline & BP 136 & 65,2 & 42185 & 0,17 \\
\hline & BP 157 & 80,4 & 7770 & 0,45 \\
\hline Média $(n=10)$ & & 74,0 & 13399 & 0,28 \\
\hline Amplitude & & $65,2-80,7$ & $3099-19537$ & $0,17-0,45$ \\
\hline \multicolumn{5}{|l|}{ Machos Imaturos } \\
\hline Subadultos & BP 19 & 78,9 & 14811 & 0,22 \\
\hline & BP 56 & 61,7 & 6128 & 0,18 \\
\hline & BP 63 & 75,3 & 4834 & 0,25 \\
\hline & BP 72 & 79,9 & 5931 & 0,23 \\
\hline & BP 75 & 70,7 & 9689 & 0,17 \\
\hline & BP 82 & 78,5 & 6154 & 0,22 \\
\hline & BP 84 & 76,0 & 4281 & 0,25 \\
\hline & BP 85 & 69,9 & 4418 & 0,27 \\
\hline & BP 120 & 78,1 & 3351 & 0,37 \\
\hline & BP 125 & 79,0 & 4826 & 0,21 \\
\hline Média $(n=10)$ & & 74,8 & 6442 & 0,24 \\
\hline Amplitude & & $61,7-79,9$ & $3351-14811$ & $0,17-0,37$ \\
\hline Filhotes & BP 46 & 81,5 & 1100 & 0,25 \\
\hline & BP 59 & 85,6 & 8660 & 0,06 \\
\hline & BP 66 & 71,0 & 6495 & 0,24 \\
\hline & BP 70 & 87,8 & 2834 & 0,18 \\
\hline & BP 88 & 88,6 & 1480 & 0,19 \\
\hline & BP 94 & 84,6 & 5551 & 0,23 \\
\hline & BP 107 & 87,9 & 2290 & 0,19 \\
\hline & BP 112 & 84,2 & 3160 & 0,19 \\
\hline & BP 116 & 86,5 & 8971 & 0,24 \\
\hline Média $(n=9)$ & & 83,0 & 4505 & $\mathbf{0 , 2 0}$ \\
\hline Amplitude & & $71-88,6$ & $1100-8971$ & $0,06-0,25$ \\
\hline
\end{tabular}


Tabela 3.4- Concentração de PCBs (ng.g ${ }^{-1}$ lipídios) e razão DDTs/PCBs na gordura subcutânea de toninhas ( $P$. blainvillei) fêmeas do litoral paulista.

\begin{tabular}{|c|c|c|c|c|}
\hline Sexo e Maturidade & Num. Tombo & Lipidios (\%) & $\begin{array}{c}\sum \text { PCBs } \\
\text { (ng. } \mathrm{g}^{-1} \text { lipidios) }\end{array}$ & DDTs/PCBs \\
\hline \multicolumn{5}{|l|}{ Fêmeas Maduras } \\
\hline & BP 16 & 77,2 & 6074 & 0,20 \\
\hline & BP 43 & 83,5 & 2331 & 0,23 \\
\hline & BP 44 & 80,8 & 2322 & 0,27 \\
\hline & BP 48 & 85,1 & 2753 & 0,19 \\
\hline & BP 50 & 63,2 & 8660 & 0,28 \\
\hline & BP 62 & 61,8 & 873 & 0,12 \\
\hline & BP 93 & 67,7 & 4025 & 0,17 \\
\hline & BP 132 & 73,4 & 2809 & 0,18 \\
\hline & BP 137 & 86,9 & 326 & 0,46 \\
\hline & BP 152 & 75,6 & 2971 & 0,14 \\
\hline & BP 153 & 81,2 & 3068 & 0,19 \\
\hline Média (n= 11) & & 76,0 & 3292 & 0,22 \\
\hline Amplitude & & $61,8-86,9$ & $326-8660$ & $0,12-0,46$ \\
\hline \multicolumn{5}{|l|}{ Fêmeas Imaturas } \\
\hline \multirow[t]{8}{*}{ Subadultos } & BP 83 & 76,6 & 5553 & 0,07 \\
\hline & BP 90 & 77,7 & 3208 & 0,21 \\
\hline & BP 101 & 71,3 & 22181 & 0,06 \\
\hline & BP 102 & 75,4 & 7098 & 0,06 \\
\hline & BP 109 & 81,6 & 2804 & 0,09 \\
\hline & BP 113 & 77,9 & 2829 & 0,54 \\
\hline & BP 124 & 74,1 & 7418 & 0,08 \\
\hline & BP 126 & 80,7 & 3303 & 0,19 \\
\hline Média $(\mathrm{n}=8)$ & & 77,1 & 6799 & 0,16 \\
\hline Amplitude & & $71,3-81,6$ & $1204-22181$ & $0,06-0,54$ \\
\hline \multirow[t]{5}{*}{ Filhotes } & BP 45 & 70,3 & 3137 & 0,24 \\
\hline & BP 89 & 68,5 & 1482 & 0,21 \\
\hline & BP 100 & 73,8 & 8152 & 0,17 \\
\hline & BP 108 & 63,8 & 3644 & 0,05 \\
\hline & BP 146 & 80,4 & 2412 & 0,18 \\
\hline Média $(\mathrm{n}=5)$ & & 71,4 & 3765 & 0,17 \\
\hline Amplitude & & $63,8-80,4$ & 1482-8152 & $0,05-0,24$ \\
\hline
\end{tabular}

Nos machos, as médias de concentrações de PCBs foram maiores nos adultos (14.000 ng. $\mathrm{g}^{-1}$ lipídios), enquanto que nas fêmeas, os maiores níveis foram encontrados nos indivíduos subadultos (6.800 ng. $\mathrm{g}^{-1}$ lipídios) e equivalem à quase metade dos valores encontrados nos machos. Existem inúmeras fontes de PCBs na Baixada Santista que podem contribuir com essas concentrações, entre elas no estuário de Santos (Bacia da área da COSIPA, Rio Piaçaguera), na área da saída do emissário submarino na Baía de Santos; no solo em Cubatão na Vila Couto e na área Industrial, em Santos na 
Alemoa, Macuco, no Guarujá em Conceiçãozinha, em São Vicente em Samaritá, entre outros (Lamparelli et al., 2001; Regalado, 2002, Freitas-Guimarães, 2005).

As razões de DDTs/PCBs foram abaixo de 0,6 (Tabela 3.3 e 3.4) indicando uma maior influência de resíduos industriais do que agrícolas na área de estudo. Comparativamente Kannan et al. (1993) encontraram uma razão de DDTs/PCBs de 0,36 para os golfinhos do Mar Báltico, uma região altamente industrializada, refletindo assim o meio em que habitam.

Os congêneres de PCBs dominantes em ordem decrescente foram o $153>138>$ $180>118>101$ (Figura 3.4 e 3.5) que possuem de 5 a 7 átomos de cloro em suas moléculas, indicando uma pequena proporção de moléculas leves (abaixo do 56/60, coeluídos, incluindo-o) e extremamente pesadas (acima do 199, incluindo-o). Tais limites representam os bifenilos tetraclorados e octaclorados, bem como foi encontrado no estudo de Yogui (2002) em cetáceos de São Paulo. No trabalho de Leonel (2007) o grupo predominante de PCBs nas amostras de toninhas do Rio Grande do Sul pertencem quase que exclusivamente aos grupos com 6 e 7 átomos de cloro, ou seja, com baixos níveis de metabolização devido a ausência de hidrogênios vicinais.



Fig. 3.4 Porcentagem relativa dos congêneres de PCB (números IUPAC) em machos e fêmeas de toninhas de São Paulo.

A somatória da porcentagem da contribuição destes 5 congêneres no total de 51 congêneres de PCBs equivale a mais de 50\% nas amostras. Tal padrão foi encontrado em diversos trabalhos com mamíferos marinhos ao redor do mundo (e.g. Minh et al, 1999; 
Corsolini et al., 1995). Em Yogui (2002) na mesma área de estudo, foi relatado em cetáceos a presença de 58\% de congêneres hexaclorados em relação aos PCBs totais.

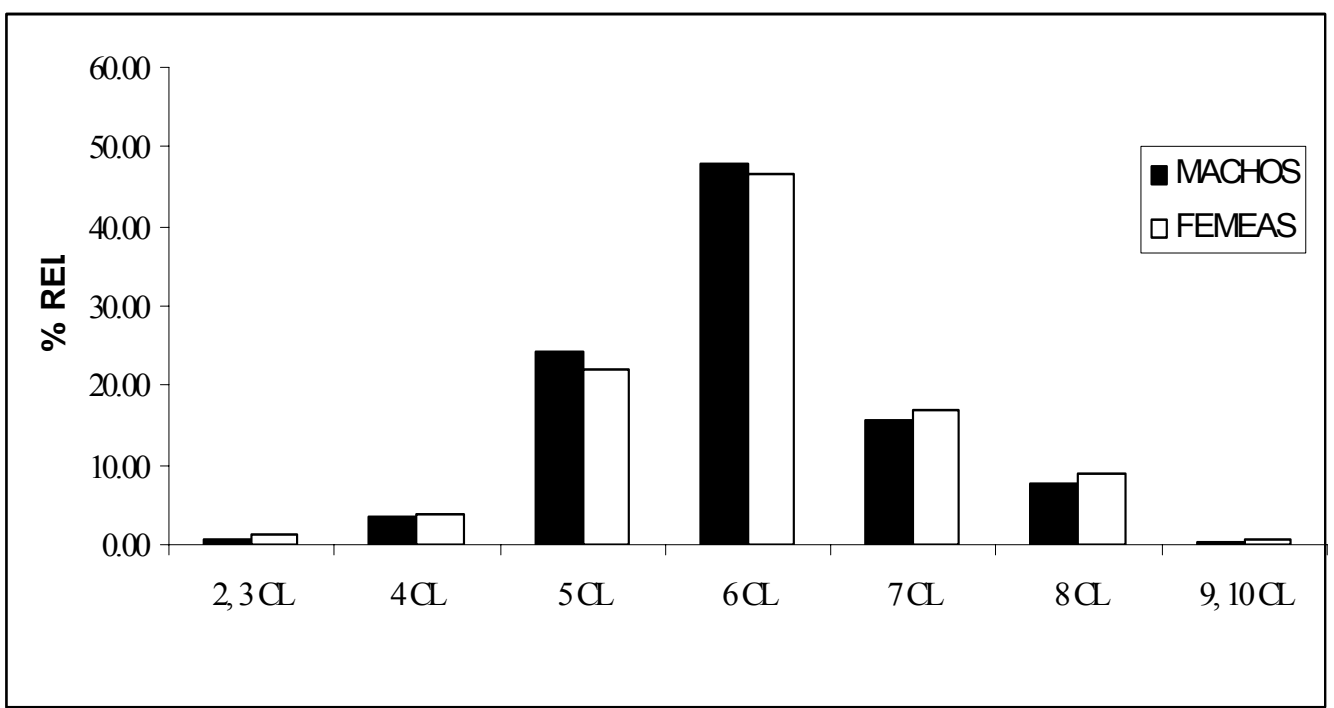

Fig. 3.5 Porcentagem relativa dos PCBs de acordo com o número de cloros na molécula, em machos e fêmeas de toninhas de São Paulo.

Em relação aos DDTs, os machos apresentaram as médias de concentração uma ordem de grandeza maior do que as fêmeas nos adultos e subadultos, enquanto nos filhotes as concentrações médias foram próximas. Essas médias foram 4,5 vezes maior nos machos adultos, em comparação com as fêmeas de mesma classe etária (Figura 3.1). Isso pode indicar uma transferência de DDTs das fêmeas adultas para a prole.

Para entender as características de acumulação, foram consideradas as porcentagens de composição dos OCs. A Figura 3.6 mostra a composição dos p,p'- DDTs na gordura das toninhas do estado de São Paulo, que foram os compostos predominantes entre os DDTs. Entre eles, o p-p'-DDE foi o composto dominante, indicando sua alta persistência em todas as amostras analisadas. O p-p'-DDT na formulação comercial do DDT, uma vez descartado no ambiente degrada-se em $p$ - $p$ '-DDE e $p$-p'-DDD, que são os metabólitos estáveis do DDT, os quais se utilizam para saber se seu uso no ambiente foi recente (Aguilar, 1984). A razão de $p, p$-DDE/ $\sum$ DDT variou nas fêmeas e nos machos de 0,5 a 0,9 e é um indicativo de antiga aplicação de DDT na área de estudo. No Brasil, o uso na agricultura de DDT e outros OCs persistentes foi proibido em 1985, mas eles ainda são utilizados para propósitos de saúde pública (Paumgartten et al, 2000). 

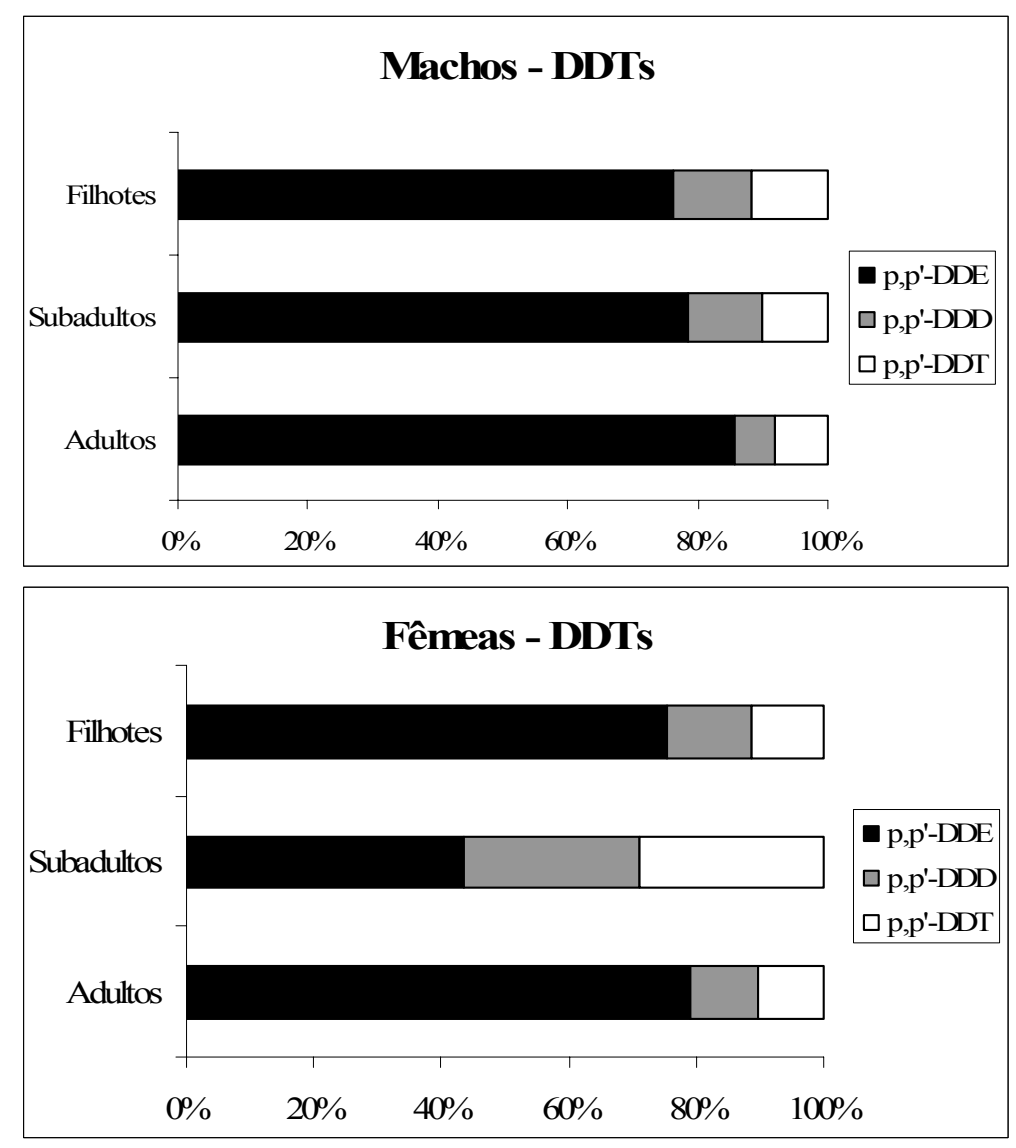

Figura 3.6 Porcentagem relativa de DDT e seus metabólitos nas toninhas do litoral paulista, machos e fêmeas de acordo com suas faixas etárias.

Para o Mirex, as fêmeas e os machos tiveram um grau crescente de concentração conforme a classe etária (Figura 3.2), por ser um dos pesticidas clorados mais estáveis e de difícil metabolização. Nos filhotes e juvenis de ambos os sexos as concentrações foram similares, enquanto nos machos adultos as concentrações de Mirex quase triplicaram quando comparados aos juvenis. Estes machos adultos poderiam ter uma idade avançada devido à alta concentração, ou poderia existir uma mudança no tamanho das presas, consumindo assim presas maiores e mais contaminadas ou de áreas mais poluídas. Nas fêmeas essa diferença foi menos acentuada, sugerindo assim uma possível transferência de Mirex das fêmeas maduras para a prole, assim como ocorreu para os DDTs.

Entre as clordanas, a oxiclordana foi o composto que apresentou as maiores concentrações em todas as amostras, estando presente em torno de $70 \%$ ou mais no total das clordanas, pois este é um dos metabólitos mais persistentes dessa classe de compostos (Figura 3.7 e 3.8). Estes resultados corroboram com os dados apresentados em 
Kajiwara et al. (2004), onde elevadas porcentagens deste metabólito foram encontradas na gordura das toninhas, as maiores entre os cetáceos analisados, indicando uma alta capacidade metabólica da espécie para decompor ou transformar os compostos das clordanas. Essas figuras também mostram uma diferente acumulação destes compostos entre machos e fêmeas.

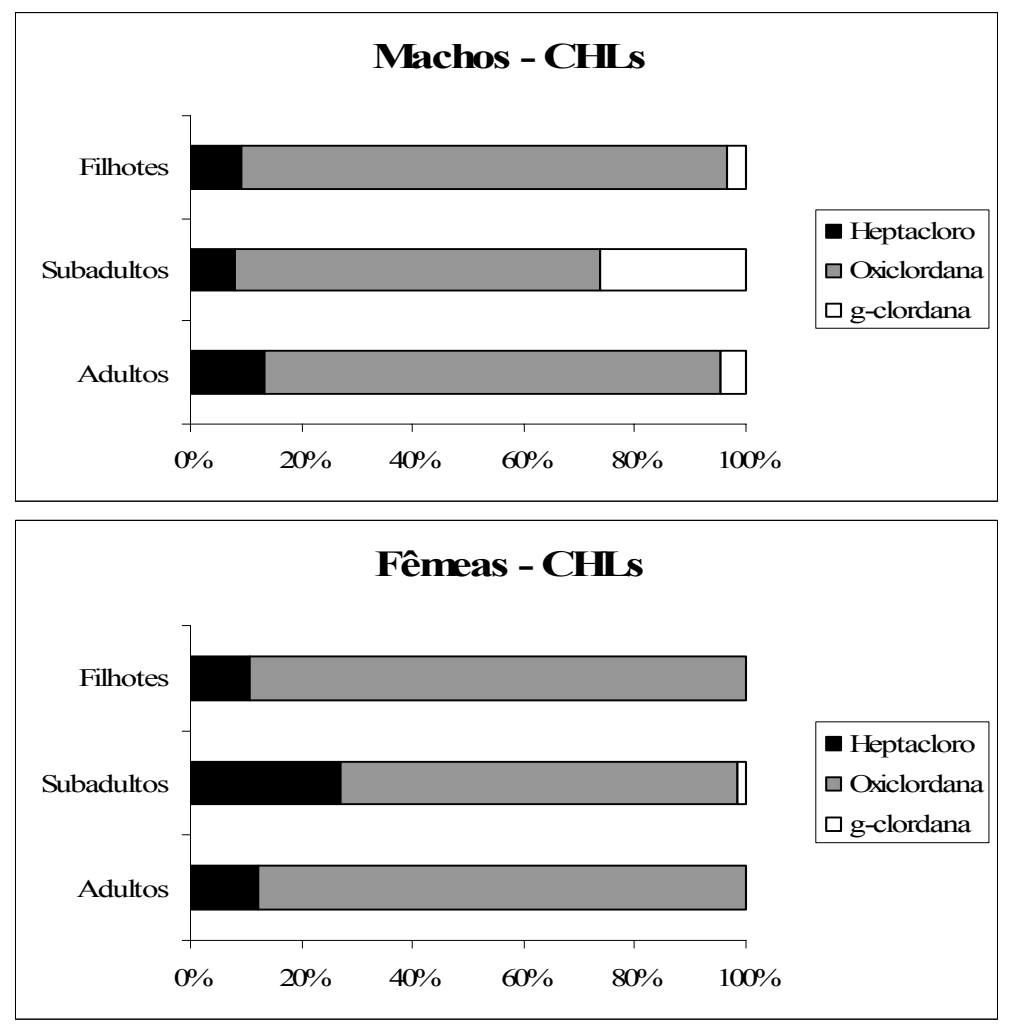

Figura 3.7 Porcentagem relativa das clordanas nas toninhas do litoral paulista, machos e fêmeas, de acordo com suas faixas etárias.



Figura 3.8 Diferenças entre machos e fêmeas nas composições das clordanas na gordura das toninhas (P. blainvillei) do litoral paulista. 
As concentrações de HCHs estão muito próximas do LDM. No Brasil, o produto comercial (mistura dos 4 isômeros do $\mathrm{HCH}$ ), que era mais barato que o $\gamma$-HCH (lindano), foi largamente utilizado. Conforme se verifica na Figura 3.9, há predominância do $\beta$ $\mathrm{HCH}$, o mais persistente dos isômeros do $\mathrm{HCH}$ em organismos. Esse isômero também tem maior porcentagem de ocorrência nos cetáceos do hemisfério norte (Tanabe et al., 1981; Muir et al., 1996, Aono et al., 1997). Entretanto, para as fêmeas maduras o $\gamma$-HCH foi predominante, o que mostra uma diferente acumulação entre os sexos.

No geral HCHs e HCB tendem a ser pouco retidos em mamíferos marinhos, particularmente o HCB é pouco retido em mamíferos de regiões tropicais. Entretanto sua ocorrência nos animais do litoral de São Paulo pode ser proveniente dos lixões de HCH às margens do estuário de Santos (Lixão de Pilões, Rios Perequê e Santo Amaro), estuário de São Vicente e Ilha da Moela, Guarujá (por disposição de material dragado do canal do Porto de Santos). Igualmente, existem estoques de HCB às margens do estuário de Santos (Lixão da Rhodia no Rio Perequê, Rio Cubatão, Alemoa, Saboó/ Valongo, Ilha Barnabé, TEFER), estuário de São Vicente e Quarentenário (Lamparelli et al., 2001; MPESP, 2002; Freitas-Guimarães, 2005). Pode haver também a contribuição do escoamento superficial, já que pela baixa polaridade estes compostos podem estar associados à matéria orgânica do solo. A biomagnificação e bioacumulação também são fatores que devem ser considerados.

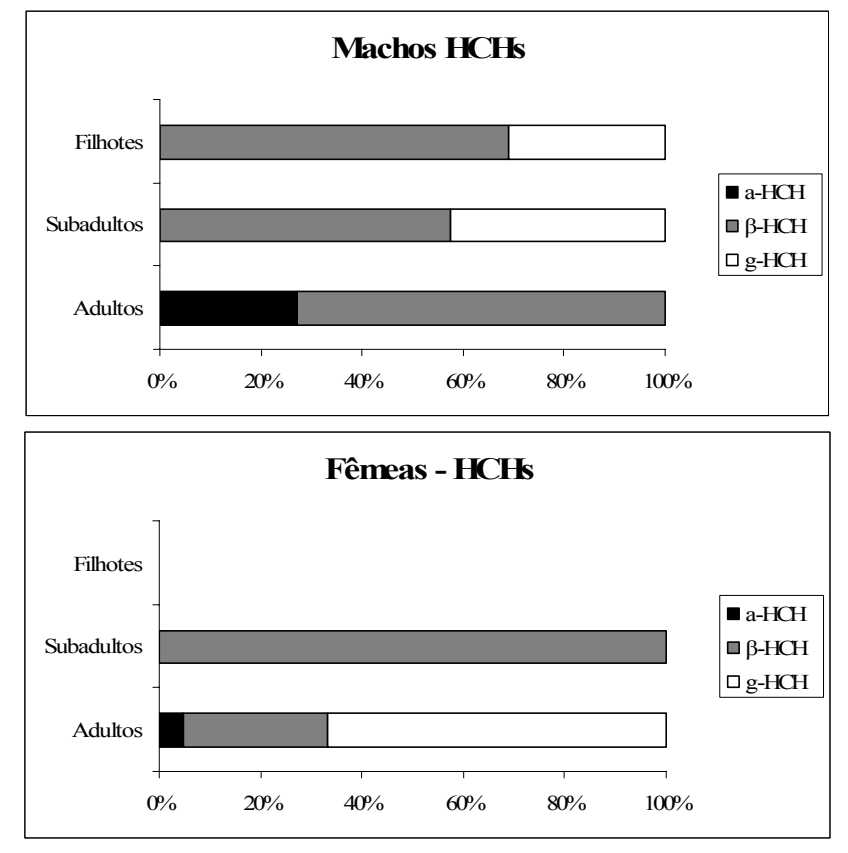

Figura 3.9 Porcentagem dos $\mathrm{HCHs}$ na gordura das toninhas (P. blainvillei) do litoral paulista, machos e fêmeas, de acordo com suas faixas etárias. 
Houve correlação nos indivíduos machos deste estudo $(n=29)$ entre comprimento total (CT) e concentrações de Mirex $(r=0,6451, p<0,05)$, DDTs $(r=0,6181, p<0,05)$ e PCBs $(r=0,4742, p<0,05)$. Não houve correlação entre CT e as concentrações de HCB, HCHs e CHLs nestes indivíduos. Não houve correlação entre CT e concentrações de OCs nas fêmeas $(\mathrm{n}=24)$, provavelmente devido a transferência desses compostos aos filhotes durante a gestação e lactação (Figuras 3.10).
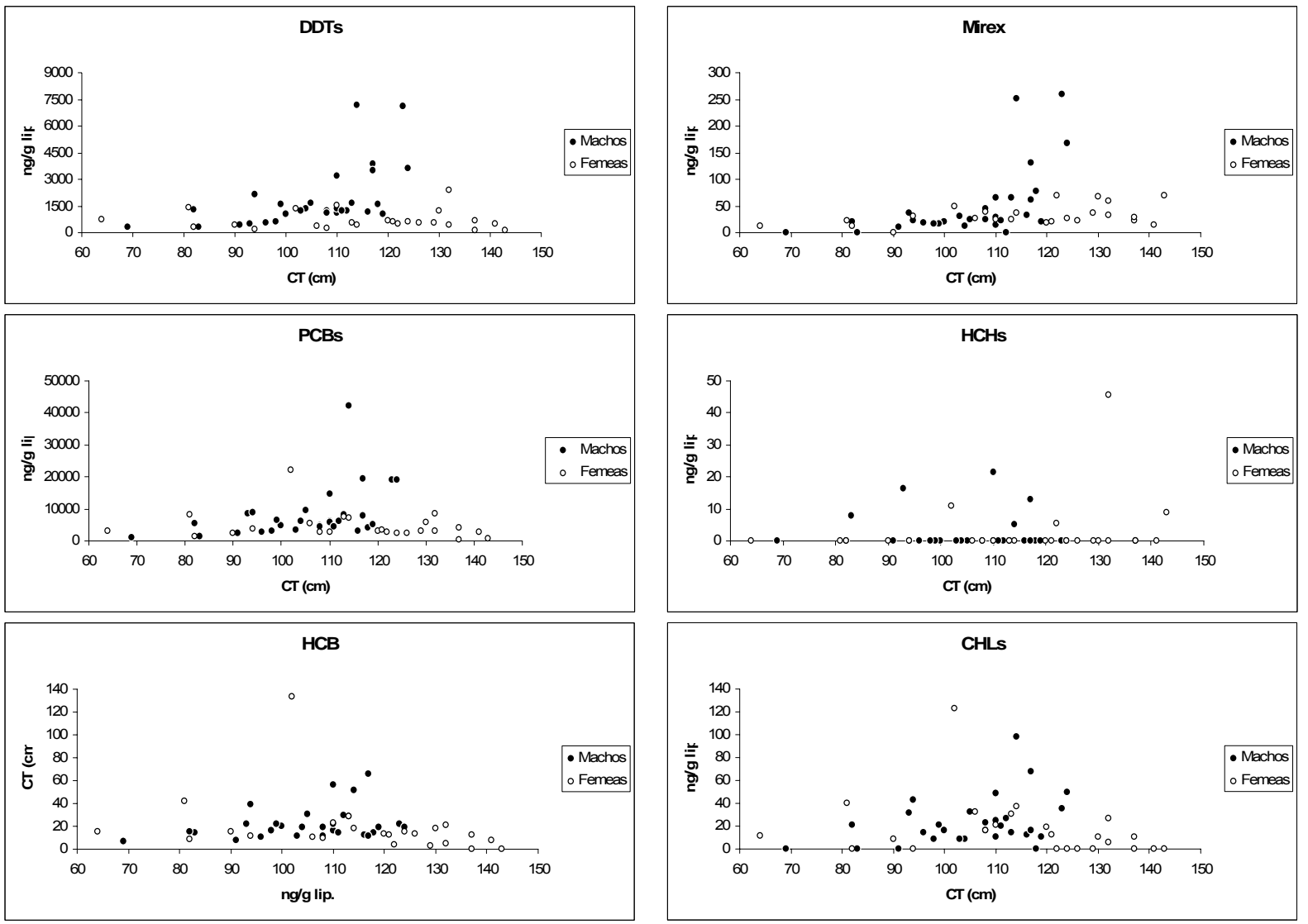

Fig. 3.10 Concentração de DDTs, PCBs, HCB, Mirex, HCHs e CHLs (ng.g ${ }^{-1}$ lipídios) na gordura de $P$. blainvillei machos e fêmeas do litoral paulista relacionados com o comprimento total dos animais.

Nos machos, quando separados em maduros $(\mathrm{n}=10)$ e imaturos $(\mathrm{n}=19)$, nas concentrações dos seguintes compostos foram encontradas diferenças significativas: Mirex $(\mathrm{p}=0,0009)$, DDTs $(\mathrm{p}=0,0067)$ - $p, p^{\prime}-\mathrm{DDE}$ e $p, p^{\prime}-\mathrm{DDT}(\mathrm{p}=0,0038)$ e PCBs $(\mathrm{p}$ $=0,0389$ ) (Figura 3.1 a 3.3). Um estudo com machos adultos do golfinho-de-Dall (Phocoenoides dalli) do Norte do Pacífico Norte mostrou a redução dos níveis de testosterona no sangue com o acréscimo dos níveis residuais de DDE na gordura subcutânea, sugerindo um efeito anti-androgênico do DDE ou a quebra de esteróides por 
estes OCs (Tanabe et al., 1994). Os níveis de DDE nos machos de toninhas, tanto nos juvenis quanto nos adultos, podem ter o mesmo efeito anti-androgênico, pondo em risco a fertilidade desses machos.

Quando separados em machos e fêmeas, os pesticidas: $p, p^{\prime}$-DDE, $p, p^{\prime}-\mathrm{DDD}$, $p, p^{\prime}$-DDT $(\mathrm{p}=0,0001 ; 0,0304 ; 0,0304)$ e o HCB $(\mathrm{p}=0,0458)$ apresentaram diferenças significativas.

Nas fêmeas, houve 2 correlações entre os compostos: PCBs e DDTs ( $r=0,7818$, $\mathrm{p}<0,05)$ e HCB e DDTs $(\mathrm{r}=0,7166, \mathrm{p}<0,05)$, sendo essas correlações maiores entre as fêmeas maduras em comparação às fêmeas no geral. Houve diferença significativa nas concentrações de $p$-p'-DDT entre as fêmeas maduras (não-lactantes e lactantes) e as juvenis $(\mathrm{p}=0,0206 ; 0,0247)$, as maduras e as juvenis no $p, p^{\prime}-\operatorname{DDD}(\mathrm{p}=0,0143)$ e no $o, p^{\prime}$-DDD $(\mathrm{p}=0,0412)$, onde as concentrações foram maiores nas juvenis.

As maiores diferenças significativas ocorreram entre fêmeas lactantes e juvenis de ambos os sexos, com concentrações até 37 vezes mais elevadas nas juvenis. Os principais compostos que apresentaram essas diferenças foram os DDTs: $p, p^{\prime}$-DDD, $p, p^{\prime}$-DDT $\mathrm{e}$ $o, p^{\prime}-\mathrm{DDD}(\mathrm{p}=0,0066 ; 0,0089$ e 0,0119) e $\mathrm{HCB}(\mathrm{p}=0,0066)$.

Em relação aos congêneres de PCBs, houve diferença significativa no PCB 153 (p $=0,0208)$ e no PCB $118(\mathrm{p}=0,0274)$ entre as fêmeas maduras não-lactantes e juvenis, e neste último congênere, uma diferença significativa ainda maior $(p=0,0143)$ entre lactantes e juvenis, onde as juvenis tiveram concentrações 10 vezes acima das fêmeas lactantes.

Esses dados podem ser um indício que o HCB, os DDTs e os PCBs são os principais compostos transferidos à prole via lactação por estas toninhas, como já foi reportada a ocorrência destes 3 compostos em leites de cetáceos e humanos (Fukushima \& Kawai, 1981 apud Reddy et al., 2001; Colborn et al., 1996; UNEP, 2002). O DDT tem efeito estrogênico (Colborn et al, 1996), podendo agir nessas fêmeas em épocas de início de maturação sexual, colocando em risco a reprodução da espécie.

Segundo Fukushima \& Kawai, (1981) apud Reddy et al. (2001) a transferência destes compostos da fêmea para os filhotes pode ocorrer através da gestação mas principalmente pela amamentação. Nos cetáceos, a transferência materna de OCs é considerada significativa, especialmente para o primeiro filhote. Cockcroft et al., 1989 sugeriu que, até ao final do primeiro ciclo reprodutivo, um golfinho nariz-de-garrafa (Tursiops truncatus) transfere cerca de $80 \%$ do peso corporal materno ao filhote. Fukushima e Kawai, 1981 apud Reddy et al. (2001) sugeriram que o primeiro filhote de 
golfinho-listrado (Stenella coeruleoalba) recebe 4 vezes mais concentrações de OCs do que os irmãos subseqüentes, com mais de $90 \%$ da carga de OCs transferida através da amamentação.

As fêmeas maduras apresentaram menores concentrações de PCBs e DDTs do que as juvenis, estando possivelmente transferindo esses compostos também aos seus fetos, via placenta, em fases críticas de desenvolvimento de seus aparelhos reprodutivos. Exposições pré-natais a esses compostos podem levar a alterações permanentes nos indivíduos. Altos níveis de DDTs e PCBs nessas fêmeas podem alterar seus níveis hormonais e como os fetos em desenvolvimento são extremamente sensíveis aos níveis hormonais, quantidades baixas podem ser tão devastadoras quanto quantidades altas (Colborn et al., 1996).

\subsubsection{DIFERENÇAS ENTRE AS LOCALIDADES}

Houve correlações entre o CT dos machos coletados na Baixada Santista (BS) (n $=20)$ e as concentrações de 4 grupos de compostos: DDTs $(\mathrm{r}=0,6867, \mathrm{P}<0,05)$, Mirex $(\mathrm{r}=0,6344, \mathrm{P}<0,05), \operatorname{PCBs}(\mathrm{r}=0,5888, \mathrm{P}<0,05)$ e $\mathrm{HCB}(\mathrm{r}=0,4638, \mathrm{P}<0,05)$. Houve diferença significativa entre a maturidade destes indivíduos e as concentrações dos mesmos compostos: Mirex ( $\mathrm{p}=0,0037)$; DDTs $(\mathrm{p}=0,0061)$; PCBs $(\mathrm{p}=0,0081)$ e HCB $(\mathrm{p}=0,0472)$, provavelmente devido ao fato da maturidade sexual neste estudo ter sido inferida de acordo com os comprimentos totais (CT).

Comparando-se esse grupo de animais $(\mathrm{n}=20)$ com o grupo de machos em geral deste estudo $(n=29)$, os animais da BS apresentaram maiores valores dos índices de correlação entre CT e os DDTs $(r=0,6867, p<0,05)$ e PCBs $(r=0,5888, p<0,05)$. Estes animais apresentaram 4 grupos de compostos que se correlacionam com o CT em relação a 3 grupos nos machos em geral, onde nos machos da BS, o HCB também se correlaciona. Existem 10 correlações entre os OCs nos machos da BS contra 9 nos machos em geral, onde 78\% dessas correlações foram mais fortes nos machos da BS. Todas as correlações entre os compostos e os PCBs foram maiores nos machos da BS, indicando a influência de resíduos industriais nesses indivíduos quando comparados com os machos do Estado em geral.

Nos machos imaturos da Baixada Santista $(n=16)$ as correlações entre compostos também foram maiores que nos machos imaturos em geral. São elas PCBs x HCB (r = 
0,9147, $\mathrm{p}<0,05)$; PCBs x CHLs e Mirex x CHLs $(\mathrm{r}=0,7670, \mathrm{p}<0,05)$ e HCB x DDTs $(\mathrm{r}=0,7323, \mathrm{p}<0,05)$.

Comparando-se os machos da Baixada Santista com os do Litoral Sul (LS), foram encontradas diferenças significativas nos seguintes compostos: PCB $70(\mathrm{p}=0,0056)$; PCB $44(\mathrm{p}=0,0144) ;$ PCB $49(\mathrm{p}=0,0233)$; PCB $31(\mathrm{p}=0,030)$ e PCB $66(\mathrm{p}=0,0355)$. Todos esses congêneres são considerados PCBs leves, contendo de 3 a 4 átomos de cloro ligados ao grupo bifenila, com os animais da BS apresentando concentrações aproximadamente 6 vezes maiores (Figura 3.11).

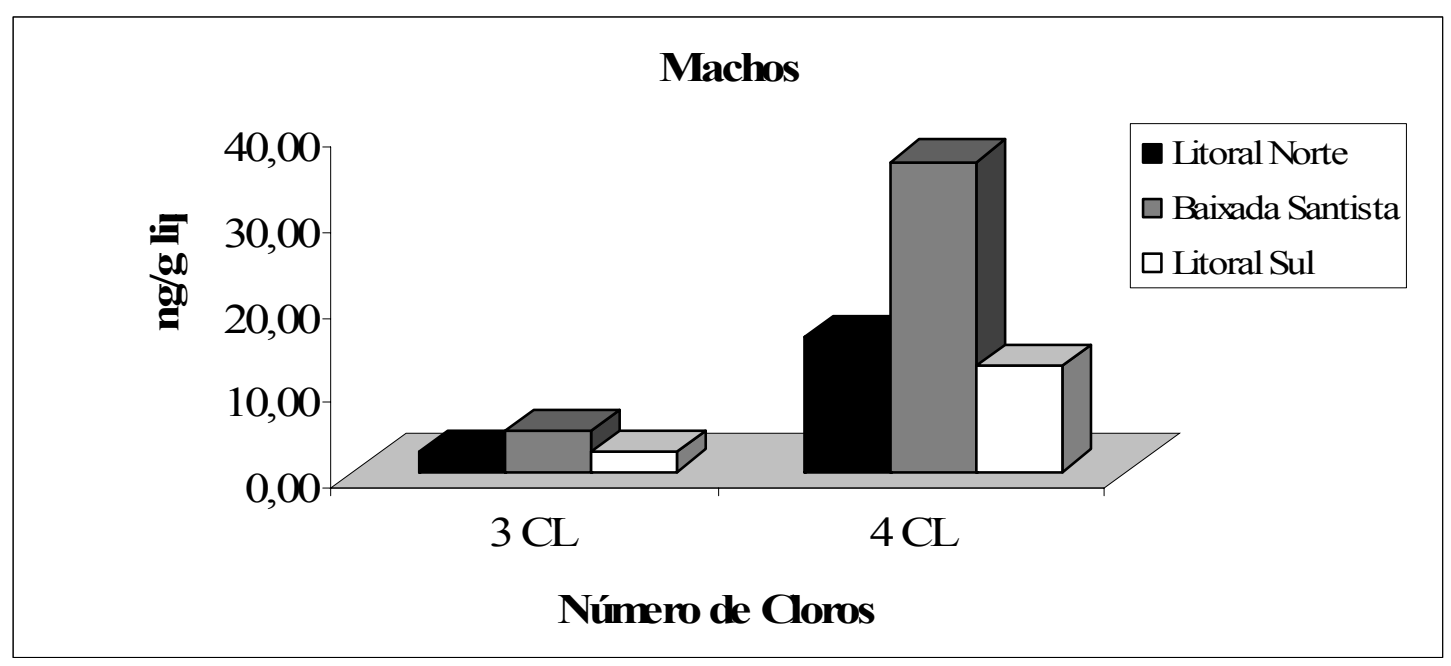

Figura 3.11 Médias das concentrações dos PCBs de 3 e 4 cloros, nos machos de toninha das 3 regiões do litoral paulista.

Houve diferenças significativas entre os machos maduros da Baixada Santista $(\mathrm{n}=$ 4) e do Litoral Sul $(n=5)$ e as concentrações de PCBs $(p=0,0143)$ e DDTs $(p=0,0274)$, com os indivíduos da BS apresentando o dobro das concentrações do LS em ambos os grupos de compostos. Devido à proximidade do Pólo industrial de Cubatão aos animais da Baixada Santista, isso pode se explicar quanto às maiores concentrações de PCBs, mas não se aplica o mesmo aos DDTs na $\mathrm{BS}$, onde em outros estudos com toninhas os animais do LS tiveram as maiores concentrações destes pesticidas em anos anteriores (Yogui, 2002; Kajiwara et al., 2004).

Houve 5 correlações entre compostos nas fêmeas, mas comparando-se com as correlações entre todas as fêmeas, 2 foram maiores nas fêmeas da BS: HCB e DDTs ( $\mathrm{r}=$ $0,7105, \mathrm{p}<0,05)$ e PCBs e DDTs $(\mathrm{r}=0,5819, \mathrm{p}<0,05)$. As maiores correlações entre os compostos ocorreram nas fêmeas da BS. Quando analisamos as fêmeas maduras da BS (n 
=9) e imaturas da BS $(\mathrm{n}=11)$ com as fêmeas maduras e imaturas em geral, as correlações são mais fortes nas fêmeas da BS. São elas, nas maduras: HCB e DDTs (r = 0,7380, $\mathrm{P}<0,05)$ e PCBs e DDTs $(\mathrm{r}=0,8000, \mathrm{P}<0,05)$ e nas imaturas: HCB e PCBs $(\mathrm{r}$ $=0,6227, \mathrm{P}<0,05)$ e HCB e DDTs $(\mathrm{r}=0,8090, \mathrm{P}<0,05)$. Os grupos de compostos que tiveram maior influência nas fêmeas da BS, segundo as correlações, foram os PCBs, o HCB e os DDTs.

Essas diferenças significativas entre as 3 localidades do litoral paulista podem indicar diferentes usos de áreas geográficas entre as toninhas e/ou de suas presas, podendo sugerir que essas toninhas tenham áreas de ocorrência diferenciadas e restritas a certas áreas dentro do litoral de São Paulo. Dados de telemetria por satélite nas toninhas da Argentina sugeriram distribuição restrita em certas regiões, confirmado por dados genéticos ao menos 2 populações distintas na Argentina (FMA IV), cujo estoque ainda é considerado com uma única população (Mendez et al., 2008).

\subsection{CONCENTRAÇÃO DE POLUENTES EM COMPARAÇÃO COM TONINHAS DE OUTRAS LOCALIDADES (INTRA-ESPECÍFICA)}

As concentrações médias de PCBs totais deste estudo foram as mais elevadas entre os estudos de OCs em toninhas, incluindo outras regiões geográficas, em ambos os sexos, tanto em maduros como em imaturos (Borrel et al., 1995; Castello et al., 2000; Yogui, 2002; Kajiwara et al., 2004; Leonel, 2007). Também são comparáveis ao trabalho de O'Shea et al. (1980) no Uruguai, considerando as limitações da época (Tabela 3.5). Segundo Aguilar et al. (2002) as colunas cromatográficas empacotadas superestimam as concentrações de PCBs em até 50\% e subestimam as concentrações de DDT em aproximadamente 30 a 40\%, dificultando a comparação com o estudo de O'Shea et al. (1980). Outro fator que também dificulta essa comparação é a utilização de diferentes congêneres de PCBs para análises nos diversos estudos.

As maiores médias de PCBs foram encontradas neste estudo, nos machos maduros com 13.400 e fêmeas imaturas com $5.630 \mathrm{ng} \cdot \mathrm{g}^{-1}$ em peso lipídico. As maiores concentrações encontrados em machos e fêmeas para PCBs também foram deste estudo, machos com 42.185 e fêmeas com $22.180 \mathrm{ng} \cdot \mathrm{g}^{-1}$ lipídios. Essas fêmeas com maiores concentrações possuem uma ordem de grandeza maior do que as de outros estudos, e as médias dos níveis nos machos são de 2 a 3 vezes superiores que os machos de mesma maturidade. Se compararmos este estudo com um anterior realizado com alguns animais da mesma região nos anos de 1999-2000 (Yogui, 2002), nota-se que os níveis de PCBs 
aumentaram aproximadamente o dobro nesses anos. Existem inúmeras fontes de PCBs na Baixada Santista que podem contribuir com esses níveis nos golfinhos do litoral paulista, entre elas na Bacia da área da COSIPA no estuário de Santos, no Rio Piaçaguera, na área da saída do emissário submarino na Baía de Santos; no solo em Cubatão na Vila Couto e na área Industrial, em Santos na Alemoa, Macuco, no Guarujá em Conceiçãozinha, em São Vicente em Samaritá, entre outros (Lamparelli et al., 2001; Regalado, 2002, Freitas-Guimarães, 2005).

Tabela 3.5 - Comparação intra-específica de concentrações de compostos organoclorados em gordura de toninhas (P. blainvillei) expressos em $\mathrm{ng}^{-1} \mathrm{ge}^{-1}$ peso lipídico.

\begin{tabular}{|c|c|c|c|c|c|c|c|c|c|c|c|c|c|}
\hline $\begin{array}{r}\text { Ano de } \\
\text { coleta }\end{array}$ & Localização & $\begin{array}{c}\text { Mat. } \\
\text { sexual }\end{array}$ & Sexo & $n$ & CT $(\mathrm{cm})$ & $\begin{array}{c}\text { Lipidios } \\
(\%)\end{array}$ & PCBs & DDTs & $\mathrm{HCHs}$ & CHLs & $\mathrm{HCB}$ & Mirex & Ref. \\
\hline \multirow[t]{6}{*}{$2000-2007$} & SP, BR & $\mathrm{Im}$ & $\mathrm{F}$ & 14 & $\begin{array}{c}101 \\
(64-121)\end{array}$ & $\begin{array}{c}75 \\
(64-82)\end{array}$ & $\begin{array}{c}5630 \\
(1480-22180)\end{array}$ & $\begin{array}{c}710 \\
(200-1520)\end{array}$ & $\begin{array}{c}0,7^{\mathrm{a}} \\
\text { (n.d.-11) }\end{array}$ & $\begin{array}{c}25^{\mathrm{c}} \\
\text { (n.d.-120) }\end{array}$ & $\begin{array}{c}25 \\
(10-130)\end{array}$ & $\begin{array}{c}25 \\
\text { (n.d.-50) }\end{array}$ & 1 \\
\hline & & Ma & $\mathrm{F}$ & 11 & $\begin{array}{c}133 \\
(122-143)\end{array}$ & $\begin{array}{c}76 \\
(62-87)\end{array}$ & $\begin{array}{c}3290 \\
(330-8660)\end{array}$ & $\begin{array}{c}710 \\
(107-2405)\end{array}$ & $\begin{array}{c}5 \\
\text { (n.d.-46) }\end{array}$ & $\begin{array}{c}5 \\
\text { (n.d.-30) }\end{array}$ & $\begin{array}{c}10 \\
\text { (n.d.-20) }\end{array}$ & $\begin{array}{c}40 \\
(15-70)\end{array}$ & \\
\hline & & $\mathrm{Im}$ & M & 20 & $\begin{array}{c}98 \\
(69-111)\end{array}$ & $\begin{array}{c}79 \\
(62-89)\end{array}$ & $\begin{array}{c}5520 \\
(1100-14810)\end{array}$ & $\begin{array}{c}1145 \\
(280-3190)\end{array}$ & $\begin{array}{c}2 \\
\text { (n.d.-21) }\end{array}$ & $\begin{array}{c}20 \\
\text { (n.d.-50) }\end{array}$ & $\begin{array}{c}19 \\
(6 \mathrm{a} 60)\end{array}$ & $\begin{array}{c}20 \\
\text { (n.d.-65) }\end{array}$ & \\
\hline & & Ma & M & 10 & $\begin{array}{c}117 \\
(112-124)\end{array}$ & $\begin{array}{c}74 \\
(65-81)\end{array}$ & $\begin{array}{c}13400 \\
(3100-42185)\end{array}$ & $\begin{array}{c}3202 \\
(1070-7185)\end{array}$ & $\begin{array}{c}2 \\
\text { (n.d.-13) }\end{array}$ & $\begin{array}{c}30 \\
\text { (n.d.-100) }\end{array}$ & $\begin{array}{c}27 \\
(10 \mathrm{a} 65)\end{array}$ & $\begin{array}{c}106 \\
\text { (n.d.-260) }\end{array}$ & \\
\hline & & & $\mathrm{F}$ & 25 & $\begin{array}{c}115 \\
(64-143)\end{array}$ & $\begin{array}{c}75 \\
(62-87)\end{array}$ & $\begin{array}{c}4560 \\
(330-22180)\end{array}$ & $\begin{array}{c}710 \\
(107-2405)\end{array}$ & $\begin{array}{c}3 \\
\text { (n.d. - 46) }\end{array}$ & $\begin{array}{c}15 \\
\text { (n.d. }-120)\end{array}$ & $\begin{array}{c}20 \\
(<2-135)\end{array}$ & $\begin{array}{c}30 \\
\text { (n.d.-70) }\end{array}$ & \\
\hline & & & M & 30 & $\begin{array}{c}105 \\
(69-124)\end{array}$ & $\begin{array}{c}77 \\
(62-89)\end{array}$ & $\begin{array}{c}8240 \\
(1100-42185)\end{array}$ & $\begin{array}{c}1830 \\
(280-7185)\end{array}$ & $\begin{array}{c}2 \\
\text { (n.d. - 21) }\end{array}$ & $\begin{array}{c}20 \\
\text { (n.d. - 100) }\end{array}$ & $\begin{array}{c}20 \\
(6-65)\end{array}$ & $\begin{array}{c}50 \\
\text { (n.d.-260) }\end{array}$ & \\
\hline \multirow[t]{4}{*}{ 1997-1999 } & $\begin{array}{c}\text { Sul de SP e } \\
\text { Norte de PR, BR }\end{array}$ & Im & $\mathrm{F}$ & 8 & $\begin{array}{c}100 \\
(75-114)\end{array}$ & $\begin{array}{c}87 \\
(79-95)\end{array}$ & $\begin{array}{c}2200 \\
(970-5000)\end{array}$ & $\begin{array}{c}2800 \\
(670-3200)\end{array}$ & $\begin{array}{c}3^{\mathrm{b}} \\
(1,5-5)\end{array}$ & $\begin{array}{c}40^{\mathrm{d}} \\
(17-75)\end{array}$ & $\begin{array}{c}10 \\
(6-20)\end{array}$ & & 2 \\
\hline & & Ma & $\mathrm{F}$ & 2 & $\begin{array}{c}126 \\
(124-127)\end{array}$ & $\begin{array}{c}79 \\
(72-85)\end{array}$ & $\begin{array}{c}2300 \\
(1500-3000)\end{array}$ & $\begin{array}{c}1200 \\
(950-1400)\end{array}$ & $\begin{array}{c}5 \\
(2-7)\end{array}$ & $\begin{array}{c}40 \\
(31-47)\end{array}$ & $\begin{array}{c}10 \\
(6-10)\end{array}$ & & \\
\hline & & $\mathrm{Im}$ & M & 11 & $\begin{array}{c}99 \\
(66-112)\end{array}$ & $\begin{array}{c}87 \\
(82-99)\end{array}$ & $\begin{array}{c}2100 \\
(320-4900)\end{array}$ & $\begin{array}{c}1700 \\
(580-3600)\end{array}$ & $\begin{array}{c}2 \\
(<1-4)\end{array}$ & $\begin{array}{c}40 \\
(5-94)\end{array}$ & $\begin{array}{c}10 \\
(1,5-20)\end{array}$ & & \\
\hline & & Ma & M & 5 & $\begin{array}{c}113 \\
(110-119)\end{array}$ & $\begin{array}{c}80 \\
(73-86)\end{array}$ & $\begin{array}{c}5300 \\
(1800-12000)\end{array}$ & $\begin{array}{c}9900 \\
(1800-35000)\end{array}$ & $\begin{array}{c}4 \\
(3-5)\end{array}$ & $\begin{array}{c}65 \\
(38-110)\end{array}$ & $\begin{array}{c}10 \\
(9-15)\end{array}$ & & \\
\hline \multirow[t]{2}{*}{ 1999-2000 } & SP, BR & & $\mathrm{F}$ & 3 & $\begin{array}{c}131 \\
(130-134)\end{array}$ & $\begin{array}{c}88 \\
(81-92)\end{array}$ & $\begin{array}{c}2970 \\
(1290-3975)\end{array}$ & $\begin{array}{c}1360 \\
(790-2280)\end{array}$ & $\begin{array}{c}\text { n.d. }{ }^{a} \\
-\end{array}$ & $\begin{array}{c}5^{\mathrm{e}} \\
(1-6)\end{array}$ & $\begin{array}{c}15 \\
(11-15)\end{array}$ & $\begin{array}{c}55 \\
(40-66)\end{array}$ & 3 \\
\hline & & & M & 2 & $\begin{array}{c}118 \\
(106-130)\end{array}$ & $\begin{array}{c}84 \\
(81-88)\end{array}$ & $\begin{array}{c}5340 \\
(4540-6140)\end{array}$ & $\begin{array}{c}2130 \\
(1380-2890)\end{array}$ & $\begin{array}{c}2 \\
\text { (n.d.-4) }\end{array}$ & $\begin{array}{c}5 \\
(5-7)\end{array}$ & $\begin{array}{c}30 \\
(20-35)\end{array}$ & $\begin{array}{c}50 \\
(50-55)\end{array}$ & \\
\hline 1994-2004 & RS, BR & & & 27 & & & 4150 & 1080 & & $110^{\mathrm{f}}$ & 40 & 60 & 4 \\
\hline $1991-1996$ & RS, BR & & $\begin{array}{c}M \\
F\end{array}$ & 32 & & & $\begin{array}{l}3490 \\
1690\end{array}$ & & & & & & 5 \\
\hline \multirow[t]{2}{*}{$1991-1996$} & Buenos Aires, AR & & $\mathrm{M}$ & & & & 3220 & & & & & & \\
\hline & & & $\mathrm{F}$ & 8 & & & 3350 & & & & & & \\
\hline \multirow[t]{4}{*}{ 1988-1992 } & Necochea, AR & Im & $\mathrm{F}$ & 26 & & 82 & 2100 & 1540 & & & & & 6 \\
\hline & & Ma & $\mathrm{F}$ & 5 & & 79 & 1215 & 645 & & & & & \\
\hline & & Im & M & 25 & & 80 & 2400 & 1660 & & & & & \\
\hline & & Ma & M & 18 & & 82 & 3060 & 3100 & & & & & \\
\hline \multirow[t]{2}{*}{ 1968-1976 } & Uruguai* & & $\mathrm{F}$ & 3 & $116-138$ & & 5620 & 3880 & & $35^{\mathrm{g}}$ & 95 & & 7 \\
\hline & & & $\mathrm{M}$ & 5 & $114-145$ & & 11260 & 5180 & & 90 & 115 & & \\
\hline
\end{tabular}

Em relação aos DDTs, as concentrações médias nos machos imaturos de toninhas possuem valores próximos nas 3 localidades onde constam esses dados: São Paulo (Yogui, 2002; Kajiwara et al., 2004), Paraná (Kajiwara et al., 2004) e Argentina (Borrel et al., 1995) (Tabela 3.5). Nos machos maduros, as concentrações deste estudo 
encontram-se próximas as da Argentina, e as maiores médias foram encontradas na região da divisa de SP-PR (Kajiwara et al, 2004), com concentrações 3 vezes superiores. Nas fêmeas, tanto maduras quanto imaturas, as maiores médias foram obtidas na mesma região que os machos maduros, seguido da Argentina. Isso provavelmente pode ser devido ao litoral sul de São Paulo e norte do Paraná possuírem características agrícolas, mostrando um uso mais acentuado nessa região. Nos 3 estudos onde constam médias de DDTs em machos e fêmeas, as maiores foram no Uruguai (O'Shea et al., 1980) mesmo com os valores estando subestimados, seguido de São Paulo em Yogui (2002) e neste estudo. Este fato pode estar ligado a época de coleta dos exemplares no Uruguai nas décadas de 60 e 70, onde ainda não havia restrição de uso desses compostos.

Em relação aos HCHs, as concentrações médias deste estudo encontram-se na mesma ordem de magnitude e com valores próximos aos 2 trabalhos onde estes compostos foram analisados, em São Paulo e Paraná (Yogui, 2002; Kajiwara et al., 2004). Entre os maiores valores obtidos, os machos e as fêmeas deste estudo apresentaram 1 ordem de magnitude maior que dos outros estudos e nas fêmeas maduras este valor foi 6 vezes maior que do estudo da divisa SP-PR (Kajiwara et al., 2004). Em estudo anterior realizado em São Paulo, nos anos 1999-2000 (Yogui, 2002) este composto não foi detectado nas fêmeas, mas pode ter sido devido ao baixo número de amostras $(\mathrm{n}=3)$, comparando-se com este estudo em que $80 \%$ das fêmeas também tiveram valores não detectáveis. Nos machos maduros, as concentrações mais elevadas obtidas neste estudo foram de 4 a 5 vezes maiores que nos outros 2 estudos, sendo uma provável fonte os lixões de $\mathrm{HCH}$ às margens do estuário de Santos e de São Vicente e na Ilha da Moela, Guarujá (Lamparelli et al., 2001; MPESP, 2002).

No grupo das CHLs, diferentes compostos foram analisados em cada trabalho dificultando as comparações. Entre as médias de concentrações, os animais do Rio Grande do Sul (Leonel, 2007), Uruguai (O’Shea et al., 1980) e da divisa SP-PR (Kajiwara et al., 2004) foram as maiores, mas isso pode ser devido ao fato de um maior número de clordanas terem sido analisadas naqueles estudos. Dentre os trabalhos onde as maiores concentrações obtidas foram apresentadas, as fêmeas imaturas deste estudo mostraram as concentrações mais elevadas, mesmo com um menor número de compostos analisados. Comparando-se com os dados de 1999-2000 (Yogui, 2002), os níveis no presente estudo encontram-se uma ordem de magnitude maior em ambos os sexos, mas não se pode chegar a conclusões de aumento dos níveis no decorrer desses anos devido ao composto com maiores concentrações neste estudo não ter sido 
analisado no anterior, o metabólito oxiclordana. Segundo relatório da UNEP (2002), 162 toneladas de Heptacloro estão disponíveis no Brasil para conservantes de madeira, o que indica uma fonte contínua de heptacloro para o ambiente.

Entre os trabalhos realizados com a espécie que apresentaram dados de concentrações de $\mathrm{HCB}$, as maiores médias foram encontradas nos animais do Uruguai (O’Shea et al., 1980) com uma ordem de magnitude maior nos machos, seguido dos animais do Rio Grande do Sul (Leonel, 2007). Os estudos na costa de São Paulo apresentaram concentrações médias muito próximas, declinando nos animais da divisa SP-PR. Um dos locais altamente contaminados por HCB na costa brasileira e com estoques desse composto é o Pólo Industrial de Cubatão (Rio Perequê, Rio Cubatão, Estuário de São Vicente e Quarentenário) (MPESP, 2002) na região central de São Paulo. O HCB é um composto bastante volátil e que apresenta alta estabilidade química, tendo preferência de acumulação em regiões mais frias, podendo este ser um fator para os animais do Uruguai e RS apresentaram valores maiores que os animais de SP.

O mirex foi encontrado em concentrações médias muito próximas nos 3 estudos onde este foi analisado, em São Paulo neste estudo e em Yogui (2002), e no Rio Grande do Sul (Leonel, 2007); mas se compararmos os valores mais elevados obtidos, os machos deste estudo apresentaram concentrações 4 vezes maiores que no estudo anterior realizado com animais da mesma região. Esse composto foi utilizado principalmente no controle de formigas no Brasil, Argentina e Uruguai, mas no Uruguai este produto ainda não foi banido (UNEP, 2002).

\subsection{CONCENTRAÇÃO DE POLUENTES EM COMPARAÇÃO COM OUTROS CETÁCEOS (INTER-ESPECÍFICA)}

Foram feitas comparações entre as concentrações dos organoclorados nos cetáceos ao redor do mundo e das toninhas deste estudo a fim de se obter informações da contaminação das diversas áreas geográficas utilizando-se os cetáceos como bioindicadores da saúde de seus ecossistemas. Para isso existem algumas limitações. Os trabalhos onde o peso em lipídios não era expresso foram utilizadas as concentrações em peso úmido divididas pelo conteúdo de lipídios na amostra, e se esse valor não estava disponível, as concentrações em peso úmido eram divididas por 0,7 (Aguilar et al., 2002). Informações de organoclorados em cetáceos não são homogeneamente distribuídas no espaço ou tempo. Dado que as espécies ocupam cadeias tróficas, papéis 
ecológicos e distribuição distintos, os valores dos poluentes são altamente variáveis, às vezes até em ordens de magnitude. Entretanto, padrões geográficos distintos limitam algumas comparações, devendo ser analisados de forma cuidadosa.

As concentrações de HCHs, HCB e Mirex no tecido adiposo subcutâneo de cetáceos ao redor do mundo e deste estudo constam na Tabela 3.6. Em relação às concentrações médias de $\mathrm{HCHs}$, no presente estudo foram encontradas os menores valores comparados aos demais cetáceos ao redor do globo, apresentando a mesma ordem de grandeza apenas de animais do hemisfério sul: fêmeas do boto-cinza (Sotalia guianensis) de Cananéia, SP, Brasil (Yogui, 2002; Kajiwara et al., 2004) e a baleia minke antártica (Balaenoptera acutorostrata) (Aono et al., 1997). Apenas os cachalotes (Physeter macrocephalus) da Tasmânia, Austrália (Evans et al., 2004), animais oceânicos apresentaram as menores concentrações, com valores próximos ao limite de detecção do método.

Os valores médios de $\mathrm{HCH}$ s foram de 1 a 3 ordens de grandeza maiores do que os do presente estudo, sendo os animais do Pacífico Noroeste, na região próxima ao Japão os mais afetados por estes compostos (Kajiwara et al., 2002; 2006). Os botos-cinza machos da costa de São Paulo e Paraná (Yogui, 2002; Kajiwara et al., 2004; Alonso et al., 2006), bem como os golfinhos-nariz-de garrafa da costa dos EUA no Atlântico Norte (Hansen et al., 2004) foram os que apresentaram valores similares aos deste estudo, mas apresentavam 1 ordem de grandeza acima. A maioria dos estudos continha valores 2 ordens de grandeza maiores que este, atingindo animais estudados no hemisfério norte: Pacífico Norte próximo a Hong Kong, Japão; Oceano Índico próximo à Índia e Filipinas, Atlântico Norte próximo a Europa e ao Mar Mediterrâneo e até mesmo animais do Ártico (Kannan et al., 2005; Kajiwara et al., 2002; 2006; Ramu et al., 2005; Borrel et al., 2005; Vorkamp et al., 2004; Aono et al., 1997; de Kock et al., 1994; Norstrom \& Muir, 1994).

Os cetáceos dos oceanos Atlântico (Norte e Sul) e Índico apresentaram a mesma ordem de grandeza das concentrações médias para o HCB em relação às deste estudo, nos seguintes países: Brasil, Índia, África do Sul e costa Leste dos EUA nos costeiros e nos oceânicos da África do Sul e da Itália (Yogui, 2002; Kajiwara et al., 2004; Alonso et al., 2006; Kajiwara et al., 2006; Kannan et al., 2005; de Kock et al., 1994; Hansen et al., 2004; Storelli \& Marcotrigiano, 2000). Os maiores valores de HCB seguem um padrão de distribuição similar ao do $\mathrm{HCH}$, mas também suas concentrações são elevadas em 
Tabela 3.6 - Médias, máximo e mínimo de concentrações de HCHs, HCB e mirex em cetáceos de diversas regiões do planeta (em ug.g ${ }^{-1}$ lipídios). Adaptado de Aguilar et al., 2002.

\begin{tabular}{|c|c|c|c|c|c|c|c|c|c|c|c|c|c|c|c|}
\hline Espécie & Ano de coleta & Área & Localização & Sexo & $n$ & $\mathrm{HCHs}$ & $\max$ & $\min$ & $\mathrm{HCB}$ & $\max$ & $\min$ & Mirex & $\max$ & $\min$ & Referência \\
\hline \multicolumn{16}{|l|}{ Odontocetos costeiros } \\
\hline \multirow[t]{7}{*}{ Toninha (Pontoporia blainvillei) } & $2004-2007$ & Atlântico SW & SP, Brasil & M & 25 & 0,002 & 0,021 & $<0,002$ & 0,022 & 0,065 & 0,006 & 0,051 & 0,258 & $<0,007$ & Este estudo \\
\hline & & & & $\mathrm{F}$ & 30 & 0,003 & 0,045 & $<0,002$ & 0,020 & 0,133 & $<0,002$ & 0,033 & 0,069 & $<0,007$ & \\
\hline & & & & M Ma & 10 & 0,002 & 0,013 & $<0,002$ & 0,027 & 0,065 & 0,011 & 0,106 & 0,258 & $<0,007$ & \\
\hline & & & & M Im & 20 & 0,002 & 0,021 & $<0,002$ & 0,019 & 0,056 & 0,006 & 0,023 & 0,064 & $<0,007$ & \\
\hline & & & & $\mathrm{F}$ ma & 11 & 0,005 & 0,046 & $<0,002$ & 0,009 & 0,021 & $<0,002$ & 0,041 & 0,070 & 0,015 & \\
\hline & & & & F Im & 14 & 0,001 & 0,010 & $<0,002$ & 0,025 & 0,133 & 0,009 & 0,023 & 0,049 & $<0,007$ & \\
\hline & & & & $\mathrm{Ju}$ & 34 & 0,001 & 0,021 & $<0,002$ & 0,022 & 0,133 & 0,006 & 0,023 & 0,064 & $<0,007$ & \\
\hline \multirow{14}{*}{ Golfinho Nariz-de-garrafa (Tursiops truncatus) } & 2002 & Atlântico NW & Indian River Lagoon, FL, EUA & M & 9 & 0,068 & & & nd $(0,02)$ & & & 0,061 & 0,168 & 0,012 & Hansen et al, 2004 \\
\hline & & & & $\mathrm{F}$ & 2 & 0,068 & & & nd $(0,02)$ & 0,021 & 0,016 & 0,020 & 0,043 & 0,010 & \\
\hline & $1995,1999-2000$ & & Beaufort, NC, EUA & $\mathrm{Ju}$ & 8 & 0,079 & & & 0,057 & 0,129 & 0,015 & 0,310 & 1,244 & 0,014 & \\
\hline & & & & M & 3 & 0,079 & & & nd $(0,04)$ & & & 0,508 & 1,244 & 0,014 & \\
\hline & & & & $\mathrm{F}$ & 2 & 0,079 & & & nd $(0,04)$ & & & 0,161 & 0,174 & 0,148 & \\
\hline & $1999-2001$ & & Charleston, SC, EUA & $\mathrm{Ju}$ & 2 & 0,068 & & & 0,052 & 0,077 & 0,035 & 0,233 & 0,615 & 0,088 & \\
\hline & & & & M & 4 & 0,068 & & & nd $(0,02)$ & & & 0,663 & 1,101 & 0,306 & \\
\hline & & & & $\mathrm{F}$ & 5 & 0,068 & & & nd $(0,02)$ & & & 0,166 & 0,592 & 0,084 & \\
\hline & $1978-2001$ & Mar Mediterrâneo & Catalônia, Espanha & $\mathrm{M}, \mathrm{F}$, ? & $2,3,2$ & 0,620 & & & & & & & & & Borrell \& Aguilar, 2006 \\
\hline & & & Valência, Espanha & $\mathrm{M}, \mathrm{F}$, ? & $3,2,1$ & 0,580 & & & & & & & & & \\
\hline & & & Ilhas Baleáricas, Espanha & $\mathrm{M}, \mathrm{F}$, ? & $1,1,5$ & 0,520 & & & & & & & & & \\
\hline & & Atlântico NE & Portugal & $\mathrm{M}, \mathrm{F}$ & 4,3 & 0,380 & & & & & & & & & \\
\hline & & & Huelva, Espanha & $\mathrm{M}, \mathrm{F}$ & 2,3 & 0,320 & & & & & & & & & \\
\hline & $1976-1987$ & Atlântico SE & África do Sul & $\mathrm{F}$ & 1 & & & & 0,014 & & & & & & de Kock et al, $1994 *$ \\
\hline Golfinho do Porto (Phocoena phocoena) & 1999 & Pacífico NW & Japão & M & 3 & 0,730 & 0,890 & 0,430 & 0,710 & 0,930 & 0,330 & & & & Kajiwara et al, 2006 \\
\hline \multirow[t]{12}{*}{ Golfinho de Dall (Phocoenoides dalli) } & $1984-1999$ & Pacífico NW & Sanriku, Japão & M & 35 & 2,043 & 4,571 & 0,657 & 1,206 & 2,286 & 0,486 & & & & Kajiwara et al, $2002 *$ \\
\hline & & & & $\mathrm{F}$ & 17 & 0,793 & 1,400 & 0,046 & 0,643 & 1,357 & 0,046 & & & & \\
\hline & $1995-1999$ & & Hokkaido, Japão & M & 9 & 2,357 & 4,286 & 1,257 & 0,650 & 0,957 & 0,400 & & & & \\
\hline & & & & $\mathrm{F}$ & 14 & 1,214 & 2,286 & 0,143 & 0,479 & 1,000 & 0,023 & & & & \\
\hline & $1984-1999$ & & Sanriku, Japão & M Ma & 27 & 2,286 & 4,571 & 1,057 & 1,057 & 2,286 & 0,486 & & & & \\
\hline & & & & M Im & 8 & 1,071 & 1,714 & 0,657 & 0,743 & 1,029 & 0,543 & & & & \\
\hline & & & & $\mathrm{F} \mathrm{Ma}$ & 10 & 0,400 & 0,700 & 0,171 & 0,171 & 0,314 & 0,046 & & & & \\
\hline & & & & $\mathrm{FIm}$ & 7 & 1,186 & 1,400 & 0,929 & 1,114 & 1,357 & 0,971 & & & & \\
\hline & $1995-1999$ & & Hokkaido, Japão & M Ma & 9 & 2,357 & 4,286 & 1,257 & 1,300 & 0,957 & 0,400 & & & & \\
\hline & & & & $\mathrm{F} \mathrm{Ma}$ & 10 & 0,429 & 1,043 & 0,143 & 0,114 & 0,257 & 0,023 & & & & \\
\hline & & & & $\mathrm{F}$ Im & 4 & 2,000 & 2,286 & 1,857 & 0,843 & 1,000 & 0,643 & & & & \\
\hline & 2000 & & Japão & $\mathrm{M}$ & 10 & 1,550 & 3,000 & 1,000 & 0,720 & 0,970 & 0,520 & & & & Kaijwara et al, 2006 \\
\hline \multirow[t]{5}{*}{ Golfinho sem-dorsal (Neophocaena phocaenoides) } & $2000-2001$ & Pacífico NW & Hong Kong & M & 5 & 0,329 & 0,860 & 0,170 & 0,174 & 0,310 & 0,080 & & & & Ramu et al, 2005 \\
\hline & & & & $\mathrm{F}$ & 1 & 0,100 & & & 0,280 & & & & & & \\
\hline & $1998-2000$ & & Japão & M & 7 & 2,125 & 14,000 & 0,500 & 0,485 & 0,810 & 0,110 & & & & Kajiwara et al, 2006 \\
\hline & $2000-2001$ & & Hong Kong & M & 6 & 0,250 & 0,860 & 0,032 & 0,160 & 0,280 & 0,075 & & & & \\
\hline & & & & M & 5 & & & & 0,031 & 0,043 & 0,014 & & & & \\
\hline \multirow{4}{*}{ Golfinho-corcunda do Indo-Pacifico (Sousa chinensis) } & $1995-2001$ & Pacífico NW & Hong Kong & M & 8 & 0,893 & 2,200 & 0,120 & 0,384 & 0,860 & 0,150 & & & & Ramu et al, 2005 \\
\hline & & & & $\mathrm{F}$ & 2 & 0,235 & 0,360 & 0,110 & 0,195 & 0,240 & 0,150 & & & & \\
\hline & $1997-2001$ & & Hong Kong & M & 7 & 0,720 & 2,200 & 0,110 & 0,280 & 0,430 & 0,150 & & & & Kajiwara et al, 2006 \\
\hline & 1992 & Índico & India & M & 2 & 0,110 & 0,130 & 0,085 & 0,016 & 0,019 & 0,013 & & & & \\
\hline
\end{tabular}


Tabela 3.6 (continuação)

\begin{tabular}{|c|c|c|c|c|c|c|c|c|c|c|c|c|c|c|c|}
\hline Espécie & Ano de coleta & Área & Localização & Sexo & $n$ & $\mathrm{HCHs}$ & $\max$ & $\min$ & $\mathrm{HCB}$ & $\max$ & $\min$ & Mirex & $\max$ & $\min$ & Referência \\
\hline \multirow[t]{2}{*}{ Golfinho Irrawaddy (Orcaella brevirostris) } & $2000-2001$ & Índico & Baía de Bengal, Índia & $\mathrm{M}$ & 2 & 0,690 & 1,200 & 0,180 & 0,010 & 0,017 & 0,003 & & & & Kannan et al, 2005 \\
\hline & & & & $\mathrm{F}$ & 3 & 0,383 & 1,000 & 0,059 & 0,009 & 0,016 & 0,004 & & & & \\
\hline \multirow{8}{*}{ Boto-cinza (Sotalia guianensis) } & $1997-1999$ & Atlântico SW & Sul de SP e Norte do PR, Brasil & F Im & 4 & 0,012 & 0,014 & $<0,001$ & 0,025 & 0,057 & 0,001 & & & & Kajiwara et al, 2004 \\
\hline & & & & $\mathrm{F} \mathrm{Ma}$ & 5 & 0,002 & 0,003 & $<0,001$ & 0,019 & 0,079 & 0,002 & & & & \\
\hline & & & & M Im & 9 & 0,015 & 0,061 & 0,0045 & 0,016 & 0,028 & 0,004 & & & & \\
\hline & & & & M Ma & 8 & 0,019 & 0,038 & 0,0077 & 0,068 & 0,400 & 0,007 & & & & \\
\hline & $1996-2001$ & & Cananéia, SP, Brasil & $\mathrm{M}$ & 4 & 0,028 & 0,044 & n.d. & 0,018 & 0,023 & 0,090 & 0,149 & 0,178 & 0,129 & Yogui, 2002 \\
\hline & & & & $\mathrm{F}$ & 5 & 0,006 & 0,011 & n.d. & 0,013 & 0,024 & n.d. & 0,153 & 0,312 & 0,014 & \\
\hline & $2004-2006$ & & SP, Brasil & M & 5 & 0,028 & 0,069 & 0,013 & 0,038 & 0,550 & $<0,003$ & 0,389 & 0,535 & 0,162 & Alonso et al, 2006 \\
\hline & & & & $\mathrm{F}$ & 1 & 0,033 & & & 0,113 & & & 0,205 & & & \\
\hline \multirow{2}{*}{ Golfinho-listrado (Stenella coeruleoalba ) } & $1984-1986$ & Atlântico SE & África do Sul & $\mathrm{F}$ & 1 & & & & 0,029 & & & & & & \\
\hline & & & & M & 1 & & & & 0,043 & & & & & & \\
\hline \multirow{2}{*}{ Golfinho comum de bico-curto (Delphinus delphis) } & $1984-1987$ & & África do Sul & $\mathrm{F}$ & 7 & & & & 0,061 & 0,114 & 0,014 & & & & \\
\hline & & & & M & 10 & & & & 1,381 & 0,571 & 0,014 & & & & \\
\hline \multirow{2}{*}{ Golfinho de Heaviside (Cephalorhynchus heavisidii ) } & $1977-1987$ & & África do Sul & $\mathrm{F}$ & 3 & & & & 0,053 & 0,086 & 0,014 & & & & \\
\hline & & & & M & 5 & & & & 0,063 & 0,114 & 0,014 & & & & \\
\hline \multirow{2}{*}{ Golfinho Dusky (Lagenorhynchus obscurus) } & 1977 - 1987 & & África do Sul & $\mathrm{F}$ & 6 & & & & 0,040 & 0,086 & 0,014 & & & & Kajiwara et al, 2006 \\
\hline & & & & M & 6 & & & & 0,086 & 0,200 & 0,029 & & & & \\
\hline \multirow{2}{*}{ Orca (Orcinus orca) } & 1994-1997, 2001 & Atlântico NE & Irlanda, Inglaterra e Escócia & $\mathrm{F}$ & 4 & & & & 3,285 & & & & & & McHugh et al, 2007 \\
\hline & & & & M & 2 & & & & 0,603 & & & & & & \\
\hline \multirow{2}{*}{ Golfinho-rotador (Stenella longirostris) } & 1990- 1992 & Índico & Índia & M & 3 & 0,220 & 0,340 & 0,130 & 0,028 & 0,042 & 0,016 & & & & \\
\hline & 1996 & Pacífico NW & Filipinas & M & 3 & 0,110 & 0,190 & 0,066 & 0,220 & 0,430 & 0,110 & & & & \\
\hline \multicolumn{16}{|l|}{ Odontocetos oceânicos } \\
\hline \multirow[t]{2}{*}{ Golfinho de Risso (Grampus griseus) } & 1996 & Mar Mediterrâneo & Itália & $\mathrm{F}$ & 3 & & & & 0,023 & & & & & & Storelli \& Marcotrigiano, 2000 \\
\hline & $1984-1986$ & Atlântico SE & África do Sul & $\mathrm{F}$ & 1 & & & & 0,043 & & & & & & de Kock et al, 1994 * \\
\hline \multirow{4}{*}{ Cachalote (Physeter macrocephalus) } & 1998 & Pacífico SW & Tasmânia, Austrália & F Im & 3 & nd & & & & & & & & & Evans et al, 2004 \\
\hline & & & & $\mathrm{F} \mathrm{Ma}$ & 25 & 0,020 & & & & & & & & & \\
\hline & & & & M Im & 2 & nd & & & & & & & & & \\
\hline & & & & M Ma & 3 & nd & & & & & & & & & \\
\hline \multirow{2}{*}{ Cachalote pigméia (Kogia breviceps) } & 1978-1987 & Atlântico SE & África do Sul & $\mathrm{F}$ & 3 & & & & 0,081 & 0,086 & 0,071 & & & & de Kock et al, 1994 * \\
\hline & & & & M & 2 & & & & 0,079 & 0,114 & 0,043 & & & & \\
\hline Cachalote anã (Kogia simus) & $1976-1984$ & Atlântico SE & África do Sul & M & 4 & & & & 0,046 & 0,043 & 0,057 & & & & \\
\hline \multirow[t]{2}{*}{ Baleia-bicuda de Blainville (Mesoplodon densirostris) } & $1984-1986$ & Atlântico SE & África do Sul & $\mathrm{F}$ & 4 & & & & 0,082 & 0,029 & 0,214 & & & & \\
\hline & & & & M & 2 & & & & 0,129 & 0,029 & 0,229 & & & & \\
\hline \multicolumn{16}{|l|}{ Odontocetos de regiốes polares } \\
\hline \multirow[t]{3}{*}{ Beluga (Delphinapterus leucas) } & 2000 & Atlântico N & Groenlândia & & 10 & & & & 0,250 & 0,550 & 0,021 & 0,013 & 0,015 & 0,004 & Vorkamp et al, 2004 \\
\hline & $1983-1989$ & Ártico & Baía de Buffin & M & 103 & 0,300 & 0,390 & 0,190 & & & & & & & Norstrom \& Muir, 1994 \\
\hline & & & & $\mathrm{F}$ & 105 & 0,210 & 0,300 & 0,150 & & & & & & & \\
\hline \multirow[t]{3}{*}{ Narval (Monodon monoceros) } & $1982-1983$ & Ártico & Baía de Buffin & $\mathrm{M}$ & 15 & 0,160 & & & & & & & & & Norstrom \& Muir, 1994 \\
\hline & & & & $\mathrm{F}$ & 6 & 0,160 & & & & & & & & & \\
\hline & 2000 & Atlântico N & Groenlândia & & 3 & & & & 0,430 & 0,790 & 0,370 & 0,012 & 0,021 & 0,009 & Vorkamp et al, 2004 \\
\hline \multicolumn{16}{|l|}{ Misticetos } \\
\hline \multirow[t]{2}{*}{ Baleia Minke (Balaenoptera acutorostrata ) } & $\begin{array}{l}1998 \\
1987,1994\end{array}$ & $\begin{array}{l}\text { Aunatico N } \\
\text { Pacífo N }\end{array}$ & Groenlanara & & 28 & & & & 0,100 & 0,010 & 0 & ,000 & 0,100 & n.a. & Aono et al, 1997 \\
\hline & $1984-1993$ & Antártica & & M & 79 & 0,003 & 0,007 & 0,0009 & 0,135 & 0,362 & 0,049 & & & & \\
\hline
\end{tabular}

* = (peso úmido)/0.7 
animais de altas latitudes, como os de regiões polares possivelmente como resultado do processo de destilação global.

Existem poucos estudos onde foi analisado o mirex no tecido de cetáceos, mas dentre eles, os que apresentaram valores de concentrações médias similares aos do presente estudo foram nos cetáceos da Flórida (EUA) e da Groenlândia (Hansen et al., 2004; Vorkamp et al., 2004). Entre as concentrações médias, os menores valores foram encontrados nas baleias-minke da Groenlândia (Vorkamp et al., 2004) e os maiores foram uma ordem de grandeza maior que deste estudo nos botos-cinza de São Paulo (Brasil) e os golfinhos-nariz-de-garrafa (Tursiops truncatus) da Carolina do Norte e do Sul (EUA) (Yogui, 2002; Alonso et al., 2006; Hansen et al., 2004).

As concentrações de PCBs e DDTs em tecido adiposo subcutâneo de cetáceos ao redor do mundo e deste estudo constam na Tabela 3.7. As concentrações médias de PCBs e DDTs nesse estudo foram comparáveis a contaminação em cetáceos da América do Norte (EUA e Canadá), Europa e Ásia (Japão e Hong Kong) (Langelier et al., 1988; Borrel, 1993; Wells et al., 1994; Kuehl \& Haebler, 1995; Jarman et al., 1996; Smyth et al., 2000; Minh et al., 2000; Hansen et al., 2004; Ramu et al., 2005; Kajiwara et al., 2002; 2006). Todas essas áreas têm em comum um alto grau de industrialização, agricultura, e densas populações humanas, além de possuírem indústrias químicas.

Em contraste, também foram encontradas concentrações comparáveis de PCBs em cetáceos do hemisfério sul, na Argentina; nos botos-cinza (Sotalia guianensis) de São Paulo, Brasil e na África do Sul (Corcuera et al., 1995; Kajiwara et al., 2004; Yogui, 2002; Cockroft et al., 1989; de Kock et al., 1994), países esses considerados pouco industrializados e em desenvolvimento, demonstrando uma poluição global por PCBs nos cetáceos. Isso pode ocorrer em regiões moderadamente poluídas, como no hemisfério sul em certas localidades restritas, como desembocaduras de rios, ou baías semi-fechadas, que podem ser especialmente contaminadas como um resultado de fontes pontuais de poluição (Aguilar et al., 2002).

Nos animais do Ártico e Groenlândia também foram encontrados valores similares aos deste estudo (Norstrom \& Muir, 1994; Van Scheppingen et al., 1996). As belugas (Delphinapterus leucas) realizam migrações sazonais, habitam ambientes poluídos durante certos períodos do ano e podem, quando ocupam as altas latitudes de regiões polares, carregar concentrações relativamente altas de organoclorados (Rejinders \& Ruiter-Dijkman, 1995). 
Tabela 3.7 - Médias, máximo e mínimo de concentrações de PCBs e DDTs em cetáceos de diversas regiões do planeta (em ug. $\mathrm{g}^{-1}$ lipídios).

Adaptado de Aguilar et al., 2002.

\begin{tabular}{|c|c|c|c|c|c|c|c|c|c|c|c|c|}
\hline Espécie & Ano de coleta & Área & Localização & Sexo & $\mathrm{n}$ & PCBs & Máx. & Min. & DDTs & Máx. & Min. & Referência \\
\hline \multirow{9}{*}{$\begin{array}{l}\text { Odontocetos costeiros } \\
\text { Toninha (Pontoporia blainvillei) }\end{array}$} & & & & & & & & & & & & \\
\hline & $2004-2007$ & Atlântico SW & SP, Brasil & M & 25 & 8,24 & 42,19 & 1,10 & 1,83 & 7,19 & 0,28 & Este estudo \\
\hline & & & & F & 30 & 4,56 & 22,18 & 0,33 & 0,71 & 2,40 & 0,11 & \\
\hline & & & & M Ma & 10 & 13,40 & 42,19 & 3,10 & 3,20 & 7,19 & 1,07 & \\
\hline & & & & M Im & 20 & 5,52 & 14,81 & 1,10 & 1,15 & 3,19 & 0,28 & \\
\hline & & & & $\mathrm{F} \mathrm{ma}$ & 11 & 3,29 & 8,66 & 0,33 & 0,71 & 2,40 & 0,11 & \\
\hline & & & & F Im & 14 & 5,63 & 22,18 & 1,48 & 0,71 & 1,52 & 0,20 & \\
\hline & & & & $\mathrm{Ju}$ & 34 & 5,38 & 22,18 & 1,10 & 0,92 & 3,19 & 0,28 & \\
\hline & & & & $\mathrm{M}, \mathrm{F}$ & 55 & 6,66 & 42,19 & 0,33 & 1,32 & 7,19 & 0,11 & \\
\hline \multirow[t]{36}{*}{ Golfinho Nariz-de-garrafa (Tursiops truncatus ) } & 2002 & Atlântico NW & Indian River Lagoon, FL, EUA & $\mathrm{M}$ & 9 & 20,04 & 27,95 & 14,72 & 12,65 & 23,89 & 8,29 & Hansen et al, 2004 \\
\hline & & & & F & 2 & 9,26 & 17,02 & 5,04 & 4,31 & 10,37 & 1,79 & \\
\hline & $1995,1999-2000$ & & Beaufort, NC, EUA & $\mathrm{Ju}$ & 8 & 28,28 & 52,25 & 15,91 & 28,85 & 87,28 & 11,31 & \\
\hline & & & & M & 3 & 53,28 & 52,25 & 15,91 & 51,91 & 87,28 & 11,31 & \\
\hline & & & & $\mathrm{F}$ & 2 & 11,63 & 40,60 & 3,33 & 3,99 & 18,96 & 1,59 & \\
\hline & $1999-2001$ & & Charleston, SC, EUA & $\mathrm{Ju}$ & 2 & 27,39 & 60,36 & 12,42 & 17,78 & 40,18 & 7,87 & \\
\hline & & & & M & 4 & 50,38 & 84,63 & 23,64 & 3,31 & 54,47 & 17,69 & \\
\hline & & & & $\mathrm{F}$ & 5 & 7,98 & 31,19 & 2,71 & 4,45 & 22,17 & 1,15 & \\
\hline & $1987-1988$ & & EUA & M & 3 & 138,40 & 47,20 & 0,20 & 38,58 & 80,00 & 3,75 & Kuehl et al, 1991 \\
\hline & & & & $\mathrm{F}$ & 9 & 62,37 & 17,40 & 0,16 & 7,46 & 21,20 & 0,52 & \\
\hline & $1983-1985$ & & EUA & M & 8 & 97,73 & 195,48 & 5,72 & 31,81 & 63,97 & 4,30 & King, 1987 apud Aguilar et al, 2002 \\
\hline & & & & $\mathrm{F}$ & 7 & 22,47 & 41,26 & 2,25 & 4,62 & 8,02 & 0,69 & \\
\hline & 1990 & & México & M & 6 & 93,00 & 187,00 & 64,00 & 38,00 & 78,00 & 15,00 & Kuehl \& Haebler, 1995 \\
\hline & & & & $\mathrm{F}$ & 10 & 7,20 & 18,00 & 1,50 & 3,70 & 14,00 & 0,60 & Salata et al, 1995 \\
\hline & ? & & México & $\mathrm{M}, \mathrm{F}$ & 33 & 36,10 & 149,00 & 4,10 & 15,30 & 74,60 & 0,43 & \\
\hline & & Atlântico NE & Portugal & $\mathrm{M}, \mathrm{F}$ & 4,3 & 75,31 & & & 31,03 & & & Borrell \& Aguilar, 2006 \\
\hline & & & Huelva, Espanha & $\mathrm{M}, \mathrm{F}$ & 2,3 & 182,58 & & & 113,95 & & & \\
\hline & $1989-1991$ & & Escócia & $\mathrm{M}$ & 1 & 30,72 & & & & & & Wells et al, 1994 \\
\hline & & & & $\mathrm{F}$ & 5 & 21,26 & 39,66 & 3,89 & 8,91 & 15,90 & 2,20 & \\
\hline & $1978-2001$ & Mar Mediterrâneo & Catalônia, Espanha & $\mathrm{M}, \mathrm{F}$, ? & $2,3,2$ & 161,23 & & & 52,82 & & & Borrell \& Aguilar, 2006 \\
\hline & & & Valência, Espanha & $\mathrm{M}, \mathrm{F}$, ? & $3,2,1$ & 174,35 & & & 66,31 & & & \\
\hline & & & Ilhas Baleáricas, Espanha & $\mathrm{M}, \mathrm{F}$, ? & $1,1,5$ & 117,34 & & & 64,63 & & & \\
\hline & 19871992 & & Itália & $\mathrm{M}$ & 5 & 44,63 & 174,84 & 0,25 & 15,00 & 57,68 & 0,64 & Marsili \& Focardi, 1997 \\
\hline & & & & $\mathrm{F}$ & 2 & 30,03 & 29,04 & 3,98 & 4,66 & 4,66 & 3,30 & \\
\hline & 1992 & & Itália & M & 5 & 1204,00 & 2100 & 0,25 & 399,60 & 1100,00 & 48,00 & Corsolini et al, 1995 \\
\hline & & & & $\mathrm{F}$ & 5 & 590,00 & 95 & 23,00 & 140,00 & 260,00 & 20,00 & \\
\hline & $1978-1984$ & Pacífico NW & EUA & M & 3 & 100,43 & 183 & 13,86 & 1297,62 & 2745,71 & 328,57 & Schafer et al, 1984 \\
\hline & & & & F & 3 & 38,77 & 63,57 & 13,97 & 1356,67 & 2957,14 & 180,00 & \\
\hline & ? & Pacífico SW & Austrália & ? & 6 & 0,09 & & & & 3,44 & 0,26 & Kemper et al, 1994 \\
\hline & 1990 & Índico & Índia & M & 2 & 1,19 & 1,68 & 0,70 & 9,23 & 13,21 & 5,25 & Tanabe et al, 1993 \\
\hline & & & & $\mathrm{F}$ & 2 & 0,75 & 0,94 & 0,57 & 14,72 & 20,90 & 8,55 & \\
\hline & $1980-1987$ & & África do Sul & M & 52 & 13,74 & 67,18 & & 20,01 & 85,66 & 0,45 & Cockroft et al, 1989 \\
\hline & & & & $\mathrm{F}$ & 52 & 8,45 & 47,57 & 0,09 & 5,70 & 49,70 & 0,00 & \\
\hline & & & África do Sul & M & 4 & 3,15 & 10,02 & & 11,89 & 26,25 & 2,03 & Cockroft, 1999 \\
\hline & & & & $\mathrm{F}$ & 2 & 2,12 & 4,23 & & 5,26 & 9,60 & 0,91 & \\
\hline & $1980-1987$ & Atlântico SE & África do Sul & M & 4 & 4,54 & 11,84 & 0,23 & 6,64 & 17,56 & 0,24 & Cockroft, 1999; de Kock et al, 1994 \\
\hline
\end{tabular}


Tabela 3.7 (continuação)

\begin{tabular}{|c|c|c|c|c|c|c|c|c|c|c|c|c|}
\hline \multirow{38}{*}{$\begin{array}{l}\text { Espécie } \\
\text { Golfinho do Porto (Phocoena phocoena) }\end{array}$} & Ano de coleta & Área & Localização & Sexo & $\frac{\mathrm{n}}{8}$ & $\begin{array}{ll}\text { PCBs } \\
2112\end{array}$ & $\begin{array}{ll}\text { Máx. } \\
1957 \\
\end{array}$ & $\begin{array}{ll}\text { Min. } \\
1857\end{array}$ & DDTs & Máx. & Min. & $\begin{array}{c}\text { Referência } \\
\text { Minh het al } 2000\end{array}$ \\
\hline & 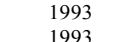 & Mar Negro & & & 8 & 31,43 & 48,57 & 18,57 & 257,14 & & & $\begin{array}{l}\text { Minh et al, } 2000 \\
\text { Tanabe et al, } 1997\end{array}$ \\
\hline & $1989-1990$ & Atlântico NE & Polônia & $\mathrm{F}$ & 3 & 33,93 & 47,03 & 25,76 & $\begin{array}{c}22,59 \\
12,59\end{array}$ & $\begin{array}{l}3,01 \\
14,56\end{array}$ & 11,20 & Kannan et al, 1993 \\
\hline & $1990-1994$ & & Polônia & M & 4 & 11,83 & 22,00 & 5,00 & 3,93 & 8,50 & 2,20 & Kawano et al, 1997 apud Aguilar et al, 2002 \\
\hline & $1980-1981$ & & Dinamarca & M & 29 & 116,12 & 382,02 & 26,97 & 35,88 & 202,25 & 7,53 & Clausen \& Andersen, 1988 \\
\hline & & & & $\mathrm{F}$ & 22 & 61,49 & 123,60 & 4,16 & 13,89 & 42,70 & 1,57 & \\
\hline & $1988-1995$ & & Mar do Norte & $\mathrm{M}, \mathrm{F}$ & 16 & & & & 6,35 & 18,76 & 1,36 & Vetter et al, 1996 \\
\hline & & & Holanda & $\begin{array}{l}\mathrm{M} \\
\mathrm{F}\end{array}$ & $\begin{array}{l}10 \\
12\end{array}$ & $\begin{array}{l}36,53 \\
19,95\end{array}$ & $\begin{array}{l}63,61 \\
39,19\end{array}$ & $\begin{array}{c}13,24 \\
4,13\end{array}$ & & & & Van Scheppingen et al, 1996 \\
\hline & $1989-1991$ & & Escócia & M & 21 & 15,98 & 44,15 & 0,57 & 4,88 & 12,62 & 0,78 & Wells et al, 1994 \\
\hline & & & & $\mathrm{F}$ & 15 & 6,57 & 32,00 & 2,71 & 2,57 & 10,40 & 0,91 & \\
\hline & $1990-1994$ & & Irlanda & M & 6 & 6,15 & 10,42 & 2,91 & 3,15 & 4,94 & 1,84 & Smyth et al, 2000 \\
\hline & & & & $\mathrm{F}$ & 6 & 8,00 & 12,27 & 3,04 & 4,66 & 5,99 & 1,64 & \\
\hline & $1989-1992$ & & Reino Unido & $\mathrm{M}$ & 23 & 40,10 & 109,49 & 0,44 & 11,07 & 33,06 & 0,63 & Kuiken et al, 1994 \\
\hline & & & & $\mathrm{F}$ & 25 & 18,69 & 86.97 & 1,63 & 5,73 & 22,86 & 0,40 & \\
\hline & $1988-1992$ & & Reino Unido & $\mathrm{M}$ & 50 & 25,61 & 109.51 & 0,13 & 6.84 & 33,06 & 0,04 & Law, 1994 \\
\hline & & & & $\mathrm{F}$ & 47 & 17,58 & 138,75 & 0,13 & 4,82 & 22,98 & 0,06 & \\
\hline & $1990-1996$ & & Reino Unido & M & 13 & 61,43 & & & & & & Jepson et al, 1999 \\
\hline & & & & $\mathrm{F}$ & 14 & 20,00 & & & & & & \\
\hline & $1987-1991$ & & Noruega & $\mathrm{M}, \mathrm{F}$ & 27 & 21,90 & 65,00 & 3,71 & 15,60 & 45,09 & 3,22 & Kleivane et al, 1995 \\
\hline & $1987-1991$ & & Noruega & $\mathrm{M}, \mathrm{F}$ & 7 & 25,89 & 44,00 & 17,25 & 18,28 & 36,18 & 12,04 & \\
\hline & $1987-1988$ & & Ilhas Faroe & M & 3 & 13,39 & 15,77 & 10,13 & 6,56 & 8,00 & 5,77 & Borrel, 1993 \\
\hline & & & & F & 3 & 8,83 & 10,31 & 7,95 & 4,43 & 4,90 & 3,99 & \\
\hline & 1989 & & Groenlândia & M & 1 & 7,86 & & & & & & Van Scheppingen et al, 1996 \\
\hline & & & & $\mathrm{F}$ & 3 & 2,76 & 3,14 & 2,13 & & & & \\
\hline & 1996 & Atlântico NW & Groenlândia & $\mathrm{M}$ & 46 & 2,42 & 5,13 & 0,64 & 3,45 & 7,90 & 0,96 & Borrel, et al, 1999 \\
\hline & & & & $\mathrm{F}$ & 54 & 1,75 & 3,33 & 0,45 & 2,25 & 4,94 & 0,38 & \\
\hline & 1987 & & EUA & $\mathrm{M}, \mathrm{F}$ & 5 & 21,14 & 32,29 & 10,60 & 10,40 & 16,00 & 6,70 & Becker et al, 1997 \\
\hline & 1987 & Pacífico NE & Canadá & $\mathrm{M}$ & 3 & 0,10 & 0,10 & 0,10 & 6,98 & 9,10 & 3,45 & Langelier et al, 1988 \\
\hline & & & & $\mathrm{F}$ & 3 & 9,27 & 16,00 & 0,10 & 5,75 & 12,30 & 1,84 & \\
\hline & $1986-1989$ & & Canadá & ? & 7 & 9,13 & & & 8,91 & & & Jarman et al, 1996 \\
\hline & & & EUA & $?$ & 3 & 13,70 & & & 16,30 & & & \\
\hline & $1980-1985$ & & EUA & M & 8 & 29,18 & 129,80 & 3,72 & 79,61 & 206,12 & 9,09 & O'Shea et al, 1980 \\
\hline & & & & $\mathrm{F}$ & 15 & 17,48 & 57,53 & 2,28 & 51,96 & 139,73 & 9,02 & \\
\hline & $1981-1985$ & & EUA & M & 3 & 31,80 & 36,34 & 23,94 & 31,01 & 40,45 & 20,38 & O'Shea et al, 1980 \\
\hline & & & & $\mathrm{F}$ & 3 & 22,83 & 31,29 & 10,96 & 14,08 & 17,88 & 9,66 & \\
\hline & $1990-1995$ & & EUA & M. F & 12 & 3,00 & 34,71 & & 3,57 & 13,43 & 0,71 & Hayteas \& Duffield, 1997 \\
\hline & 1993 & Pacífico NW & Japão & $?$ & 3 & 10,26 & 15,58 & 5,32 & 12,47 & 27,27 & 3,25 & Minh et al, 2000 \\
\hline & 1999 & & Japão & M & 3 & 2,20 & 3,00 & 0,86 & 3,30 & 5,00 & 1,10 & Kajiwara et al, 2006 \\
\hline \multirow{2}{*}{ Golfinho de Burmeister (Phocoena spinipinnis) } & $1989-1990$ & Atlântico SW & Argentina & $\mathrm{F}$ & 4 & 2,28 & 3,87 & 0,56 & 2,21 & 4,63 & 0,25 & Corcuera et al, 1995 \\
\hline & & & & M & 4 & 3,90 & 5,57 & 1,94 & 5,64 & 8,54 & 1,32 & \\
\hline \multirow[t]{12}{*}{ Golfinho de Dall (Phocoenoides dalli) } & $1984-1999$ & Pacífico NW & Sanriku, Japão & M & 35 & 24,69 & 55,71 & 5,14 & 16,69 & 50,00 & 2,14 & Kajiwara et al, 2002* \\
\hline & & & & $\mathrm{F}$ & 17 & 7,21 & 12,43 & 3,00 & 4,43 & 7,71 & 1,34 & \\
\hline & $1995-1999$ & & Hokkaido, Japão & M & 9 & 25,00 & 40,00 & 14,00 & 20,07 & 40,00 & 8,57 & \\
\hline & & & & & 14 & 10,36 & 18,57 & 2,14 & 9,14 & 15,71 & 1,43 & Kajiwara et al, $2002 *$ \\
\hline & $1984-1999$ & & Sanriku, Japão & M Ma & 27 & 28,93 & 55,71 & 11,43 & 19,89 & 50,00 & 6,00 & Kajiwara et al, $2002 *$ \\
\hline & & & & M Im & 8 & 7,71 & 13,86 & 5,14 & 3,86 & 7,00 & 2,14 & \\
\hline & & & & $\mathrm{F} \mathrm{Ma}$ & 10 & 5,71 & 8,14 & 3,00 & 3,14 & 4,57 & 1,34 & \\
\hline & & & & F Im & 7 & 8,71 & 12,43 & 5,00 & 5,71 & 7,71 & 3,43 & \\
\hline & $1995-1999$ & & Hokkaido, Japão & M Ma & 9 & 25,00 & 40,00 & 14,00 & 20,07 & 40,00 & 8,57 & \\
\hline & & & & F Ma & 10 & 5,00 & 11,14 & 2,14 & 4,00 & 10,71 & 1,43 & \\
\hline & & & & F Im & 4 & 15,71 & 18,57 & 12,29 & 14,29 & 15,71 & 14,00 & \\
\hline & 2000 & & Japão & $\mathrm{M}$ & 10 & 13,50 & 23,00 & 6,80 & 21,00 & 41,00 & 7,70 & Kajiwara et al, 2006 \\
\hline
\end{tabular}


Tabela 3.7 (continuação)

\begin{tabular}{|c|c|c|c|c|c|c|c|c|c|c|c|c|}
\hline Espécie & Ano de coleta & Área & Localização & Sexo & $\mathrm{n}$ & PCBs & Máx. & Min. & DDTs & Máx. & Min. & Referência \\
\hline \multirow{4}{*}{$\begin{array}{l}\text { Golfinho sem-dorsal (Neophocaena phocaenoides) } \\
\text { Ge }\end{array}$} & $1998-2000$ & Pacífico NW & Japão & $\mathrm{M}$ & 7 & 74,50 & 370,00 & 13,00 & 54,00 & 270,00 & 11,00 & Kajiwara et al, 2006 \\
\hline & $2000-2001$ & & Hong Kong & M & 6 & 13,00 & 28,00 & 1,40 & 120,00 & 260,00 & 10,00 & \\
\hline & $2000-2001$ & & Hong Kong & $\mathrm{M}$ & 5 & 12,66 & 28,00 & 1,40 & 132,00 & 260,00 & 26,00 & Ramu et al, 2005 \\
\hline & & & & $\mathrm{F}$ & 1 & 18,00 & & & 110,00 & & & \\
\hline \multirow[t]{4}{*}{ Golfinho-corcunda do Indo-Pacifico (Sousa chinensis) } & $1997-2001$ & Pacífico NW & Hong Kong & M & 7 & 45,00 & 83,00 & 9,40 & 190,00 & 470,00 & 51,00 & Kajiwara et al, 2006 \\
\hline & 1992 & & Índia & M & 2 & 2,00 & 2,60 & 1,40 & 75,00 & 84,00 & 66,00 & \\
\hline & $1995-2001$ & & Hong Kong & $\mathrm{M}$ & 8 & 43,86 & 83,00 & 5,20 & 169,24 & 380,00 & 1,10 & Ramu et al, 2005 \\
\hline & & & & $\mathrm{F}$ & 2 & 13,20 & 17,00 & 9,40 & 63,50 & 76,00 & 51,00 & \\
\hline \multirow[t]{8}{*}{ Boto-cinza (Sotalia guianensis) } & $1997-1999$ & Atlântico SW & Sul de SP e Norte do PR, Brasil & F Im & 4 & 12,00 & 20,00 & 6,00 & 14,00 & 25,00 & 1,40 & Kajiwara et al, 2004 \\
\hline & & & & $\mathrm{F} \mathrm{Ma}$ & 5 & 11,00 & 49,00 & 1,30 & 7,60 & 29,00 & 1,00 & \\
\hline & & & & M Im & 9 & 9,70 & 22,00 & 2,80 & 22,00 & 64,00 & 3,90 & \\
\hline & & & & M Ma & 8 & 34,00 & 79,00 & 10,00 & 52,00 & 150,00 & 12,00 & \\
\hline & $1996-2001$ & & Cananéia, SP, Brasil & $\mathrm{F}$ & 5 & 3,74 & 9,22 & 0,20 & 6,81 & 9,90 & 0,54 & Yogui, 2002 \\
\hline & & & & M & 4 & 5,70 & 7,60 & 1,61 & 72,27 & 124,88 & 7,24 & \\
\hline & $2004-2006$ & & SP, Brasil & M & 5 & 15,48 & 20,15 & 7,39 & 12,70 & 18,37 & 4,83 & Alonso et al, 2006 \\
\hline & & & & $\mathrm{F}$ & 1 & 23,48 & & & 20,71 & & & \\
\hline \multirow[t]{2}{*}{ Golfinho Irrawaddy (Orcaella brevirostris) } & $2000-2001$ & Índico & Baía de Bengal, Índia & M & 2 & 0,21 & 0,39 & 0,03 & 5,55 & 10,00 & 1,10 & Kannan et al, 2005 \\
\hline & & & & $\mathrm{F}$ & 3 & 0,16 & 0,36 & 0,04 & 3,40 & 7,90 & 0,31 & \\
\hline \multirow{2}{*}{ Golfinho-listrado (Stenella coeruleoalba ) } & $1984-1986$ & Atlântico SE & África do Sul & $\mathrm{F}$ & 1 & 1,83 & & & 1,46 & & & de Kock et al, 1994 * \\
\hline & & & & $\mathrm{M}$ & 1 & 1,59 & & & 1,06 & & & \\
\hline \multirow[t]{2}{*}{ Golfinho-rotador (Stenella longirostris) } & 1990- 1992 & Pacífico NW & Índia & M & 3 & 1,60 & 2,20 & 1,10 & 48,00 & 77,00 & 32,00 & Kajiwara et al, 2006 \\
\hline & 1996 & & Filipinas & M & 3 & 3,60 & 5,40 & 2,60 & 16,00 & 17,00 & 15,00 & Kajiwara et al, 2006 \\
\hline \multirow{2}{*}{ Golinho comum de bico-curto (Delphinus delphis) } & $1984-1987$ & Atlântico SE & África do Sul & $\mathrm{F}$ & 7 & 4,04 & 7,24 & 0,84 & 2,81 & 4,31 & 0,81 & de Kock et al, 1994 * \\
\hline & & & & M & 10 & 8,49 & 22,16 & 0,10 & 12,97 & 36,07 & 0,10 & \\
\hline \multirow{2}{*}{ Golfinho de Heaviside (Cephalorhynchus heavisidii) } & $1977-1987$ & & África do Sul & $\mathrm{F}$ & 3 & 0,40 & 0,93 & 0,10 & 2,69 & 6,01 & 0,36 & de Kock et al, 1994 * \\
\hline & & & & M & 5 & 1,30 & 2,51 & 0,39 & 3,96 & 6,81 & 1,11 & \\
\hline \multirow{2}{*}{ Golfinho Dusky (Lagenorhynchus obscurus) } & $1977-1987$ & & África do Sul & $\mathrm{F}$ & 6 & 1,71 & 3,39 & 0,80 & 3,36 & 8,31 & 1,49 & de Kock et al, 1994 * \\
\hline & & & & M & 6 & 3,80 & 7,99 & 0,54 & 9,99 & 23,07 & 0,70 & \\
\hline \multirow[t]{2}{*}{ Orca (Orcinus orca) } & 1994-1997, 2001 & Atlântico NE & Irlanda, Inglaterra e Escócia & $\mathrm{F}$ & 4 & & & & 201,68 & 600,59 & 50,00 & McHugh et al, 2007 \\
\hline \multirow{2}{*}{\multicolumn{13}{|c|}{ Odontocetos oceânicos }} \\
\hline & & & & & & & & & & & & \\
\hline \multirow{4}{*}{ Cachalote (Physeter macrocephalus) } & 1998 & Pacífico SW & Tasmânia, Austrália & & & & & & 2,00 & & & Evans et al, 2004 \\
\hline & & & & F Ma & 25 & & & & 1,75 & & & \\
\hline & & & & M Im & 2 & & & & 4,80 & & & \\
\hline & & & & M Ma & 3 & & & & 2,10 & & & \\
\hline \multirow{3}{*}{ Golfinho de Risso (Grampus griseus) } & 1996 & Mar Mediterrâneo & Itália & $\mathrm{F}$ & 3 & 1,13 & & & 8,23 & & & Storelli \& Marcotrigiano, 2000 \\
\hline & $1984-1986$ & Atlântico SE & África do Sul & $\mathrm{F}$ & 1 & 0,56 & & & 1,84 & & & de Kock et al, $1994 *$ \\
\hline & & & & $\mathrm{M}$ & 1 & 3,89 & & & 10,73 & & & \\
\hline \multirow{2}{*}{ Cachalote pigméia (Kogia breviceps) } & 1978-1987 & & & $\mathrm{F}$ & 3 & 0,71 & 1,57 & 0,17 & 0,87 & 1,46 & 0,43 & de Kock et al, 1994 * \\
\hline & & & & M & 2 & 0,39 & 0,41 & 0,37 & 1,01 & 1,57 & 0,43 & \\
\hline \multirow{3}{*}{ Baleia-bicuda de Blainville (Mesoplodon densirostris) } & $1976-1984$ & & & M & 4 & 0,36 & 0,54 & 0,21 & 1,07 & 2,04 & 0,53 & de Kock et al, 1994 * \\
\hline & $1984-1986$ & & & F & 4 & 0,70 & 1,26 & 0,39 & 0,89 & 1,64 & 0,41 & de Kock et al, 1994 * \\
\hline & & & & M & 2 & 0,39 & 0,41 & 0,37 & 1,61 & 2,66 & 0,56 & \\
\hline \multicolumn{13}{|l|}{ Odontocetos de regiôes polares } \\
\hline \multirow[t]{2}{*}{ Beluga (Delphinapterus leucas) } & $1983-1989$ & Ártico & Baía de Buffin & $\mathrm{M}$ & 103 & 4,67 & 5,58 & 2,53 & 3,53 & 6,83 & 1,96 & Norstrom \& Muir, 1994 \\
\hline & & & & $\mathrm{F}$ & 105 & 2,91 & 4,01 & 0,96 & 2,10 & 2,88 & 0,67 & \\
\hline \multirow{3}{*}{$\begin{array}{l}\text { Narval (Monodon monoceros) } \\
\text { Misticetos } \\
\text { Baleia Minke (Balaenoptera acutrostrata) }\end{array}$} & $1982-1983$ & & & M & 15 & 5,18 & & & 5,92 & & & \\
\hline & 1987, 1994 & Pacífico $\mathrm{N}$ & & M & 28 & 3,04 & 4,19 & 0,84 & 2,64 & 4,73 & 0,31 & Aono et al, 1997 \\
\hline & $1984-1993$ & Antártica & & $\mathrm{M}$ & 79 & 0,96 & 0,26 & 0,02 & 0,17 & 0,48 & 0,03 & \\
\hline
\end{tabular}

${ }^{*}=$ (peso úmido)/0.7 
As espécies de cetáceos que apresentaram valores maiores de PCBs que as toninhas deste estudo possuíram de 1 a 3 ordens de grandeza superiores. Os cetáceos com maiores concentrações desses resíduos industriais foram os golfinhos nariz-de-garrafa (Tursiops truncatus) da Itália (Corsolini et al., 1995). As regiões costeiras mais impactadas por estes compostos, segundo as concentrações encontradas nos cetáceos foram a Europa tanto no Atlântico quanto no Mar Mediterrâneo, a América do Norte (EUA na costa do Pacífico e do Atlântico e México), Ásia (Japão, Hong Kong) e Brasil (Boto-cinza de São Paulo) (Marsili \& Focardi, 1997; Borrell \& Aguilar, 2006; Clausen \& Andersen, 1988; Kuehl et al., 1991; Schafer et al., 1984; Salata et al., 1995; Ramu et al., 2005; Kajiwara et al., 2002; 2004; 2006; Alonso et al., 2006). Todos esses locais encontram-se próximos a regiões industrializadas, indicando um reflexo do ambiente em que vivem e da alta produção e uso de PCBs no passado.

Os cetáceos que possuíram concentrações médias de PCBs menores que deste estudo foram em países pouco industrializados: Austrália, costa leste e oeste da África do Sul, Argentina, Índia e Filipinas (Kemper et al., 1994; Cockroft, 1999; de Kock et al., 1994; Corcuera et al., 1995; Tanabe et al., 1993; Ramu et al., 2005; Kajiwara et al., 2006; Kannan et al., 2005), refletindo em menores concentrações de PCBs nesses cetáceos. Mas também houve concentrações abaixo das encontradas neste estudo em animais de países que possuem um alto grau de industrialização, como Canadá, EUA e Japão (Langelier et al., 1988; Hayteas \& Duffield, 1997; Kajiwara et al., 2006).

Em relação às concentrações médias de DDTs nos cetáceos ao redor do mundo, os valores deste estudo foram considerados baixos, pois os únicos menores ocorreram nas baleias-minke (Balaenoptera acutrostrata) da Antártica (Aono et al., 1997), grandes cetáceos que se alimentam de pequenos crustáceos e peixes, portanto acumulam menos poluentes em seus tecidos. Além de serem de regiões remotas e com ausência dessas fontes, como ocorre na Antártica.

$\mathrm{Na}$ maioria dos estudos as concentrações médias de DDTs foram maiores que este, variando em até 4 ordens de grandeza superiores. Os locais que apresentaram as maiores concentrações de DDTs nos golfinhos foram no hemisfério norte: EUA, Europa (Mediterrâneo e Atlântico), Mar Negro e em Hong Kong (Schafer et al., 1984; Corsolini et al., 1995; Kannan et al., 1993; Ramu et al., 2005; Kajiwara et al., 2006; Borrell \& Aguilar, 2006). As regiões costeiras dessas áreas sustentam densas populações humanas e as atividades industriais e de agricultura também são intensas. A produção e o uso de DDT foi descontínuo até meados da década de 70 na Europa e América do Norte, 
entretanto esse pesticida foi amplamente utilizado em datas prévias e seus resíduos no ambiente permanecem extremamente elevados (Aguilar et al., 2002). Na China esse pesticida é produzido e utilizado até a presente data (Wei et al., 2007). As Orcas (O. orca) da Europa (McHugh et al., 2007) também apresentaram concentrações bastante elevadas, mas deve-se levar em conta que seu nível trófico é o mais elevado entre os cetáceos.

As maiores concentrações de organoclorados em cetáceos foram encontradas em águas temperadas do hemisfério norte, particularmente que habitam as latitudes médias da Europa e América do Norte, que apresentaram os maiores níveis de DDTs e PCBs. Esses resultados são consistentes com estudos desde a década de 1980 sobre distribuição geográfica de OCs na atmosfera e água (Tanabe et al., 1983) e com padrões globais previamente observados em mamíferos marinhos (O’Shea \& Brownell, 1994; Rejinders \& de Ruiter-Dijkman, 1995), por conta da extensiva produção e uso no passado e presente destes compostos em países industrializados nesta parte do mundo, corroborando com Rejinders (1996) e Aguilar et al. (2002).

Os PCBs e DDTs estão amplamente distribuídos nos cetáceos até o presente, mas os PCBs seguiram uma evolução diferente. O uso destes compostos foi descontinuo até meados da década de 1970, mas diferente dos DDTs, que foram prontamente substituídos por uma nova geração de pesticidas, os PCBs não tiveram substitutos. Consequentemente, esforços de controle foram poucos e os compostos permaneceram em uso em muitas aplicações. Também a alta estabilidade dos PCBs e o fato de sua disposição ser tecnicamente difícil e seus custos elevados, fez com que as indústrias armazenassem enormes quantidades desses produtos (Safe et al., 1987). Também capacitores contendo PCBs são transportados de países desenvolvidos para países em desenvolvimento, facilitando a entrada em regiões não industrializadas (Aguilar et al., 2002). Isso explica o fato de concentrações relativamente altas de PCBs serem observadas em pequenos cetáceos de certas regiões de países em desenvolvimento, como é o caso do Brasil e Hong Kong (Kajiwara et al., 2004; 2006; Ramu et al., 2005).

Isso, juntamente com a redistribuição entre compartimentos ecológicos, e a progressiva deposição de enormes quantidades de PCBs presentes na atmosfera, nos levam a concluir que os valores globais de PCBs na biota marinha são prováveis a não haver declínios num futuro próximo, nem certamente antes de 2030-2040 (Tanabe, 1988, Breivick et al., 2007). Estima-se que até meados da década de 1980 apenas 30\% de todo PCB produzido foi disperso para o ambiente. Até final dos anos 1980, Marquenie e 
Rejinders (1989) estimaram que apenas 1\% de toda produção de PCB tinha alcançado os oceanos, enquanto $30 \%$ havia sido acumulado em lixões e sedimentos de lagos, zonas costeiras e estuários, resultando em um lento declínio futuro nas concentrações desse composto no ambiente (Aguilar et al., 2002).

\section{CONCLUSÕES}

Os compostos organoclorados (OCs) estiveram presentes no tecido adiposo subcutâneo das toninhas (Pontoporia blainvillei) do litoral de São Paulo. Os PCBs (0,33 $42 \mu \mathrm{g} . \mathrm{g}^{-1}$ lipídios) foram os compostos predominantes, seguidos dos DDTs $(0,11-7,2$ $\mu \mathrm{g} . \mathrm{g}^{-1}$ lip.). Os outros organoclorados apresentaram até 3 ordens de grandeza inferior:

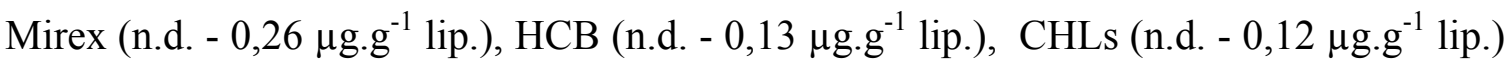
e por último os HCHs (n.d. - 0,05 $\mu \mathrm{g} . \mathrm{g}^{-1}$ lip.). Os machos apresentaram concentrações maiores que as fêmeas para todos os compostos analisados. Essas foram maiores nos machos sexualmente maduros enquanto que as fêmeas apresentaram maiores concentrações nas juvenis imaturas, com exceção do Mirex onde as maduras apresentaram os maiores valores.

Os compostos que apresentaram diferenças significativas $(p<0,05)$ entre machos e fêmeas foram o HCB e os DDTs ( $p, p^{\prime}$-DDE, $p, p^{\prime}$-DDD, $p, p^{\prime}$-DDT). Entre os machos, os compostos que apresentaram diferenças significativas entre maduros e imaturos foram o Mirex, os DDTs (p,p'-DDE, $p, p^{\prime}$-DDT) e os PCBs, enquanto entre as fêmeas foram os DDTs ( $p, p^{\prime}$-DDD, $p, p^{\prime}$-DDT e $o, p^{\prime}$-DDT). As maiores diferenças significativas ocorreram entre lactantes e juvenis de ambos os sexos, nos DDTs ( $p, p^{\prime}$-DDD, $p, p^{\prime}$-DDT e $o, p$ '-DDT), PCBs e no HCB. Esses compostos possivelmente foram transferidos pelo leite, pois aproximadamente $90 \%$ da transferência dos OCs da fêmea para a prole ocorre através da amamentação.

Houve diferenças significativas $(\mathrm{p}<0,05)$ nas toninhas das 3 localidades do litoral de São Paulo: Litoral Norte (LN), Baixada Santista (BS) e Litoral Sul (LS). Em ambos os sexos dos animais da BS as correlações entre os compostos DDTs, PCBs e HCB foram mais altas que quando comparadas aos animais no geral, com correlações mais fortes entre os PCBs. Os machos da BS apresentaram diferenças significativas nos PCBs leves (3 a 4 átomos de cloro) em relação aos machos do LS. Os animais da Baixada Santista apresentaram as maiores concentrações dos compostos analisados, com valores até 6 
vezes superiores aos dos animais do litoral Norte e Sul, devido à região ser a mais densamente povoada e industrializada.

As relações DDTs/PCBs foram menores que 0,6 em todas as toninhas do litoral do Estado de São Paulo, indicando uma influência industrial predominante sobre a agrícola em todo Estado. Isso pode demonstrar que a poluição por resíduos industriais atinge esses pequenos cetáceos em toda costa de São Paulo, não ficando restrita aos animais da Baixada Santista.

As diferenças significativas dos OCs nas 3 localidades do litoral do Estado de São Paulo podem indicar diferenças dentro do estoque populacional de toninhas do Estado de São Paulo, sugerindo que esses animais possam ter distribuição restrita a certas regiões. Isso pode contribuir na identificação de estoques dentro da FMA II (São Paulo, Paraná e Santa Catarina) no Estado de São Paulo. Isso também pode sugerir que o estoque do Litoral Norte de São Paulo seja um dos mais isolados, devido ao hiato na distribuição da espécie ao norte (entre Ubatuba, SP e Macaé, RJ).

Comparando-se os valores dos compostos predominantes (PCBs e DDTs), entre toninhas nas regiões onde houve estudos (São Paulo, Paraná, Rio Grande do Sul, Uruguai e Argentina), os PCBs apresentaram maiores valores neste estudo, mostrando uma forte influência industrial no litoral de São Paulo. Os valores de DDTs foram próximos aos da Argentina, e as maiores médias foram encontradas na região da divisa de SP-PR, provavelmente devido ao litoral sul de São Paulo e norte do Paraná possuir características agrícolas, mostrando um uso mais acentuado nessa região.

Os valores de PCBs, Mirex e HCB encontrados nesse estudo foram comparáveis aos encontrados em cetáceos do Hemisfério Norte.

\section{CONSIDERAÇÕES FINAIS}

Com base no presente trabalho realizado sugere-se:

- Dar continuidade ao monitoramento dos poluentes na população de toninhas da região do Estado de São Paulo e ampliar esse monitoramento em regiões onde ainda não foram realizados estudos com esses compostos (Espírito Santo, Rio de Janeiro, Paraná, Santa Catarina) para se avaliar o real impacto dos organoclorados na espécie; 
- Realizar análises de organoclorados no leite e fetos dessas fêmeas para se avaliar a transferência desses compostos às futuras gerações;

- Realizar análises de organoclorados nas presas das toninhas (P. blainvillei) para verificar sua principal via de contaminação, analisando a cadeia alimentar e o fluxo trófico desses contaminantes,

- Utilizar análises de organoclorados em toninhas para se diferenciar os estoques dentro das áreas de manejo da espécie (FMAs);

- Realizar estudos dos efeitos poluentes na saúde desses animais através de análises de seus sistemas endócrino (hormonais e enzimáticos) e imunológico (células do timo) e verificar possíveis potenciais genotóxicos.

\section{REFERÊNCIAS BIBLIOGRÁFICAS}

ABNT (2003). Resíduos Sólidos - Classificação - NBR 10.004, São Paulo: ABNT.

Abessa, D.M.S; Sousa, E.C.P.M. \& Tommasi, L.R. (1998). Necessidade de uma política voltada para a conservação da qualidade dos sedimentos marinhos e estuarinos. Resumos do $5^{\circ}$ Encontro Brasileiro de Ecotoxicologia, Univali, Itajaí: p.42.

Aguilar, A. (1984). Relationship of DDE/ $\sum$ DDTs in marine mammals to the chronology of DDT input into the ecosystem. Canadian Journal of Fishery and Aquatic Science $41: 840-844$.

Aguilar, A. (1987). Using organochlorine pollutants to discriminate marine mammal populations: a review and critique of the methods. Marine Mammal Science 3(3): 242-262.

Aguilar, A.; Borrell, A.; Reijnders, P.J.H. (2002). Geographical and temporal variation in levels of organochlorine contaminants in marine mammals. Marine Environmental Research, 53: 425-452.

Alonso, M. B.; Furtado, M. F.; Mourato, B. L.; Bertozzi, C. P. (2004). Monitoramento da captura acidental da toninha, Pontoporia blainvillei (Cetacea: Pontoporiidae), pela pescaria artesanal em Guarujá, São Paulo, Brasil. $11^{0}$ Reunión de Trabajo de Especialistas en Mamíferos Acuáticos de América del Sur. Quito, Equador. p.143. 
Alonso, M. B.; Marcatto, F. A.; Bertozzi, C.P. \& Zerbini, A. N. (2005). Fishery characteristics and cetacean bycatch in Guarujá and Santos, São Paulo State, southeastern Brazil. 16 ${ }^{\text {th }}$ Biennial Conference on the Biology of Marine Mammals, San Diego, California, USA.

Alonso, M. B.; Marigo, J.; Bertozzi, C. P.; Taniguchi, S. \& Montone, R. C. (2006). Occurrence of chlorinated pesticides and polychlorinated biphenyls (PCBs) in marine tucuxi (Sotalia guianensis) from São Paulo coast, Brazil. Working Paper Workshop on Research and Conservation of the Genus Sotalia, Armação dos Búzios, RJ, Brasil.

Albaigés, J. (1990). An introduction in Marine Pollution. Marine Pollution. Ed. J. Albaigés, Hemisphere Pub. Corp., N.Y., Chapter 1, 1-10.

Antonious, G.F.; Byers, M.E. (1997). Fate and movement of endosulfan under field conditions. Environmental Toxicology Chemistry 16: 644-649.

Aono, S.; Tanabe, S.; Fujise, Y.; Kato, H.; Tatsukawa, R. (1997). Persistent organochlorine in minke whale (Balaenoptera acutorostrata) and their prey species from the Antarctic and the North Pacific. Environmental Pollution, 98(1): 81-89.

Becker, P. R., Mackey, E. A., Demiralp, R., Schantz, M. M., Koster, B. J., \& Wise, S. A. (1997). Concentrations of chlorinated hydrocarbons and trace elements in marine mammal tissues archived in the US National Biomonitoring Specimen Bank. Chemosphere, 34: 2067-2098.

Bergman, A., Olson, M. Reiland, S. (1992). Skull bone lesions in the Baltic grey seals. Ambio 21: 517-519.

Bertozzi, C. P. e Zerbini, A. N. (2002). Incidental mortality of franciscana (Pontoporia blainvillei) in the artisanal fishery of Praia Grande, São Paulo State, Brazil. The Latin American Journal of Aquatic Mammals (special issue) 1: 153-160.

Bertozzi, C. P.; Barbosa, E.; Marigo, J.; Ruoppolo, V.; Zerbini, A. N. (2003). Incidental captures of franciscana, Pontoporia blainvillei, in the artisanal fishery of Praia Grande, southeastern Brazil. In: 15 ${ }^{\text {th }}$ Biennial Conference on the Biology of Marine Mammals, Greensboro, NC, USA, p.124-125.

Besnard, W. (1950). Considerações gerais em torno da região lagunar de CananéiaIguape. I - Boletim do Instituto Paulista de Oceanografia, 1 (1): 9-26.

Borrell, A. (1993). PCB and DDTs in blubber of cetaceans from the northeastern North Atlantic. Marine Pollution Bulletin, 26(3): 146-151. 
Borrel, A.; Pastor, T.; Aguilar, A.; Corcuera, J.; Monzón, F. (1995). DDTs and PCBs in La Plata dolphins (Pontoporia blainvillei) from Argentina: age and sex trends. European Research on Cetaceans, 9: 273-276.

Borrel, A.; Bloch, D.; Desportes,G. (1995). Age trends and reproductive transfer of organochlorine compounds in long-finned pilot whales from Faroe Islands. Environmental Pollution, 88: 283-292.

Borrell, A., \& Aguilar, A. (1999). A review of organochlorine and metal pollutants in marine mammals from Central and South America [special issue]. Journal of Cetacean Research and Management, 1: 195-207.

Borrel, A. \& Aguilar, A. (2006). Organochlorine concentrations declined during 19872002 in western Mediterranean bottlenose dolphins, a coastal top predator. Chemosphere 66:347-352.

Brasil. (1971a). Ministério da Agricultura. Portaria nº 356. Diário Oficial da União, Brasília, 15 out. 1971, Seç.1: 8318.

Brasil. (1971b). Ministério da Agricultura. Portaria nº 357. Diário Oficial da União, Brasília, 15 out. 1971, Seç.1: 8318.

Brasil. (1985). Ministério da Agricultura. Portaria $\mathrm{n}^{\circ}$. 329. Diário Oficial da União, Brasília, 3 set. 1985, Seç 1: 12941.

Breivik, K.; Sweetman, A.; Pacyna, J. M. \& Jones, K. C. (2007). Towards a global historical emission inventory for selected PCB congeners - A mass balance approach: 3 - An update. Science of the Total Environment, 377: 296-307.

Brooks, G.T. (1974). Chlorinated Insecticides: Technology and Application, CRC Press, Cleveland, U.S.

CETESB. (1978). Poluição das Águas no Estuário e Baía de Santos. Relatório CETESB, São Paulo: Volume 1.

Capistrano, L.; Ramos, R. e Di Beneditto, A. P. (1992). Envolvimento de pequenos cetáceos em operações de pesca no litoral norte do Estado do Rio de Janeiro, Brasil. Anais, V Reunión de Trabajos de Especialistas em Mamíferos Aquáticos de América de Sur, $14 \mathrm{p}$.

Carvalho, C.T. (1961). Stenodelphis blainvillei na costa central do Brasil, com notas osteológicas (Cetacea, Platanistidae). Revista Brasileira de Biologia 21 (1): 443-454.

Carwardine, M. (1995). Whales, Dolphins and Porpoises. The visual guide to all the world`s cetaceans. Eyewitness - handbooks. Dorling Kindersley, London. 
Carwardine, M., Hoyt, E., Fordyce, R.E., Gill, P. (1999). Whales, Dolphins and Porpoises. Weldon Owen Pty Limited, Australia.

Castello, H.P.; Junín, M.; Rotman, F.; Sarti, G.C. (2000). Analisis de contaminantes organoclorados y metales pesados en franciscana, Pontoporia blainvillei, de Argentina y Brasil. Report of the 3rd Workshop for the Coordinated Research and Conservation of the Franciscana Dolphin (Pontoporia blainvillei)in the Southwestern Atlantic. 46-50p.

Clark, R.B. (2001). Marine Pollution. 5th Edition. Oxford University Press. 172p.

Clausen, B., \& Andersen, S. (1988). Evaluation of bycatch and health status of the harbour porpoise (Phocoena phocoena) in Danish waters. Danish Review of Game Biology, 13(5): 1-20.

Cockcroft, V. G., de Kock, A. C., Lord, A. D., \& Ross, G. J. B. (1989). Organochlorines in bottlenose dolphins Tursiops truncatus from the east coast of South Africa. South African Journal of Marine Science, 8: 207-217.

Cockcroft, V. G. (1999). Organochlorine levels in cetaceans from South Africa: a review [special issue]. Journal of Cetacean Research and Management, 1, 169-176.

Colborn, T.; Dumanoski, D.; Myers, J.P. (1996). Our stolen future. L\&PM. 354p.

Corcuera, J. (1994). Incidental mortality of franciscanas in Argentine waters: the threat of small fishing camps. Rep. Int. Whal. Commn. Perrin, W. F.; Donovan, G. P. \& Barlow, J. (eds). Gillnets and cetaceans. International Whaling Commission (special issue 15), Cambrige, ix+629p: 291- 294.

Corcuera, J., Monzon, F., Aguilar, A., Borrell, A., \& Raga, J. A. (1995). Life history data, organochlorine pollutants and parasites from eight Burmeister's porpoises, Phocoena spinipinnis, caught in northern Argentine waters [special issue]. Reports of the International Whaling Commission, 16: 365-372.

Corsolini, S., Focardi, S., Kannan, K., Tanabe, S., Borrell, A., \& Tatsukawa, R. (1995). Congener profile and toxicity assessment of polychlorinated biphenyls in dolphins, sharks and tuna collected from Italian coastal waters. Marine Environmental Research, 40: 33-53.

Crespo, E. A. e Harris, G. (1992). Comentários sobre el limite sur de la distribución de la franciscana (Pontoporia blaivillei) y su tamaño de manada. Reunion de especialistas en mamíferos acuaticos de America del Sur, 5. Resumenes. Buenos Aires: Fundacion Australis, Museo Argentino de Ciencias Naturales Bernardino Rivadavia, p.18. 
Crespo, E. A., Harris, G., and González, R. (1998). Group size and distributional range of the franciscana, Pontoporia blainvillei. MarineMammal Science, 14: 845-849.

Danilewicz, D.; Secchi, E.R.; Ott, P.H.; Moreno, I.B. (2000). Analysis of the age at sexual maturity and reproductive rates of franciscanas (Pontoporia blainvillei) from Rio Grande do Sul, southern Brazil. Comun. Mus. Ciênc. Tecnol. PUCRS. Sér. Zool. Porto Alegre, 13: 89-98.

D'amato, C.; Torres, J.P.M. \& Malm, O. (2002). DDT (Dicloro Difenil Tricloroetano): Toxicidade e Contaminação Ambiental - uma Revisão. Quimica Nova 25 (6): 9951102 .

Dearth, M.A \& Hites, R.A. (1991). Chlordane accumulation in people. Environmental Science Technology 25: 1279 - 1285.

de Kock, A. C., Best, P. B., Cockcroft, V., \& Bosma, C. (1994). Persistent organochlorine residues in small cetaceans from the east and west coasts of southern Africa. Science of the Total Environment, 154, 153-162.

DeLong, R.L., Gilmartin, W.G., Simpson, J.G. (1973). Premature births in Californian sealions: association with high organchlorine pollutant residue levels. Science 181: 1168-1170.

Di Beneditto, A. P. M.; Ramos, R. M. A. e Lima, N. R. W. (1998). Fishing Activity in Northern Rio de Janeiro State (Brazil) and its Relation with Small Cetaceans. Brazilian Archives of Biology and Technology, 41 (3): 296- 302.

Edwards, P. (1992). Dangerous substances in water: A practical guide. Environmental Data Services, London, 64 pp.

Evans, K.; Hindell, M.; Hince, G. (2004). Concentrations of organochlorines in sperm whales (Physeter macrocephalus) from Southern Australian waters. Marine Pollution Bulletin, 48: 486-503.

Ferreira, J.R.; Prado Filho, L.G.; Castro, L.A.B. (1980). Alguns dados sobre a poluição por pesticidas clorados na região estuarina-lagunar de Cananéia-Iguape. Boletim do Instituto de Pesca, 7: 103-109.

Fillmann, G.; Hermanns, L.; Fileman, T.W. \& Readman. (2002). Accumulation pattern of organochlorines in juveniles of Arctocephalus australis found stranded along the coast of Southern Brazil. Organohalogen Compounds 55: 131-134.

Fossi M.C.; Savelli C.; Marsili L.; Casini S.; Jimenez B.; Junin M.; Castello H. \& Lorenzani J.A. (1997). Skin biopsy as a nondestructive tool for the toxicological 
assessment of endangered populations of pinnipeds: preliminary results on mixed function oxidize in Otaria flavensces. Chemosphere, 35: 1623-1635.

Freitas-Guimarães, J.R.P. (2005). Resíduos Industriais na Baixada Santista: Classificação e Riscos. Publicado na internet por ACPO - Associação de Combate aos POP's, Associação de Consciência à Prevenção Ocupacional <http://www.acpo.org.br> a partir de mar.2005, 9 p.

Hansen, L.J.; Schwacke, L.H.; Mitchum, G.B.; Hohn, A.A.; Wells, R.S.; Zolman, E.S.; Fair, P.A. (2004). Geographic variation in polychlorinated biphenyl and organochlorine pesticide concentrations in blubber of bottlenose dolphins from the US Atlantic coast. The Science of Total Environment, 319: 147-172.

Hayteas, D. L., \& Du.eld, D. A. (1997). The determination by HPLC of PCB and p,p'DDE residues in marine mammals stranded on the Oregon Coast, 1991-1995. Marine Pollution Bulletin, 34: 844-848.

Hoelzel, A. R. (2002). Marine mammal biology: an evolutionary approach. Oxford: Blackwell Publishing.

Hooker, S.K.; Gerber, L.R. (2004). Marine reserves as a tool for ecosystem-based management: the potential importance of megafauna. Bioscience, 54:27-39.

Hummert, K.; Vetter, W.; Luckas, B. (1995). Levels of alpha-HCH, lindane and enantiomeric ratios of alpha-HCH in marine mammals from the northern hemisphere. Chemosphere, 31(6): 3489-3500.

Hutzinger, O.; Safe, S.; Zitko, V. (1974). The Chemistry of PCBs. CRC Press, Cleveland, Ohio, U.S.

Iwata, H., Tanabe, S., \& Tatsukawa, R. (1993). A New View On The Divergence of HCH Isomer Compositions In Oceanic Air. Marine Pollution Bulletin, 26(6):302305.

Iwata, H.; Tanabe, S.; Mizuno, T. \& Tatsukawa, R. (1997). Bioaccumulation of butyltin compounds in marine mammals: the specific tissue distribution and composition. Applied Organometallic Chemistry, 11: 257-264.

IBAMA - Instituto Brasileiro do Meio Ambiente e dos Recursos Naturais e Renováveis. (2003). Mamíferos Aquáticos do Brasil. Plano de ação. $2^{a}$ Edição. Brasília: MMA/IBAMA. 96p.

IUCN (2007). 2007 IUCN Red List of Threatened Species. <www.iucnredlist.org>. (visitado em 13 Junho 2008). 
Jarman, W. M., Norstrom, R. J., Muir, D. C. G., Rosenberg, B., Simon, M., \& Baird, R. W. (1996). Levels of organochlorine compounds including PCDDs and PCDFs, in the blubber of cetaceans from the west coast of North America. Marine Pollution Bulletin, 32: 426-436.

Jepson, P. D., Bennett, P. M., Allchin, C. R., Law, R. J., Kuiken, T., Baker, J. R., Rogan, E., \& Kirkwood, J. K. (1999). Investigating potential associations between chronic exposure to polychlorinated biphenyls and infectious disease mortality in harbour porpoises from England and Wales. Science of the Total Environment, 15: 339-348.

Jenssen, B. M. (1996). An overview ofexposute to, and effects of, petroleum oil and organochlorine pollution in Grey seals (Halichoerus grypus). The Science of the Total Environmental, 186:109-118.

Jimenez, B.; Gonzalez, M.J.; Hernandez, L.M.; Elijarrat, E.; Rivera, J. \& Fossi, M.C. (1999). 2,3,7,8-substituted PCDDs and PCDFs in Sea Lion (Otaria flavescens) skin biopsies from two south-western Atlantic populations. Chemosphere, 38: 507-515.

Jones, K. C. \& Voogt, P. (1999). Persistent organic pollutants (POPs): state of the science. Environmental Pollution, 100:209-221.

Johnston, R. (1976). Marine Pollution. Academic Press. 726p.

Johnston, P.A., Stringer, R.L., Santillo, D. (1996). Cetaceans and Environmental Pollution: The Global Concerns. In: Simmonds, M.P. \& Hutchinson, J. (Eds). The conservation of whales and dolphins: science and practice. Jonh Wiley \& Sons Ltda, Baffins Lane, Chichester, England. pp. 219-261.

Junin, M.; Castello, H.P.; Secchi, E.; Moreno, I.B. (1994). Analisis cuali y cuantitativo de organoclorados y metales pesados en mamiferos marinos del Atlantico S.O. $2^{\circ}$ Encontro de Trabalho sobre a Coordenação de Pesquisa em conservação da Franciscana, Florianópolis.

Kajiwara, N.; Watanabe, M.; Tanabe, S.; Nakamatsu, K.; Amano, M.; Miyazaki, N. (2002). Specific accumulation and temporal trends of organochlorine contaminants in Dall's porpoises (Phocoenoides dalli) from Japanese coastal waters. Marine Pollution Bulletin, 44: 1089-1099.

Kajiwara, N.; Matsuoka, S.; Iwata, H.; Tanabe, S.; Rosas, F. C. W.; Fillmann, G.; Readman, J. W. (2004). Contamination by persistent organochlorines in cetaceans incidentally caught along Brazilian coastal waters. Archives of Environmental Contamination and Toxicology 46, 124-134. 
Kajiwara, N.; Kamikawa, S.; Ramu, K.; Ueno, D.; Yamada, T.K.; Subramanian, AN.; Lam, P.K.S.; Jefferson, T.A.; Prudente, M.; Chung, K.H. \& Tanabe, S. (2006). Geographical distribution of polybrominated diphenyl ethers (PBDEs) and organochlorines in small cetaceans from Asian waters. Chemosphere ,64: 287-295.

Kannan, K., Tanabe, S., Borrel, A., Aguilar, A., Focardi, S., Tatsukawa, R. (1993). Isomer-specific analysis and toxic evaluation of polychlorinated biphenyls in striped dolphins affected by an epizootic in the W Mediterranean Sea. Arch. Environ. Containation. Toxicology. 12: 227-233.

Kannan, K.; Tanabe, S.; Tatsukawa, R.; Sinha, R.K. (1994). Biodegradation capacity and residue pattern of organochlorines in Ganges river dolphins from India. Toxicological and Environmental Chemistry 42: 249-261.

Kannan, K.; Ramu, K.; Kajiwara, N.; Sinha, R.K. \& Tanabe, S. (2005). Organochlorine pesticides, polychlorinated biphenyls and polybrominated diphenyl ethers in Irrawaddy dolphins from India. Archives of Environmental Contamination \& Toxicology, 49:415-420.

Kawano, M., Tanaka, Y., Falandysz, J., \& Tatsukawa, R. (1997). Extractable organohalogens and known organochlorine xenobiotics in harbour porpoise Phocoena phocoena from the southern part of the Baltic sea. Bromatologia i Chemia Toksykologiczna, 1: 87-94.

Kemper, C.; Gibbs, P.; Obendorf, D.; Marvanek, S. \& Lenghaus, C. (1994). A rewiew of heavy metals and organochlorine levels in marine mammals in Australia. The Science of the Total Environment, 154: 129-139.

Kinas, P.G. \& Secchi, E. R. (1998). Modeling truncated data to estimate incidental kills of franciscana, Pontoporia blainvillei, by gillnets. Rep. Int. Whal. Commn, 48: 533536.

Kleivane, L., Skaare, J. U., Bjorge, A., de Ruiter, E., \& Reijnders, P. J. H. (1995). Organochlorine pesticide residue and PCBs in harbour porpoise (Phocoena phocoena) incidentally caught in Scandinavian waters. Environmental Pollution, 89: $137-146$.

Kuehl, D. W., Haebler, R., \& Potter, C. (1991). Chemical residues in dolphins from the US Atlantic coast including bottlenose obtained during the 1987/88 mass mortality. Chemosphere, 22, 1071-1084.

Kuehl, D. W., \& Haebler, R. (1995). Organochlorine, organobromine, metal, and selenium residues in bottlenose dolphins (Tursiops truncatus) collected during an 
unusual mortality event in the Gulf of Mexico, 1990. Archives of Environmental Contamination and Toxicology, 28, 494-499.

Kuiken, T., Bennet, P. M., Allchin, C. R., Kirkwood, J. K., Baker, J. R., Lockyer, C. H., Walton, M. J., \& Sheldrick, M. C. (1994). PCBs, cause of death and body condition in harbor porpoises (Phocoena phocoena) from British waters. Aquatic Toxicology, 28: $13-28$.

Kunito, T.; Nakamura, S.; Ikemoto, T.; Anan, Y.; Kubota, R.; Tanabe, S.; Rosas, F.C.W.; Fillmann, G.; Readman, J.W. (2004). Concentration and subcelllular distribution of trace elements in liver of small cetaceans incidentally caught along the brazilian coast. Marine Pollution Bulletin 49: 574-587.

Lamparelli, M.C., Costa, M.P., Prósperi, V.A., Bevilacqua, J.E., Araújo, R.P.A., Eysink, G.G.J. \& Pompéia, S. (2001). Sistema Estuarino de Santos e São Vicente. Relatório Técnico CETESB, São Paulo, 183p.

Langelier, K. N., Stacey, P. J., Baird, R. W., \& Marchetti, R. (1988). 1987 Strandings in British Columbia. Proceedings of the Joint Conference of the American Association of Zoo Veterinarians, 79-82.

Law, R. J. (1994). Collaborative UK marine mammal project: summary of data produced 1988-1992 (Fisheries Research Technical Report). Lowestoft 97: Ministry of Agriculture Fisheries and Food Directorate of Fisheries Research.

Leonel, J. (2007). Ocorrência de poluentes orgânicos persistentes em Pontoporia blainvillei. Tese de Doutorado. Universidade de São Paulo, Instituto Oceanográfico. São Paulo, 84 p.

Lodi, L.; Siciliano, S. e Capistrano, L. (1987). Primeiro registro de Pontoporia blainvillei (Cetacea, Platanistoidea) no litoral norte do Rio de Janeiro, Brasil. Anais da II Reunião de Trabalho de Especialistas em Mamíferos Aquáticos da América do Sul, Rio de Janeiro, 69-71p.

Lodi, L. \& Capistrano, L. (1990). Capturas acidentais de pequenos cetáceos no litoral norte do Estado do Rio de Janeiro. Biotemas, 3 (1): 47-65.

Lundquist, C.J.; Granek, E.F. (2005). Strategies for successful marine conservation: Integrating socioeconomic, political, and scientific factors. Conservation Biology, 19:1771-1778.

Macleod, W. D.; Brown, D. W.; Friedman, A. J.; Burrows, D. G.; Maynes, O.; Pearce, R. W.; Pearce, R.W.; Wigren, C.A.; Bogar, R.G. (1986). Standard Analytical Procedures of the NOAA National Analytical Facility, 1985-1986. 
Extractable Toxic Organic Components. Second edition, U. S. Department of Commerce, NOAA/NMFS. NOAA Tech. Memo. NMFS F/NWC-92, 121 p.

Marigo, J.; Feijó, E.C.; Oliveira, F.A.F.; Silva, D.C. da; Ruoppolo, V.; Bertozzi, C.P. (2005). Novos registros de Pontoporia blainvillei em Ubatuba, litoral norte de São Paulo e os limites do hiato. IV Encontro Nacional sobre Pesquisa e Conservação de Mamíferos Aquáticos, UNIVALI, Itajaí, Santa Catarina. Pg 38.

Marsili, L. \& Focardi, S. (1996). Organochlorine levels in subcutaneous blubber biopsies of fin whales (Balaenoptera physalus) and striped dolphins (Stenella coeruleoalba) from the Mediterraneas Sea. Environmental Pollution, 91(1):1-9.

Marsili, L., \& Focardi, S. (1997). Chlorinated hydrocarbon (HCB, DDTs and PCBs) levels in cetaceans stranded along the Italian coasts: an overview. Environmental Monitoring and Assessment, 45, 129-180.

Martineau, D.; Béland, P.; Desjardins, C.; Vézina, A. (1985). Pathology, toxicology and effects of contaminants on the population of the Saint Lawrence beluga Delphinapterus leucas, Québec, Canada. ICES: CM, 1985, N: 13.

Martineau, D., Deguise, S., Girard, C., Lagacé, A., Béland, P. (1994). Pathology and toxicology of beluga from the St. Lawrence estuary, Québec, Canada: Past, present and future. Science of Total Environment, 154: 201-215.

McHugh, B.; Law, R.J.; Allchin, C.R., Rogan, E.; Murphy, S.; Foley, M.B.; Glynn, D.; McGovern, E. (2007). Bioaccumulation and enantiomeric profiling of organochlorine pesticides and persistent organic pollutants in the killer whale (Orcinus orca) from British and Irish waters. Marine Pollution Bulletin 54: 1724-1731.

Minh, T. B., Nakata, H., Watanabe, M., Tanabe, S., Miyazaki, N., Je.erson, T. A., Prudente, M., \& Subramanian, A. (2000). Isomer-speci.c accumulation and toxic assessment of polychlorinated biphenyls, including coplanar congeners, in cetaceans from the North Pacific and Asian coastal waters. Archives of Environmental Contamination and Toxicology, 39: 398-410.

Montone, R.C., Taniguchi, S. Inomata, O.N.K.. Weber, R.R., Lara, W.H., \& Toledo, H.H.B. (1998). PCBs and DDTs in krill, penguin and Weddel seal in King George Island, Antarctica. Pesquisa Antártica Brasileira, 3(1): 73-76.

Moreira, L. M. de P. e Siciliano, S. (1991). Northward extension range for Pontoporia blainvillei. IX Biennial Conf. Biol. Mar. Mamm. 5-9 dezembro, 1991. Chicago, EUA. (Resumos). p.48. 
MPESP, Ministério Público do Estado de São Paulo. (2002). Laudo Pericial: Contaminação dos sedimentos e organismos aquáticos do estuário de Santos, São Paulo, SP, 35p.

Murty, A.S. (1986). Toxicity of Pesticides to Fish. CRC Press, 1(5). 178p.

Muir, D.C.G.; Ford, C.A.; Rosenberg, B.R. Norstrom, R.J.; Simon, M.; Beland, P. (1996). Persistent organochlorines in Beluga whales (Delphinapterus leucas) from St Lawrence River Estuary--I. Concentrations and patterns of specific PCBs, chlorinated pesticides and polychlorinated dibenzo-p-dioxins and dibenzofurans. Environmental Pollution 93(2):219-234.

Norstrom, R.J. \& Muir, D.C.G. (1994). Chlorinated hydrocarbon contaminants in arctic marine mammals. The Science of Total Environment, 154: 107-128.

Ott, P.H.; Secchi, E.R.; Moreno, I.B.; Danilewicz, D.; Crespo, E.A.; Bordino, P.; Ramos, R; Di Beneditto, A.P.; Bertozzi, C.P.; Bastida, R.; Zanelatto, R.; Perez, J.E. and Kinas, P.G. (2002). Report of the Working Group on Fishery Interactions. Latin American Journal of Aquatic Mammals (special issue) 1: 55-64.

O’Shea, T. J., \& Brownell, R. L. (1994). Organochlorine and metal contaminants in baleen whales: a review and evaluation of conservation implications. Science of the Total Environment, 154: 179-200.

O’Shea, T. J., Brownell, R. L. Jr., Clark, D. R. Jr., Walker, W. A., Gay, M. L., \& Lamont, T. G. (1980). Organochlorine pollutants in small cetaceans from the Pacific and South Atlantic oceans, November 1968-June 1976. Pesticides Monitoring Journal, 14, 35-46.

Paumgartten, F.J.R.; Crus, C.M.; Chahoud, I.; Palavinskas, R.; Mathar, W. (2000). PCDDs, PCDFs, PCBs, and other organochlorine compounds in human milk from Rio de Janeiro, Brazil. Environmental Research Sect A 83:293-297.

Perez-Macri, G.; Crespo, E.A. (1989). Survey of the franciscana, Pontoporia blainvillei, along the Argentine coast, with a preliminary evaluation of mortality in coastal fisheries. Perrin, W. F.; Brownell, R. L. Jr.; Zhou Kaiya and Liu Jiankang (eds). Biology and Conservation of the River Dolphins. Hong Kong, IUCN: 57-63.

Pinedo, M. C. (1986). Mortalidade de Pontoporia blainvillei, Tursiops gephyreus, Otaria flavescens e Arctocephalus australis na costa do Rio Grande do Sul, Brasil, 19761983. Actas I Reunión de Trabajo de Especialistas en Mamíferos Acuáticos de America del Sur, Buenos Aires, 187-199p. 
Pinedo, M. C.; Praderi, R.and Brownell, R. L. Jr. (1989). Review of the biology and status of the franciscana Pontoporia blainvillei (Gervais e D' Orbigny, 1844). Perrin, W. F.; Brownell, R. L. Jr.; Zhou Kaiya and Liu Jiankang (eds). Biology and Conservation of the River Dolphins. Hong Kong, IUCN: 46-51.

Pinedo, M.C. (1991). Development and variation of the franciscana, Pontoporia blainvillei. Ph. D. Dissertation, University of Califórnia, 406 p.

Praderi, R.; Pinedo, M. C. e Crespo, E. A. (1989). Conservation and managment of Pontoporia blainvillei in Uruguai, Brazil and Argentina. Perrin, W. F.; Brownell R. L. Jr.; Zhou, K.; Jiankang, L. (eds.). Biology and Conservation of River Dolphins. Hong Kong, IUCN: 52-56.

Ramu, K.; Kajiwara, N.; Tanabe, S.; Lam, P.K.S.; Jefferson, T. (2005). Polybrominated diphenyl ethers (PBDEs) and organochlorines in small cetaceans from Hong Kong waters: levels, profiles and distribution. Marine Pollution Bulletin 51: 669-676.

Rawson, A.J., Patten, G.W. Hofmann, S., Pietra, G.G. Johns, L. (1993). Liver abnormalities associated with chronic mercury accumulation in strandede Atlantic bottlenose dolphins. Ecotox. Environ. Safety 25: 41-47.

Reddy, M. (2001). Opportunities for using Navy marine mammals to explore associations between organochlorine contaminants and unfavorable effects on reproduction. The Science of the Total Environment; 274: 171-182.

Reeves, R.R.; Smith, B.D.; Crespo, E.A. and Nortabartolo, G. D. (2003). Dolphins, Whales and Porpoises: 2004-2010 Conservation Action Plan for the World's Cetaceans. IUCN/SSC Cetacean Specialist Group. IUCN, Gland, Switzerland and Cambridge, UK. ix $+139 p p$.

Regalado, N. (2002). Ameaça que vem do solo. A Tribuna, Santos, 22 maio 2002. Caderno A, Seção Local, p.3.

Reijnders, P.J.H. (1980). Organochlorine and heavy metal residues in harbor seal from the Wadden Sea and their possible effects on reproduction. Netherlands Journal of the Sea Research, 14: 30-65.

Reijnders, P.J.H. (1986). Reprodutive failure in commom seals feeding on fish from polluted waters. Nature, 324: 456-457.

Reijnders, P. J. H., \& de Ruiter-Dijkman, E. M. (1995). Toxicological and epidemiological significance of pollutants in marine mammals. In A. S. Blix, L. Walløe, \& Ø Ulltang (Eds.), Whales, seals, fish and man. Amsterdam: Elsevier Science BV. pp. 575-587. 
Reijnders, P.J.H. (1996). Organohalogen and Heavy Metal Contamination in Cetaceans: Observed effects, potential impact and future prospects. In: Simmonds, M.P. \& Hutchinson, J. (Eds). The conservation of whales and dolphins: science and practice. Jonh Wiley \& Sons Ltda, Baffins Lane, Chichester, England. pp. 205-217.

Rosas, F. C. W. \& E. L. A. Monteiro-Filho. (2002). Reproductive Parameters of Pontoporia blainvillei (Cetacea, Pontoporiidae) on the Coast of São Paulo and Paraná States, Brazil. Mammalia, 66 (2): 231-245.

Rosas, F. C. W. (2000). Interações com a pesca, mortalidade, idade, reprodução e crescimento de Sotalia guianensis e Pontoporia blainvillei no litoral sul de São Paulo e norte do Paraná, Brasil. Tese de Doutorado, Universidade do Paraná, Curitiba, Brasil. 145p.

Ross, P. (2002). The role of immunotoxic environmental contaminants in facilitating the emergence of infectious diseases in marine mammals. Human an Ecological Risk Assessment, 8 (2): 277-292.

Safe, S., Safe, L., \& Mullin, M. (1987). Polychlorinated biphenyls: environmental occurrence and analysis. In S. Safe (Ed.), Polychlorinated biphenyls (PCBs): mammalian and environmental toxicology (pp. 1-13). Berlin: Springer-Verlag.

Salata, G. G., Wade, T. L., Sericano, J. L., Davis, J. W., \& Brooks, J. M. (1995). Analysis of Gulf of Mexico bottlenose dolphins for organochlorine pesticides and PCBs. Environmental Pollution, 88, 167-175.

Santos, M. C. O. (1997). Franciscana, Pontoporia blainvillei (Cetacea, Pontoporiidae) ao longo do litoral de São Paulo: a urgência da aplicação de programas adequados de pesquisa e de conservação. Resumos expandidos do VII Congresso Latino Americano sobre Ciências do Mar, Santos. P 405-406.

Schafer, H. A., Gossett, R. W., Ward C. F., \& Westcott, A. M. (1984). Chlorinated hydrocarbons in marine mammals. Southern California Coastal Water Research Project (Biennal Report, 1983-1984).

Secchi, E. R.; Zerbini, A. N.; Bassoi, M.; Dalla Rosa, L.; Moller, L. M. and RochaCampos, C. C. (1997). Mortality of franciscanas, Pontoporia blainvillei, in coastal gillnetting in southern Brazil: period 1994 - 1995. Rep. Int. Whal. Commn. 47: 653658.

Secchi, E. R.; Wang, J. Y.; Murray, B.; Rocha-Campos, C. C. e White B. N. (1998). Population differentiation in the franciscana (Pontoporia blainvillei) from two 
geographic locations in Brazil as determined from mitochondrial DNA control region sequences. Canadian Journal of Zoology, 76: 1622-1627.

Secchi, E. R., Ott, P. H., and Danilewicz, D. (2002). Report of the fourth workshop for the coordinated research and conservation of the franciscana dolphin (Pontoporia blainvillei) in the western South Atlantic. The Latin American Journal of Aquatic Mammals (special issue) 1: 11-20.

Secchi, E.R. \& Wang, J.Y. (2003). Pontoporia blainvillei (Rio Grande do Sul/Uruguay subpopulation). In: IUCN 2007. 2007 IUCN Red List of Threatened Species. $<$ www.iucnredlist.org $>$. (Visitado em 13 Junho 2008).

Secchi, E.R.; Danilewicz, D.; Ott, P.H. (2003). Applying the phylogeographic concept to identify franciscana dolphin stocks: implication to meet management objectivies. Journal of Cetacean Research and Management, 5(1): 61-68.

Sericano, J. L. (1998). Quantitative Determination of Chlorinated Hydrocarbons by Gas Chromatography/ electron capture detection in Geochemical and Environmental Research Group - Standard Operating Procedures, SOP-9810, revision n 1, October $29,1-21$.

Shane, B.S. (1994). Introduction to ecotoxicology. In: Cockerhan, L.G. and Shane, B.S. (Eds) Basic Environmental Toxicology, CRC Press, Boca Raton, pp. 3-10.

Siciliano, S. (1994). Review of small cetaceans and interactions in coastal waters of Brazil. Report of International Whale Committing (special issue 15): 241-250.

Siciliano, S., Di Beneditto, A. P. M., and Ramos, R. M. A. A. (2002). Toninha Pontoporia blainvillei nos Estados do Rio de Janeiro e Espírito Santo, costa sudeste do Brasil: caracterização dos hábitats e fatores de isolamento das populações. Boletim do Museu Nacional, 476: 1-15.

Simões-Lopes, P. C. e Ximenes, A. (1993). Annotated list of the cetaceans of Santa Catarina coastal waters, southern Brazil. Biotemas, 6:67-92.

SMA/CPLEA. (2005). São Paulo (Estado). Secretaria do Meio Ambiente. Coordenadoria de Planejamento Ambiental Estratégico e Educação Ambiental. Zoneamento Ecológico-Econômico - Litoral Norte São Paulo / Secretaria de Estado do Meio Ambiente. Coordenadoria de Planejamento Ambiental Estratégico e Educação Ambiental. - São Paulo: 56p.

Smyth, M., Berrow, S., Nixon, E., \& Rogan, E. (2000). Polychlorinated biphenyls and organochlorines in by-caught harbour porpoises Phocoena phocoena and common 
dolphins Delphinus delphis from Irish coastal waters. Biology and Environment: Proceedings of the Royal Irish Academy, 2: 85-96.

Storelli, M.M. \& Marcotrigiano, G.O. (2000). Persistent organochlorine residues in Risso's dolphins (Grampus griseus) from the Mediterranean Sea (Italy). Marine Pollution Bulletin, 40: 555-558.

Subramanian, A.; Tanabe, S.; Tatsukawa, R.; Saito, S. \& Miyazaki, N. (1987). Reproduction in Testosterone Levels by PCBs and DDE in Dall's Porpoises of northwestern north pacific. Marine Pollution Bulletin, 18(12): 643-646.

Tanabe, S.; Tatsukawa, R.; Tanaka, H.; Maruyama, K.; Miyazaki, N. (1981). Distribution and total burden of chlorinated hydrocarbons in bodies of Striped dolphins (Stenella coeruleoalba). Agricultural and Biological Chemistry, 4(11): 2569-2578.

Tanabe, S., Mori, T., Tatsukawa, R., Myazaki, N. (1983). Global pollution of marine mammals by PCBs, DDTs, and HCHs (BHCs). Chemosphere, 12: 1269-1275.

Tanabe, S., Tatsukawa, R., \& Phillips, D. J. H. (1987) Mussels as bioindicators of PCB pollution: a case study on uptake and release of PCB isomers and congeners in green lipped mussels (Perna viridis) in Hong Kong waters. Environmental Pollution, $47: 41-62$.

Tanabe, S.; Watanabe, S.; Kan, H.; Tatsukawa, R. (1988). Capacity and Mode of PCB Metabolism In Small Cetaceans. Marine Mammal Science, 4 (2): 103-124.

Tanabe, S. \& Tatsukawa, R. (1991). Persistent organochlorine in marine mammals. Jones, K.C.. Organic Contaminants in the Environment: environmental pathways and effects. Chapter 9. Elsevier Applied Scence,. 275-289.

Tanabe, S., \& Tatsukawa, R. (1992). Chemical Modernization and Vulnerability of Cetaceans: Increasing Toxic Threat of Organochlorine Contaminants. C.H. Walker \& D.R. Livingstone (Eds.), Persistent Pollutants In Marine Ecosystems. Oxford. New York, Seoul, Tokyo: Pergamon Press, 161-177.

Tanabe, S., Subramanian, A., Ramesh, A., Kumaran, P. L., Miyazaki, N., \& Tatsukawa, R. (1993). Persistant organochlorine residues in dolphins from the Bay of Bengal, South India. Marine Pollution Bulletin, 26, 311-316.

Tanabe, S.; Iwata,H.; Tatsukawa,R. (1994). Global Contamination by Persistent Organochlorines and Their Ecotoxicological Impact on Marine Mammals. Science of Total Environment, 154:163-177.

Tanabe, S., Madhusree, B., Oeztuerk, A. A., Tatsukawa, R., Miyazaki, N., Oezdamar, E., Aral, O.,Samsun, O., \& Oeztuerk, B. (1997). Persistent organochlorine residues in 
harbour porpoise (Phocoena phocoena) from the Black Sea. Marine Pollution Bulletin, 34(5): 338-347.

Tanabe, S.; Prudente, M.; Mizuno, T.; Hasegawa, J.; Iwata, H. \& Miyazaki, N. (1998). Butyltin contamination in marine mammals from North Pacific and Asian coastal waters. Environmental Science \& Technology, 32(2): 193-198.

Taniguchi, S. (1995). Pesticidas organoclorados e bifenilas policlorados em bivalves ao longo da costa brasileira - International Mussel Watch. Dissertação de Mestrado. Universidade de São Paulo, Instituto Oceanográfico. São Paulo, 65 p.

Tommasi, L.R. (1987). Poluição Marinha No Brasil: Síntese do Conhecimento. Publicação Especial Do Instituto Oceanográfico, Universidade De São Paulo (5): 130.

Tommasi, L.R. (1988). Tendências da Poluição dos Oceanos. Boletim do Instituto Geográfico da Universidade de São Paulo (IG- Usp), 6: 94-98.

UNEP/FAO/IOC/IAEA (1986). Determination of DDTs and PCBs in selected marine organisms by packed column gas cromatography. Reference Methods for Marine Pollution Studies No. 14, Rev. 1, UNEP, 20p.

UNEP/IOC/IAEA/FAO (1989). Contaminant monitoring programmes using marine organisms: Quality Assurance and Good Laboratory Practice. Reference Methods for Marine Pollution Studies No. 57, UNEP, 27p.

USEPA (1988). (United States Environmental Protection Agency). Methoxychlor. Pesticide Fact Sheet No. 187, PB 891386531, Washington, DC, USA.

UNEP (2002). Regionally Based Assessment of Persistent Toxic Substances. Eastern and Western South America Regional Report. UNEP Chemicals 11-13, Switzerland, $102 \mathrm{p}$.

Van Scheppingen, W. B., Verhoeven, A. J. I. M., Mulder, P., Addink, M. J., \& Smeenk, C. (1996). Polychlorinated biphenyls, dibenzo-p-dioxins, and dibenzofurans in harbor porpoises (Phocoena phocoena) stranded on the Dutch coast between 1990 and 1993. Archives of Environmental Contamination and Toxicology, 30: 492-502.

Vetter, W., Luckas, B., Heidemann, G., \& Skirnisson, K. (1996). Organochlorine residues in marine mammals from the northern hemisphere. A consideration of the composition of organochlorine residues in the blubber of marine mammals. Science of the Total Environment, 186: 29-39.

Vorkamp, K.; Riget, F.; Glasius, M.; Pécseli, M.; Lebeuf, M.; Muir, D. (2004). Chlorobenzenes, chlorinated pesticides, coplanar chlorobiphenyls and others 
organochlorine compounds in Greenland biota. Science of the Total Environment, 331: $157-175$.

Wade, T. L.; Cantillo, A. Y. (1994). Use of standards and reference materials in the measurement of chlorinated hydrocarbon residues. Chemistry Workbook. NOAA Technical Memorandum NOS ORCA 77, Silver Spring, Maryland, 59p.

Wei, D.; Kameya, T.; Urano, K. (2007). Environmental management of pesticidal POPs in China: Past, present and future. Environment International, 33: 894-902.

Wells, D. E., Campbell, L. A., Ross, H. M., Thompson, P. M., \& Lockyer, C. H. (1994). Organochlorine residues in harbour porpoise and bottlenose dolphins stranded on the coast of Scotland, 1988-1991. Science of the Total Environment, 151, 77-99.

World Health Organization - WHO (1978). Principles and methods for evaluating the toxicity of chemicals. Part I. Geneva, World Health Organization (Environment Health Criteria 6).

World Health Organization - WHO (1979). DDTs and its derivatives. Environmental Health Criteria, $\mathrm{n}^{\circ} 9$.

Windom, H.L. (1992). Contamination of the marine environment from land-based sources. Marine Pollution Bulletin, 25(1-4): 32-36.

Yogui, G.T. (2002). Ocorrência de compostos organoclorados em mamíferos marinhos da costa de São Paulo (Brasil) e Ilha Rei George (Antártica). Dissertação de Mestrado. Universidade de São Paulo, Instituto Oceanográfico. São Paulo: p.157.

Yogui, G. T.; Santos, M. C. O. \& Montone, R. C. (2003). Chlorinated pesticides and polychlorinated biphenyls in marine tucuxi dolphins (Sotalia fluviatilis) from the Cananéia estuary, Southeastern Brazil. Science of the Total Environment, 312:67-78.

Zanelatto, R.C. (1997). Captura acidental de toninha, Pontoporia blainvillei, (Gervais D’Orbigni, 1844) (Cetacea, Pontoporiidae) no litoral do estado de Paraná, Brasil. Pinedo, M.C., Barreto, A.S. (eds). Anais do $2^{O}$ Encontro sobre Coordenação de Pesquisa e Manejo da Franciscana, FURG, Rio Grande, 22-29p. 
Anexo 1: Planilhas 
Planilha 1 - Concentração de clordanas (CHLs) em ng.g $\mathrm{g}^{-1}$ lipídios na gordura subcutânea de toninhas ( $P$. blainvillei) machos do estado de São Paulo.

\begin{tabular}{|c|c|c|c|c|c|}
\hline Sexo e Maturidade & Num. Tombo & \multirow{2}{*}{\multicolumn{4}{|c|}{ (ng.g ${ }^{-1}$ lipídios) }} \\
\hline \multicolumn{2}{|l|}{ Machos Maduros } & & & & \\
\hline & BP 13 & $<3.1$ & 63.16 & 4.28 & 67.44 \\
\hline & BP 21 & $<3.1$ & 14.54 & $<2.3$ & 14.54 \\
\hline & BP 64 & 13.3 & 22.23 & $<2.3$ & 35.51 \\
\hline & BP 91 & $<3.1$ & $<6.3$ & $<2.3$ & n.d. \\
\hline & BP 103 & $<3.1$ & 10.69 & $<2.3$ & 10.69 \\
\hline & BP 104 & $<3.1$ & 11.91 & $<2.3$ & 11.91 \\
\hline & BP 110 & 9.1 & 40.33 & $<2.3$ & 49.43 \\
\hline & BP 133 & 6.7 & 9.81 & 10.18 & 26.66 \\
\hline & BP 136 & 14.9 & 83.22 & $<2.3$ & 98.09 \\
\hline & BP 157 & $<3.1$ & 15.97 & $<2.3$ & 15.97 \\
\hline Média $(n=10)$ & & 4.4 & 27.2 & $<2.3$ & 33.0 \\
\hline Amplitude & & $3.1-14.9$ & $<6.3-83.22$ & $<2.3-10.18$ & n.d.- 98.09 \\
\hline \multicolumn{6}{|l|}{ Machos Imaturos } \\
\hline \multirow[t]{10}{*}{ Subadultos } & BP 19 & $<3.1$ & $<6.3$ & 48.31 & 48.31 \\
\hline & BP 56 & 6.1 & 18.47 & $<2.3$ & 24.54 \\
\hline & BP 63 & $<3.1$ & 16.07 & $<2.3$ & 16.07 \\
\hline & BP 72 & $<3.1$ & 10.71 & $<2.3$ & 10.71 \\
\hline & BP 75 & $<3.1$ & 32.12 & $<2.3$ & 32.12 \\
\hline & BP 82 & $<3.1$ & 8.42 & $<2.3$ & 8.42 \\
\hline & BP 84 & $<3.1$ & 23.17 & $<2.3$ & 23.17 \\
\hline & BP 85 & 3.4 & 16.62 & $<2.3$ & 20.03 \\
\hline & BP 120 & 8.1 & $<6.3$ & $<2.3$ & 8.12 \\
\hline & BP 125 & $<3.1$ & 12.96 & 2.92 & 15.88 \\
\hline Média $(n=10)$ & & $<3.1$ & 13.9 & 5.1 & 20.7 \\
\hline Amplitude & & $<3.1-8.1$ & $<6.3-32.12$ & $<2.3-48.31$ & $8.12-48.31$ \\
\hline \multirow[t]{10}{*}{ Filhotes } & BP 46 & $<3.1$ & $<6.3$ & $<2.3$ & n.d. \\
\hline & BP 59 & 4.7 & 27.06 & $<2.3$ & 31.77 \\
\hline & BP 66 & $<3.1$ & 20.78 & $<2.3$ & 20.78 \\
\hline & BP 70 & $<3.1$ & 9.63 & 5.06 & 14.69 \\
\hline & BP 80 & $<3.1$ & 10.52 & $<2.3$ & 10.52 \\
\hline & BP 88 & $<3.1$ & $<6.3$ & $<2.3$ & n.d. \\
\hline & BP 94 & $<3.1$ & 20.76 & $<2.3$ & 20.76 \\
\hline & BP 107 & $<3.1$ & $<6.3$ & $<2.3$ & n.d. \\
\hline & BP 112 & $<3.1$ & 8.35 & $<2.3$ & 8.35 \\
\hline & BP 116 & 8.3 & 34.68 & $<2.3$ & 42.94 \\
\hline Média $(n=10)$ & & $<3.1$ & 13.2 & $<2.3$ & 14.98 \\
\hline Amplitude & & $<3.1-8.3$ & $<6.3-34.68$ & $<2.3-5.06$ & n.d. -42.94 \\
\hline
\end{tabular}


Planilha 2 - Concentração de clordanas (CHLs) em ng.g ${ }^{-1}$ lipídios na gordura subcutânea de toninhas ( $P$. blainvillei) fêmeas do estado de São Paulo.

\begin{tabular}{|c|c|c|c|c|c|}
\hline Sexo e Maturidade & Num. Tombo & \multicolumn{4}{|c|}{ (ng.g ${ }^{-1}$ lipídios) } \\
\hline \multicolumn{6}{|l|}{ Fêmeas Maduras } \\
\hline & BP 16 & $<3.1$ & 10.84 & $<2.3$ & 10.84 \\
\hline & BP 43 & $<3.1$ & $<6.3$ & $<2.3$ & n.d. \\
\hline & BP 44 & $<3.1$ & $<6.3$ & $<2.3$ & n.d. \\
\hline & BP 48 & $<3.1$ & $<6.3$ & $<2.3$ & n.d. \\
\hline & BP 50 & $<3.1$ & 27.06 & $<2.3$ & 27.06 \\
\hline & BP 62 & $<3.1$ & $<6.3$ & $<2.3$ & n.d. \\
\hline & BP 93 & $<3.1$ & 10.73 & $<2.3$ & 10.73 \\
\hline & BP 132 & $<3.1$ & $<6.3$ & $<2.3$ & n.d. \\
\hline & BP 137 & $<3.1$ & $<6.3$ & $<2.3$ & n.d. \\
\hline & BP 152 & 6.16 & $<6.3$ & $<2.3$ & 6.16 \\
\hline & BP 153 & $<3.1$ & $<6.3$ & $<2.3$ & n.d. \\
\hline Média $(n=12)$ & & $<3.1$ & $<6.3$ & $<2.3$ & 4.98 \\
\hline Amplitude & & $<3.1-6.16$ & $<6.3-27.06$ & $<2.3$ & n.d. - 27.06 \\
\hline \multicolumn{6}{|l|}{ Fêmeas Imaturas } \\
\hline \multirow[t]{9}{*}{ Subadultos } & BP 22 & $<3.1$ & $<6.3$ & $<2.3$ & n.d. \\
\hline & BP 83 & 13.63 & 18.67 & $<2.3$ & 32.30 \\
\hline & BP 90 & 10.30 & 8.93 & $<2.3$ & 19.23 \\
\hline & BP 101 & 16.36 & 101.64 & 4.8 & 122.82 \\
\hline & BP 102 & 8.13 & 29.10 & $<2.3$ & 37.23 \\
\hline & BP 109 & 4.90 & 10.82 & $<2.3$ & 15.72 \\
\hline & BP 113 & 8.50 & 12.22 & $<2.3$ & 20.71 \\
\hline & BP 124 & 11.46 & 18.96 & $<2.3$ & 30.42 \\
\hline & BP 126 & 4.04 & 7.93 & $<2.3$ & 11.97 \\
\hline Média $(n=9)$ & & 8.59 & 23.14 & $<2.3$ & 32.27 \\
\hline Amplitude & & $<3.1-13.63$ & $<6.3-101.64$ & $<2.3-4.8$ & n.d.- 122.82 \\
\hline \multirow[t]{5}{*}{ Filhotes } & BP 45 & $<3.1$ & 11.79 & $<2.3$ & 11.79 \\
\hline & BP 89 & $<3.1$ & $<6.3$ & $<2.3$ & n.d. \\
\hline & BP 100 & 6.58 & 33.83 & $<2.3$ & 40.41 \\
\hline & BP 108 & $<3.1$ & $<6.3$ & $<2.3$ & n.d. \\
\hline & BP 146 & $<3.1$ & 8.35 & $<2.3$ & 8.35 \\
\hline Média $(n=5)$ & & $<3.1$ & 10.8 & $<2.3$ & 12.1 \\
\hline Amplitude & & $<3.1-6.58$ & $<6.3-33.83$ & $<2.3$ & n.d. - 40.41 \\
\hline
\end{tabular}


Planilha 3 - Concentração de DDTs em ng.g ${ }^{-1}$ lipídios na gordura subcutânea de toninhas (P. blainvillei) machos do estado de São Paulo.

\begin{tabular}{|c|c|c|c|c|c|c|c|c|}
\hline Sexo e Maturidade & Num. Tombo & \multicolumn{7}{|c|}{ (ng.g-1 lipídios) } \\
\hline \multicolumn{9}{|l|}{ Machos Maduros } \\
\hline & BP 13 & 31.2 & 2826.4 & 47.5 & 436.9 & 61.1 & 480.2 & 3883.3 \\
\hline & BP 21 & 15.0 & 1194.1 & 63.0 & 198.0 & $<9.7$ & 193.4 & 1663.6 \\
\hline & BP 64 & 11.9 & 6289.3 & 150.9 & 192.1 & 146.4 & 323.2 & 7113.8 \\
\hline & BP 91 & $<2.8$ & 1311.0 & 33.3 & 105.6 & $<9.7$ & 138.9 & 1588.8 \\
\hline & BP 103 & $<2.8$ & 771.8 & 50.7 & 99.2 & 27.0 & 120.2 & 1068.9 \\
\hline & BP 104 & $<2.8$ & 966.8 & 28.5 & 87.1 & $<9.7$ & 110.6 & 1193.1 \\
\hline & BP 110 & $<2.8$ & 3005.6 & 138.0 & 185.1 & 52.7 & 258.5 & 3639.8 \\
\hline & BP 133 & $<2.8$ & 847.8 & 76.3 & 132.9 & 15.1 & 150.7 & 1222.7 \\
\hline & BP 136 & 18.1 & 5824.0 & 337.0 & 422.2 & 90.6 & 493.6 & 7185.5 \\
\hline & BP 157 & 4.3 & 3042.2 & 80.9 & 101.7 & 32.3 & 199.7 & 3461.0 \\
\hline Média $(n=10)$ & & 8.1 & 2607.9 & 100.6 & 196.1 & 42.5 & 246.9 & 3202.1 \\
\hline Amplitude & & $<2.8-31.2$ & $771.8-6289.3$ & $28.5-337$ & 87.1 - 436.9 & $<9.7-146.4$ & 110.6 - 493.6 & $1068.9-7185.5$ \\
\hline \multicolumn{9}{|l|}{ Machos Imaturos } \\
\hline Subadultos & BP 19 & 23.4 & 2266.1 & 92.5 & 388.9 & 41.9 & 376.3 & 3189.0 \\
\hline & BP 56 & 14.5 & 801.4 & 61.2 & 130.9 & $<9.7$ & 111.9 & 1119.9 \\
\hline & BP 63 & 213.8 & 654.1 & 51.0 & 114.6 & 45.3 & 123.8 & 1202.6 \\
\hline & BP 72 & 9.2 & 1090.0 & 64.6 & 118.7 & 15.3 & 74.7 & 1372.5 \\
\hline & BP 75 & 23.1 & 1251.3 & 105.9 & 194.3 & 18.1 & 80.0 & 1672.8 \\
\hline & BP 82 & 15.3 & 908.1 & 204.6 & 142.6 & 16.4 & 75.2 & 1362.1 \\
\hline & BP 84 & 12.4 & 834.1 & 50.0 & 97.3 & 16.0 & 72.3 & 1082.2 \\
\hline & BP 85 & 6.4 & 910.5 & 38.3 & 105.7 & 18.4 & 119.8 & 1199.1 \\
\hline & BP 120 & 11.7 & 912.4 & 48.2 & 76.0 & 33.0 & 167.1 & 1248.4 \\
\hline & BP 125 & 12.2 & 683.0 & 53.9 & 132.2 & 20.8 & 132.6 & 1034.7 \\
\hline Média $(n=10)$ & & 34.2 & 1031.1 & 77.0 & 150.1 & 22.5 & 133.4 & 1448.3 \\
\hline Amplitude & & $6.45-213.8$ & $654.1-2266.1$ & $38.3-204.6$ & $76-388.9$ & $<9.7-45.3$ & $72.3-376.3$ & $1034.7-3189$ \\
\hline Filhotes & BP 46 & 6.5 & 182.4 & 14.7 & 38.5 & 17.2 & 17.0 & 276.3 \\
\hline & BP 59 & 12.0 & 26.8 & 90.2 & 165.6 & 37.6 & 148.7 & 480.9 \\
\hline & BP 66 & 10.7 & 1258.3 & 56.8 & 75.8 & 15.9 & 165.3 & 1582.7 \\
\hline & BP 70 & $<2.8$ & 404.7 & 31.0 & 57.4 & $<9.7$ & 29.1 & 522.2 \\
\hline & BP 80 & 6.8 & 672.6 & 25.4 & 80.5 & $<9.7$ & 48.4 & 833.5 \\
\hline & BP 88 & 5.0 & 200.5 & 14.6 & 32.2 & $<9.7$ & 28.4 & 280.6 \\
\hline & BP 94 & 9.0 & 976.1 & 41.1 & 111.9 & 19.8 & 115.1 & 1273.1 \\
\hline & BP 107 & 4.7 & 309.1 & 17.9 & 43.4 & $<9.7$ & 53.3 & 428.4 \\
\hline & BP 112 & 7.1 & 408.6 & 27.4 & 78.6 & $<9.7$ & 87.6 & 609.4 \\
\hline & BP 116 & 14.3 & 1548.0 & 80.2 & 238.7 & 34.8 & 225.9 & 2142.0 \\
\hline Média $(n=10)$ & & 7.6 & 598.7 & 39.9 & 92.3 & 12.5 & 91.9 & 842.9 \\
\hline Amplitude & & $<2.8-14.3$ & $26.8-1258.3$ & $14.7-90.2$ & $32.2-238.7$ & $<9.7-37.6$ & $17-225.9$ & $276.3-2142$ \\
\hline
\end{tabular}


Planilha 4 - Concentração de DDTs em ng.g ${ }^{-1}$ lipídios na gordura subcutânea de toninhas (P. blainvillei) fêmeas do estado de São Paulo.

\begin{tabular}{|c|c|c|c|c|c|c|c|c|}
\hline Sexo e Maturidade & Num. Tombo & \multicolumn{7}{|c|}{ (ng.g-1 lipídios) } \\
\hline \multicolumn{9}{|l|}{ Fêmeas Maduras } \\
\hline & BP 16 & 7.0 & 917.8 & 45.4 & 123.5 & 15.5 & 101.3 & 1210.5 \\
\hline & BP 43 & 4.4 & 400.9 & 19.1 & 69.6 & $<9.7$ & 52.8 & 546.8 \\
\hline & BP 44 & 5.2 & 473.7 & 23.2 & 78.9 & $<9.7$ & 55.9 & 637.0 \\
\hline & BP 48 & 87.2 & 242.5 & 74.1 & 45.0 & 20.5 & 50.6 & 519.9 \\
\hline & BP 50 & 438.5 & 1312.6 & 243.4 & 196.4 & 32.3 & 181.6 & 2404.8 \\
\hline & BP 62 & 11.0 & 96.0 & $<9.7$ & $<10.2$ & $<9.7$ & $<7.6$ & 107.1 \\
\hline & BP 93 & 6.9 & 516.0 & 48.0 & 71.2 & $<9.7$ & 58.8 & 700.9 \\
\hline & BP 132 & $<2.8$ & 413.9 & 34.9 & 35.5 & $<9.7$ & 24.3 & 508.6 \\
\hline & BP 137 & $<2.8$ & 101.8 & $<9.7$ & 21.3 & $<9.7$ & 27.2 & 150.4 \\
\hline & BP 152 & $<2.8$ & 313.9 & 26.9 & 26.9 & $<9.7$ & 56.0 & 423.7 \\
\hline & BP 153 & $<2.8$ & 434.1 & 30.6 & 38.9 & $<9.7$ & 69.3 & 572.9 \\
\hline Média $(n=12)$ & & 51.0 & 474.8 & 49.6 & 64.3 & 6.2 & 61.6 & 707.5 \\
\hline Amplitude & & $<2.8-438.5$ & $96-1312.6$ & $<9.7-243.4$ & $<10.2-196.4$ & $<9.7-32.3$ & $<7.6-181.6$ & $150.4-2404.8$ \\
\hline \multicolumn{9}{|l|}{ Fêmeas Imaturas } \\
\hline Subadultos & BP 22 & 8.4 & 815.0 & 31.6 & 121.6 & 14.3 & 61.7 & 1052.6 \\
\hline & BP 83 & 10.9 & 15.1 & 38.3 & 133.2 & 21.7 & 152.6 & 371.8 \\
\hline & BP 90 & 7.2 & 475.3 & 35.5 & 72.1 & 14.9 & 65.2 & 670.2 \\
\hline & BP 101 & 32.8 & 63.8 & 125.3 & 552.5 & 74.0 & 500.9 & 1349.4 \\
\hline & BP 102 & 9.8 & 21.3 & 57.0 & 155.7 & 28.4 & 156.9 & 429.0 \\
\hline & BP 109 & 11.4 & 17.9 & 32.3 & 88.2 & 13.6 & 91.6 & 255.0 \\
\hline & BP 113 & 14.7 & 1056.9 & 103.1 & 115.9 & 38.9 & 187.3 & 1516.8 \\
\hline & BP 124 & 15.0 & 20.2 & 73.6 & 194.3 & 30.8 & 234.2 & 568.1 \\
\hline & BP 126 & 5.9 & 446.9 & 32.6 & 73.2 & $<9.7$ & 79.8 & 638.4 \\
\hline Média (n = 9) & & 12.9 & 325.8 & 58.8 & 167.4 & 26.3 & 170.0 & 761.3 \\
\hline Amplitude & & $5.9-32.8$ & $15.1-1056.9$ & $31.6-125.3$ & $72.1-552.5$ & $<9.7-38.9$ & $61.7-500.9$ & $255-1516.8$ \\
\hline Filhotes & BP 45 & 8.9 & 611.1 & 29.1 & 38.8 & 13.8 & 53.6 & 755.4 \\
\hline & BP 89 & 5.0 & 210.6 & 22.7 & 38.8 & $<9.7$ & 34.6 & 311.7 \\
\hline & BP 100 & 17.4 & 991.6 & 62.3 & 170.2 & 16.0 & 137.8 & 1395.3 \\
\hline & BP 108 & 7.4 & 10.6 & 46.9 & 72.2 & $<9.7$ & 60.4 & 197.4 \\
\hline & BP 146 & 9.5 & 299.1 & 34.7 & 59.6 & $<9.7$ & 37.7 & 440.6 \\
\hline Média $(n=5)$ & & 9.7 & 424.6 & 39.1 & 75.9 & 6.0 & 64.8 & 620.1 \\
\hline Amplitude & & $5.0-17.4$ & 10.6 - 991.6 & $22.7-62.3$ & $38.8-170.2$ & $<9.7-16$ & $34.6-137.8$ & $197.4-1395.3$ \\
\hline
\end{tabular}


Planilha 5 - Concentração de HCHs em ng.g ${ }^{-1}$ lipídios na gordura subcutânea de toninhas (P. blainvillei) machos do estado de São Paulo.

\begin{tabular}{|c|c|c|c|c|c|c|}
\hline Sexo e Maturidade & Num. Tombo & \multicolumn{5}{|c|}{ (ng.g ${ }^{-1}$ lipídios) } \\
\hline \multicolumn{7}{|l|}{ Machos Maduros } \\
\hline & BP 13 & $<2.1$ & 12.90 & $<3.4$ & $<4.4$ & 12.90 \\
\hline & BP 21 & $<2.1$ & $<6.9$ & $<3.4$ & $<4.4$ & n.d. \\
\hline & BP 64 & $<2.1$ & $<6.9$ & $<3.4$ & $<4.4$ & n.d. \\
\hline & BP 91 & $<2.1$ & $<6.9$ & $<3.4$ & $<4.4$ & n.d. \\
\hline & BP 103 & $<2.1$ & $<6.9$ & $<3.4$ & $<4.4$ & n.d. \\
\hline & BP 104 & $<2.1$ & $<6.9$ & $<3.4$ & $<4.4$ & n.d. \\
\hline & BP 110 & $<2.1$ & $<6.9$ & $<3.4$ & $<4.4$ & n.d. \\
\hline & BP 133 & $<2.1$ & $<6.9$ & $<3.4$ & $<4.4$ & n.d. \\
\hline & BP 136 & 5.0 & $<6.9$ & $<3.4$ & $<4.4$ & 5.02 \\
\hline & BP 157 & $<2.1$ & $<6.9$ & $<3.4$ & $<4.4$ & n.d. \\
\hline Média (n = 10) & & $<2.1$ & $<6.9$ & $<3.4$ & $<4.4$ & 1.58 \\
\hline Amplitude & & $<2.1-5$ & $<6.9-12.9$ & $<3.4$ & $<4.4$ & n.d. -12.9 \\
\hline \multicolumn{7}{|l|}{ Machos Imaturos } \\
\hline \multirow[t]{10}{*}{ Subadultos } & BP 19 & $<2.1$ & $<6.9$ & $<3.4$ & $<4.4$ & n.d. \\
\hline & BP 56 & $<2.1$ & 12.31 & 9.1 & $<4.4$ & 21.37 \\
\hline & BP 63 & $<2.1$ & $<6.9$ & $<3.4$ & $<4.4$ & n.d. \\
\hline & BP 72 & $<2.1$ & $<6.9$ & $<3.4$ & $<4.4$ & n.d. \\
\hline & BP 75 & $<2.1$ & $<6.9$ & $<3.4$ & $<4.4$ & n.d. \\
\hline & BP 82 & $<2.1$ & $<6.9$ & $<3.4$ & $<4.4$ & n.d. \\
\hline & BP 84 & $<2.1$ & $<6.9$ & $<3.4$ & $<4.4$ & n.d. \\
\hline & BP 85 & $<2.1$ & $<6.9$ & $<3.4$ & $<4.4$ & n.d. \\
\hline & BP 120 & $<2.1$ & $<6.9$ & $<3.4$ & $<4.4$ & n.d. \\
\hline & BP 125 & $<2.1$ & $<6.9$ & $<3.4$ & $<4.4$ & n.d. \\
\hline Média (n = 10) & & $<2.1$ & $<6.9$ & $<3.4$ & $<4.4$ & 1.76 \\
\hline Amplitude & & $<2.1$ & $<6.9-12.31$ & $<3.4-9.1$ & $<4.4$ & n.d. -21.37 \\
\hline \multirow[t]{10}{*}{ Filhotes } & BP 46 & $<2.1$ & $<6.9$ & $<3.4$ & $<4.4$ & n.d. \\
\hline & BP 59 & $<2.1$ & 8.72 & 7.6 & $<4.4$ & 16.30 \\
\hline & BP 66 & $<2.1$ & $<6.9$ & $<3.4$ & $<4.4$ & n.d. \\
\hline & BP 70 & $<2.1$ & $<6.9$ & $<3.4$ & $<4.4$ & n.d. \\
\hline & BP 80 & $<2.1$ & $<6.9$ & $<3.4$ & $<4.4$ & n.d. \\
\hline & BP 88 & $<2.1$ & 7.85 & $<3.4$ & $<4.4$ & 7.85 \\
\hline & BP 94 & $<2.1$ & $<6.9$ & $<3.4$ & $<4.4$ & n.d. \\
\hline & BP 107 & $<2.1$ & $<6.9$ & $<3.4$ & $<4.4$ & n.d. \\
\hline & BP 112 & $<2.1$ & $<6.9$ & $<3.4$ & $<4.4$ & n.d. \\
\hline & BP 116 & $<2.1$ & $<6.9$ & $<3.4$ & $<4.4$ & n.d. \\
\hline Média (n = 10) & & $<2.1$ & $<6.9$ & $<3.4$ & $<4.4$ & 2.52 \\
\hline Amplitude & & $<2.1$ & $<6.9-8.72$ & $<3.4-7.6$ & $<4.4$ & n.d. -16.3 \\
\hline
\end{tabular}


Planilha 6 - Concentração de HCHs em ng.g ${ }^{-1}$ lipídios na gordura subcutânea de toninhas (P. blainvillei) fêmeas do estado de São Paulo.

\begin{tabular}{|c|c|c|c|c|c|c|}
\hline Sexo e Maturidade & Num. Tombo & \multicolumn{5}{|c|}{ (ng.g ${ }^{-1}$ lipídios) } \\
\hline \multicolumn{7}{|l|}{ Fêmeas Maduras } \\
\hline & BP 16 & $<2.1$ & $<6.9$ & $<3.4$ & $<4.4$ & n.d. \\
\hline & BP 43 & $<2.1$ & $<6.9$ & $<3.4$ & $<4.4$ & n.d. \\
\hline & BP 44 & $<2.1$ & $<6.9$ & $<3.4$ & $<4.4$ & n.d. \\
\hline & BP 48 & $<2.1$ & $<6.9$ & 5.4 & $<4.4$ & 5.42 \\
\hline & BP 50 & $<2.1$ & $<6.9$ & $<3.4$ & $<4.4$ & n.d. \\
\hline & BP 62 & $<2.1$ & $<6.9$ & 8.8 & $<4.4$ & 8.80 \\
\hline & BP 93 & $<2.1$ & $<6.9$ & $<3.4$ & $<4.4$ & n.d. \\
\hline & BP 132 & $<2.1$ & $<6.9$ & $<3.4$ & $<4.4$ & n.d. \\
\hline & BP 137 & $<2.1$ & $<6.9$ & $<3.4$ & $<4.4$ & n.d. \\
\hline & BP 152 & 2.18 & 16.62 & 26.2 & $<4.4$ & 45.69 \\
\hline & BP 153 & $<2.1$ & $<6.9$ & $<3.4$ & $<4.4$ & n.d. \\
\hline Média $(n=12)$ & & $<2.1$ & $<6.9$ & $<3.4$ & $<4.4$ & 5.33 \\
\hline Amplitude & & $<2.1-2.18$ & $<6.9-16.62$ & $<3.4-26.2$ & $<4.4$ & n.d. -45.69 \\
\hline \multicolumn{7}{|l|}{ Fêmeas Imaturas } \\
\hline \multirow[t]{9}{*}{ Subadultos } & BP 22 & $<2.1$ & $<6.9$ & $<3.4$ & $<4.4$ & n.d. \\
\hline & BP 83 & $<2.1$ & $<6.9$ & $<3.4$ & $<4.4$ & n.d. \\
\hline & BP 90 & $<2.1$ & $<6.9$ & $<3.4$ & $<4.4$ & n.d. \\
\hline & BP 101 & $<2.1$ & 10.90 & $<3.4$ & $<4.4$ & 10.90 \\
\hline & BP 102 & $<2.1$ & $<6.9$ & $<3.4$ & $<4.4$ & n.d. \\
\hline & BP 109 & $<2.1$ & $<6.9$ & $<3.4$ & $<4.4$ & n.d. \\
\hline & BP 113 & $<2.1$ & $<6.9$ & $<3.4$ & $<4.4$ & n.d. \\
\hline & BP 124 & $<2.1$ & $<6.9$ & $<3.4$ & $<4.4$ & n.d. \\
\hline & BP 126 & $<2.1$ & $<6.9$ & $<3.4$ & $<4.4$ & n.d. \\
\hline Média $(n=9)$ & & $<2.1$ & $<6.9$ & $<3.4$ & $<4.4$ & 1.12 \\
\hline Amplitude & & $<2.1$ & $<6.9-10.9$ & $<3.4$ & $<4.4$ & n.d. - 10.9 \\
\hline \multirow[t]{5}{*}{ Filhotes } & BP 45 & $<2.1$ & $<6.9$ & $<3.4$ & $<4.4$ & n.d. \\
\hline & BP 89 & $<2.1$ & $<6.9$ & $<3.4$ & $<4.4$ & n.d. \\
\hline & BP 100 & $<2.1$ & $<6.9$ & $<3.4$ & $<4.4$ & n.d. \\
\hline & BP 108 & $<2.1$ & $<6.9$ & $<3.4$ & $<4.4$ & n.d. \\
\hline & BP 146 & $<2.1$ & $<6.9$ & $<3.4$ & $<4.4$ & n.d. \\
\hline Média $(n=5)$ & & $<2.1$ & $<6.9$ & $<3.4$ & $<4.4$ & n.d. \\
\hline Amplitude & & $<2.1$ & $<6.9$ & $<3.4$ & $<4.4$ & n.d. \\
\hline
\end{tabular}


Planilha 7 - Concentração de pesticidas organoclorados (ng.g ${ }^{-1}$ peso úmido) na gordura subcutânea de toninhas (P. blainvillei) machos do estado de São Paulo, SP.

\begin{tabular}{|c|c|c|c|c|c|c|c|}
\hline Sexo e Maturidade & \multicolumn{7}{|c|}{ (ng.g ${ }^{-1}$ peso úmido) } \\
\hline \multicolumn{8}{|l|}{ Machos Maduros } \\
\hline & BP 13 & 65.3 & 2534.7 & 8.42 & 44.02 & 42.9 & 40.5 \\
\hline & BP 21 & 77.3 & 1285.3 & n.d. & 11.23 & 22.4 & 50.2 \\
\hline & BP 64 & 74.8 & 5322.0 & n.d. & 26.57 & 16.0 & 193.5 \\
\hline & BP 91 & 68.3 & 1084.6 & n.d. & n.d. & 9.6 & 52.9 \\
\hline & BP 103 & 77.4 & 827.3 & n.d. & 8.27 & 14.4 & 15.0 \\
\hline & BP 104 & 80.7 & 962.9 & n.d. & 9.61 & 10.2 & 27.1 \\
\hline & BP 110 & 76.0 & 2764.7 & n.d. & 37.55 & 14.8 & 126.9 \\
\hline & BP 133 & 74.3 & 908.7 & n.d. & 19.81 & 21.8 & $<7.4$ \\
\hline & BP 136 & 65.2 & 4685.0 & 3.27 & 63.95 & 33.6 & 163.1 \\
\hline & BP 157 & 80.4 & 2781.5 & n.d. & 12.84 & 8.9 & 105.4 \\
\hline Média (n = 10) & & 74.0 & 2315.67 & 1.17 & 23.29 & 19.5 & 77.4 \\
\hline Amplitude & & $65.2-80.7$ & $827.3-5322.0$ & n.d. -8.42 & n.d - 63.95 & $8.9-42.9$ & $<7.4-193.5$ \\
\hline \multicolumn{8}{|l|}{ Machos Imaturos } \\
\hline Subadultos & BP 19 & 78.9 & 2515.2 & n.d. & 38.11 & 44.7 & 50.9 \\
\hline & BP 56 & 61.7 & 691.2 & 13.19 & 15.14 & 10.3 & 17.5 \\
\hline & BP 63 & 75.3 & 905.4 & n.d. & 12.10 & 8.9 & 34.5 \\
\hline & BP 72 & 79.9 & 1097.1 & n.d. & 8.56 & 17.4 & 11.3 \\
\hline & BP 75 & 70.7 & 1182.1 & n.d. & 22.70 & 21.7 & 18.0 \\
\hline & BP 82 & 78.5 & 1069.9 & n.d. & 6.61 & 15.2 & 9.9 \\
\hline & BP 84 & 76.0 & 822.4 & n.d. & 17.61 & 14.3 & 18.4 \\
\hline & BP 85 & 69.9 & 838.3 & n.d. & 14.01 & 9.9 & 15.1 \\
\hline & BP 120 & 78.1 & 974.8 & n.d. & 6.34 & 8.7 & 24.3 \\
\hline & BP 125 & 79.0 & 817.8 & n.d. & 12.55 & 15.6 & 16.2 \\
\hline Média $(n=10)$ & & 74.8 & 1091.41 & 1.32 & 15.37 & 16.7 & 21.6 \\
\hline Amplitude & & $61.7-79.9$ & $691.2-2515.2$ & n.d. - 13.19 & $6.3-38.11$ & $8.7-44.7$ & $9.9-50.9$ \\
\hline Filhotes & BP 46 & 81.5 & 225.14 & n.d. & n.d. & 5.2 & $<7.4$ \\
\hline & BP 59 & 85.6 & 411.66 & 13.95 & 27.19 & 18.6 & 31.6 \\
\hline & BP 66 & 71.0 & 1123.73 & n.d. & 14.75 & 15.5 & 11.7 \\
\hline & BP 70 & 87.8 & 458.45 & n.d. & 12.90 & 9.2 & 15.4 \\
\hline & BP 80 & 72.8 & 607.11 & n.d. & 7.66 & 6.4 & 26.9 \\
\hline & BP 88 & 88.6 & 248.53 & 6.95 & n.d. & 12.3 & $<7.4$ \\
\hline & BP 94 & 84.6 & 1077.21 & n.d. & 17.57 & 12.6 & 18.0 \\
\hline & BP 107 & 87.9 & 376.59 & n.d. & n.d. & 6.7 & 9.3 \\
\hline & BP 112 & 84.2 & 513.14 & n.d. & 7.03 & 13.9 & 13.0 \\
\hline & BP 116 & 86.5 & 1851.96 & n.d. & 37.13 & 33.7 & 20.1 \\
\hline Média $(n=10)$ & & 83.0 & 689.35 & 2.09 & 23.73 & 13.4 & 14.6 \\
\hline Amplitude & & $71.0-88.6$ & $225.14-1851.96$ & n.d. -13.95 & n.d. -37.13 & $6.4-33.7$ & $<7.4-31.6$ \\
\hline
\end{tabular}


Planilha 8 - Concentração de pesticidas organoclorados (ng.g ${ }^{-1}$ peso úmido) na gordura subcutânea de toninhas (P. blainvillei) fêmeas do estado de São Paulo, SP.

\begin{tabular}{|c|c|c|c|c|c|c|c|}
\hline Sexo e Maturidade & \multicolumn{7}{|c|}{ (ng..$^{-1}$ peso úmido) } \\
\hline \multicolumn{8}{|l|}{ Fêmeas Maduras } \\
\hline & BP 16 & 77.2 & 934.73 & n.d. & 8.37 & 13.6 & 51.4 \\
\hline & BP 43 & 83.5 & 456.76 & n.d. & n.d. & 10.8 & 19.3 \\
\hline & BP 44 & 80.8 & 514.70 & n.d. & n.d. & 12.0 & 21.7 \\
\hline & BP 48 & 85.1 & 442.52 & 4.61 & n.d. & 3.0 & 58.8 \\
\hline & BP 50 & 63.2 & 1518.82 & n.d. & 17.09 & 13.3 & 37.5 \\
\hline & BP 62 & 61.8 & 66.17 & 5.44 & n.d. & $<2.0$ & 43.2 \\
\hline & ВР 93 & 67.7 & 474.72 & n.d. & 7.27 & 8.4 & 15.4 \\
\hline & BP 132 & 73.4 & 373.15 & n.d. & n.d. & 5.4 & 10.9 \\
\hline & BP 137 & 86.9 & 130.71 & n.d. & n.d. & $<2.0$ & 24.8 \\
\hline & BP 152 & 75.6 & 320.30 & 34.54 & 4.66 & 3.3 & 25.4 \\
\hline & BP 153 & 81.2 & 465.14 & n.d. & n.d. & 2.7 & 29.5 \\
\hline Média $(n=12)$ & & 76.0 & 517.98 & 4.05 & 3.40 & 6.6 & 30.7 \\
\hline Amplitude & & $61.8-86.9$ & $66.17-1518.82$ & n.d. -34.54 & n.d. - 17.09 & $<2.0-13.6$ & $10.9-58.8$ \\
\hline \multicolumn{8}{|l|}{ Fêmeas Imaturas } \\
\hline Subadultos & BP 22 & 78.1 & 821.90 & n.d. & n.d. & 11.3 & 23.7 \\
\hline & BP 83 & 76.6 & 284.75 & n.d. & 24.74 & 8.1 & 20.2 \\
\hline & ВР 90 & 77.7 & 520.87 & n.d. & 14.95 & 10.1 & 15.0 \\
\hline & BP 101 & 71.3 & 962.63 & 7.8 & 87.62 & 95.3 & 35.1 \\
\hline & BP 102 & 75.4 & 323.52 & n.d. & 28.07 & 13.8 & 27.3 \\
\hline & BP 109 & 81.6 & 208.20 & n.d. & 12.84 & 7.5 & 32.0 \\
\hline & BP 113 & 77.9 & 1181.52 & n.d. & 16.13 & 17.9 & 19.8 \\
\hline & BP 124 & 74.1 & 420.73 & n.d. & 22.53 & 20.8 & 17.6 \\
\hline & BP 126 & 80.7 & 515.44 & n.d. & 9.66 & 10.1 & 17.1 \\
\hline Média $(\mathrm{n}=9)$ & & 77.1 & 552.21 & 0.86 & 24.06 & 23.0 & 23.0 \\
\hline Amplitude & & 71.3-81.6 & $208.2-1181.52$ & n.d .- 7.8 & n.d. - 87.62 & $7.5-95.3$ & $15-35.1$ \\
\hline Filhotes & BP 45 & 70.3 & 531.26 & n.d. & 8.29 & 10.9 & 8.6 \\
\hline & BP 89 & 68.5 & 213.50 & n.d. & n.d. & 6.1 & 8.2 \\
\hline & BP 100 & 73.8 & 1030.25 & n.d. & 29.84 & 31.0 & 17.1 \\
\hline & BP 108 & 63.8 & 125.92 & n.d. & n.d. & 7.4 & 20.1 \\
\hline & BP 146 & 80.4 & 354.14 & n.d. & 6.71 & 12.3 & $<7.4$ \\
\hline Média $(\mathrm{n}=5)$ & & 71.4 & 451.01 & n.d. & 8.97 & 13.5 & 10.8 \\
\hline Amplitude & & 63.8-80.4 & $125.92-1030.25$ & n.d. & n.d.- 29.84 & $6.1-31$ & $<7.4-20.1$ \\
\hline
\end{tabular}


Planilha 9 - Concentrações individuais dos congêneres de PCBs (ng.g $^{-1}$ lipídios) nas toninhas (P. blainvillei) machos adultos do estado de São Paulo.

\begin{tabular}{|c|c|c|c|c|c|c|c|c|c|c|}
\hline \multirow[b]{2}{*}{ PCBs } & \multicolumn{10}{|c|}{ (ng.g $\mathrm{g}^{-1}$ lipídios) } \\
\hline & BP 13 & BP 21 & BP 64 & BP 91 & BP 103 & BP 104 & BP 110 & BP 133 & BP 136 & BP 157 \\
\hline 8 & 0.84 & 17.27 & n.d. & n.d. & 3.36 & n.d. & 1.16 & 1.78 & 2.52 & 4.73 \\
\hline 18 & 6.34 & n.d. & 2.58 & n.d. & n.d. & 1.59 & 1.84 & 4.95 & 4.49 & 1.95 \\
\hline 31 & 6.83 & 3.71 & 2.14 & 0.98 & 1.94 & 0.77 & 1.45 & 3.42 & 3.73 & 1.44 \\
\hline 28 & 1.85 & 15.89 & 5.17 & 3.69 & 4.72 & 2.52 & 2.49 & 9.38 & 8.73 & 2.13 \\
\hline 33 & n.d. & n.d. & 2.59 & n.d. & 1.56 & n.d. & 1.84 & 3.92 & 4.49 & 0.22 \\
\hline 52 & 53.64 & 171.55 & 98.29 & 35.77 & 63.36 & 25.57 & 243.24 & 79.63 & 617.48 & 38.70 \\
\hline 49 & 127.85 & 84.78 & 32.94 & 1.59 & 3.76 & 11.52 & 47.22 & 49.30 & 13.21 & 8.87 \\
\hline 44 & 24.54 & & 4.80 & 2.31 & 5.52 & 2.81 & 3.70 & 8.33 & 13.94 & 1.28 \\
\hline 74 & 129.45 & 44.50 & 39.47 & 15.84 & 2.38 & 11.15 & 73.96 & 21.85 & 164.63 & 19.89 \\
\hline 70 & 18.80 & 11.74 & 4.65 & 2.58 & 5.57 & 2.52 & 2.40 & 6.30 & 11.47 & 1.54 \\
\hline 66 & 96.14 & 53.25 & 21.95 & 12.88 & 3.87 & 13.84 & 3.19 & 38.52 & 6.24 & 1.43 \\
\hline 95 & 582.53 & 161.63 & 87.79 & 34.97 & 69.95 & 28.60 & 188.77 & 17.75 & 427.24 & 27.72 \\
\hline $56 / 50$ & 7.37 & 28.63 & 1.75 & 1.34 & 2.47 & 2.73 & 1.33 & 3.89 & 4.98 & 1.27 \\
\hline 101 & 1735.95 & 534.97 & 645.12 & 198.83 & 29.92 & 156.99 & 17.73 & 372.28 & 2388.79 & 278.49 \\
\hline 99 & 1213.42 & 435.26 & 68.43 & 177.41 & 266.42 & 14.88 & 963.42 & 344.75 & 2283.47 & 31.15 \\
\hline 97 & 197.96 & 76.75 & n.d. & n.d. & 26.51 & 14.63 & 7.13 & 37.78 & 115.48 & 1.17 \\
\hline 81 & 5.84 & 8.22 & n.d. & n.d. & n.d. & n.d. & 1.99 & n.d. & n.d. & 3.56 \\
\hline 87 & 29.48 & 72.84 & 32.15 & 13.53 & 23.58 & 15.86 & 55.21 & 32.00 & 93.54 & 12.32 \\
\hline 77 & n.d. & n.d. & 1.67 & n.d. & n.d. & n.d. & n.d. & n.d. & n.d. & n.d. \\
\hline 110 & 281.65 & 116.86 & 43.36 & 19.23 & 46.86 & 23.73 & 55.71 & 71.68 & 111.55 & 11.47 \\
\hline 151 & 211.80 & 18.82 & 86.92 & 35.26 & 74.26 & 4.59 & 18.80 & 15.93 & 223.94 & 37.85 \\
\hline 123 & 161.54 & 21.65 & n.d. & n.d. & n.d. & n.d. & 1374.39 & 22.25 & 99.19 & 16.59 \\
\hline 149 & 1128.97 & 425.25 & 127.15 & 155.26 & 214.74 & 13.69 & 929.46 & 374.99 & 251.61 & 281.74 \\
\hline 118 & 1764.79 & 518.83 & 745.13 & 227.38 & 299.17 & 174.17 & 1288.87 & 3.86 & 262.65 & 388.86 \\
\hline 114 & n.d. & n.d. & n.d. & n.d. & n.d. & n.d. & n.d. & n.d. & n.d. & n.d. \\
\hline 153 & 3226.70 & 1465.38 & 447.42 & 826.99 & 841.74 & 562.52 & 317.18 & 155.58 & 721.35 & 1676.31 \\
\hline 132 & 425.44 & 183.28 & 551.28 & 129.61 & 126.18 & 86.19 & 514.43 & 169.12 & 1158.13 & 199.82 \\
\hline 105 & 49.76 & 111.89 & 1.45 & 53.73 & 7.52 & 43.44 & 163.54 & 67.58 & 225.00 & 57.76 \\
\hline 141 & 166.47 & 81.11 & n.d. & n.d. & n.d. & n.d. & 8.75 & n.d. & 165.21 & 25.68 \\
\hline 138 & 281.71 & 1112.13 & 3189.18 & 688.88 & 837.14 & 563.38 & 2922.43 & 979.19 & 7251.69 & 136.84 \\
\hline 158 & 233.59 & 9.86 & 219.29 & 51.97 & 57.86 & 39.51 & 237.52 & 78.66 & 612.84 & 19.75 \\
\hline 126 & 38.70 & 27.12 & 68.24 & 12.85 & 16.00 & 1.57 & 47.65 & 17.88 & 12.83 & 28.49 \\
\hline 187 & 679.83 & 47.31 & 1436.75 & 26.17 & 296.88 & 22.72 & 119.95 & 373.24 & 251.56 & 584.95 \\
\hline 183 & 249.65 & 146.57 & 493.49 & 88.33 & 19.81 & 65.62 & 385.71 & 119.66 & 978.39 & 184.36 \\
\hline 128 & 292.76 & 111.52 & 143.79 & 65.98 & 11.91 & 65.27 & 21.69 & 19.83 & 376.61 & 85.89 \\
\hline 167 & 97.62 & 41.16 & 19.60 & 22.26 & 27.47 & 19.56 & 12.37 & 32.55 & 249.48 & 48.99 \\
\hline 174 & 183.95 & 9.74 & 283.43 & 36.74 & 43.50 & 27.28 & 183.26 & 77.69 & 513.24 & 77.43 \\
\hline 177 & 249.65 & 113.26 & 432.31 & 77.21 & 95.20 & 59.40 & 288.88 & 126.63 & 762.93 & 178.27 \\
\hline 156 & 228.69 & 82.87 & 186.19 & 47.20 & 52.82 & 39.42 & 22.25 & 55.18 & 482.36 & 92.63 \\
\hline 157 & 67.82 & 27.54 & 67.88 & 17.43 & 19.95 & 12.45 & 7.50 & 18.96 & 151.75 & 31.65 \\
\hline 180 & 87.25 & 523.52 & 257.54 & 371.35 & 392.40 & 264.39 & 165.72 & 429.72 & 382.15 & 845.84 \\
\hline 169 & n.d. & n.d. & n.d. & n.d. & n.d. & n.d. & n.d. & n.d. & n.d. & n.d. \\
\hline 170 & 52.15 & 288.86 & 182.30 & 195.53 & 229.54 & 153.65 & 844.46 & 262.65 & 225.25 & 451.94 \\
\hline 199 & 81.55 & 61.22 & 22.93 & 4.96 & n.d. & n.d. & 16.55 & 49.51 & 379.42 & 79.85 \\
\hline 203 & 75.74 & 74.98 & 214.74 & 37.22 & 51.23 & 27.18 & 186.58 & 37.89 & 43.73 & 78.85 \\
\hline 189 & 16.52 & n.d. & 34.71 & 7.54 & 8.28 & n.d. & 22.38 & 12.18 & 57.56 & 15.29 \\
\hline 195 & 27.98 & 38.39 & 71.62 & 13.78 & 16.90 & 12.69 & 67.45 & 15.47 & 147.82 & 31.95 \\
\hline 194 & 6.68 & 63.16 & 233.17 & 43.87 & 43.26 & 33.65 & 191.33 & 45.42 & 435.48 & 87.64 \\
\hline 206 & 17.56 & 3.45 & 48.58 & 13.37 & 14.64 & 5.28 & 62.30 & 12.19 & 116.76 & 19.16 \\
\hline 209 & 14.80 & 39.99 & 37.99 & 9.53 & 11.36 & 5.63 & 83.78 & 9.28 & 12.24 & 13.96 \\
\hline$\sum$ PCBs & 19470 & 8122 & 18903 & 4057 & 4946 & 3099 & 19177 & 6155 & 42185 & 7770 \\
\hline
\end{tabular}


Planilha 10 - Concentrações individuais dos congêneres de PCBs (ng.g ${ }^{-1}$ lipídios) nas toninhas (P. blainvillei) machos subadultos do estado de São Paulo.

\begin{tabular}{|c|c|c|c|c|c|c|c|c|c|c|}
\hline \multirow[b]{2}{*}{ PCBs } & \multicolumn{10}{|c|}{ (ng. $\mathrm{g}^{-1}$ lipídios) } \\
\hline & BP 19 & BP 56 & BP 63 & BP 72 & BP 75 & BP 82 & BP 84 & BP 85 & BP 120 & BP 125 \\
\hline 8 & 2.27 & 38.30 & 8.46 & 3.20 & 1.49 & 4.14 & 3.95 & 0.86 & 7.58 & 12.45 \\
\hline 18 & 6.88 & 6.61 & 1.45 & 2.55 & 5.43 & 0.89 & 1.95 & 1.54 & 2.56 & 4.36 \\
\hline 31 & 6.24 & 2.33 & 3.75 & 1.61 & 3.69 & 4.14 & 1.29 & 1.42 & 1.96 & 1.78 \\
\hline 28 & 9.57 & 11.75 & 12.90 & 4.94 & 1.13 & 11.75 & 6.38 & 5.24 & 13.24 & 8.49 \\
\hline 33 & n.d. & n.d. & 1.28 & 0.96 & n.d. & 1.18 & n.d. & n.d. & n.d. & 1.87 \\
\hline 52 & 375.92 & 96.21 & 75.63 & 127.17 & 227.15 & 116.20 & 77.87 & 75.65 & 34.52 & 64.25 \\
\hline 49 & 1.43 & 63.23 & 43.54 & 36.85 & 116.67 & 54.45 & 31.19 & 27.86 & 21.29 & 45.13 \\
\hline 44 & 17.38 & 8.13 & n.d. & n.d. & 14.63 & 9.92 & 4.22 & 2.87 & 4.44 & 8.73 \\
\hline 74 & 96.65 & 23.92 & 23.84 & 38.46 & 57.95 & 3.59 & 26.85 & 25.22 & 13.89 & 2.54 \\
\hline 70 & 17.64 & 8.37 & 6.38 & 3.35 & 7.37 & 6.66 & 3.38 & 3.95 & 2.60 & 9.72 \\
\hline 66 & 68.28 & 51.23 & 35.29 & 31.59 & 59.99 & 44.24 & 28.28 & 28.15 & 17.33 & 35.84 \\
\hline 95 & 434.87 & 12.67 & 75.32 & 14.47 & 232.85 & 126.72 & 76.27 & 72.43 & 4.42 & 96.17 \\
\hline $56 / 50$ & 9.74 & n.d. & n.d. & 3.73 & 3.64 & 4.65 & 5.24 & 2.88 & 2.72 & 4.72 \\
\hline 101 & 131.38 & 398.15 & 286.34 & 479.35 & 78.62 & 434.16 & 324.84 & 322.85 & 182.34 & 296.63 \\
\hline 99 & 915.24 & 368.14 & 263.31 & 48.79 & 552.16 & 385.20 & 277.92 & 278.81 & 173.51 & 264.39 \\
\hline 97 & 147.62 & 39.54 & 27.28 & 3.49 & 76.12 & 43.46 & 26.20 & 24.73 & 19.56 & 34.34 \\
\hline 81 & 6.86 & 15.34 & n.d. & 1.59 & n.d. & 2.89 & 1.26 & 1.34 & 3.94 & 4.87 \\
\hline 87 & 153.93 & 34.58 & 25.97 & 29.20 & 71.38 & 37.58 & 26.19 & 29.32 & 18.67 & 3.69 \\
\hline 77 & 12.46 & n.d. & n.d. & n.d. & n.d. & n.d. & n.d. & n.d. & n.d. & n.d. \\
\hline 110 & 21.65 & 89.90 & 44.59 & 34.90 & 148.60 & 82.73 & 39.91 & 4.58 & 37.74 & 81.33 \\
\hline 151 & 155.83 & 19.37 & 64.18 & 66.54 & 154.92 & 88.60 & 59.78 & 6.15 & 44.70 & 88.77 \\
\hline 123 & 73.66 & n.d. & 2.97 & n.d. & 41.96 & 24.22 & 16.26 & n.d. & n.d. & n.d. \\
\hline 149 & 858.94 & 327.39 & 22.49 & 252.95 & 632.62 & 371.12 & 196.68 & 197.54 & 167.83 & 284.62 \\
\hline 118 & 1314.29 & 348.47 & 283.62 & 536.92 & 595.91 & 393.33 & 349.59 & 34.65 & 185.12 & 234.43 \\
\hline 114 & n.d. & n.d. & n.d. & n.d. & n.d. & n.d. & n.d. & n.d. & n.d. & n.d. \\
\hline 153 & 2454.13 & 156.27 & 931.66 & 134.26 & 1645.48 & 1129.37 & 751.25 & 757.15 & 632.74 & 834.32 \\
\hline 132 & 37.33 & 11.23 & 72.31 & 144.14 & 146.28 & 77.52 & 47.25 & 128.39 & 1.48 & 156.22 \\
\hline 105 & 32.59 & 84.80 & 67.53 & 17.65 & 121.49 & 85.59 & 81.36 & 81.55 & 43.29 & 58.42 \\
\hline 141 & n.d. & 55.93 & n.d. & 37.39 & 97.95 & 51.14 & n.d. & 35.92 & n.d. & 53.18 \\
\hline 138 & 219.60 & 93.81 & 7.35 & 12.23 & 1485.90 & 136.15 & 757.17 & 723.34 & 582.00 & 721.74 \\
\hline 158 & 218.49 & 7.23 & 52.87 & 87.38 & 11.62 & 81.29 & 59.96 & 62.34 & 4.55 & 56.53 \\
\hline 126 & 31.53 & 17.87 & 13.84 & 15.21 & 25.95 & 16.82 & 12.20 & 1.81 & 1.27 & 13.34 \\
\hline 187 & 546.72 & 333.35 & 286.62 & 265.62 & 476.15 & 287.94 & 26.43 & 215.29 & 194.49 & 256.57 \\
\hline 183 & 21.12 & 113.13 & 93.67 & 85.76 & 167.46 & 11.49 & 64.86 & 67.26 & 6.58 & 83.47 \\
\hline 128 & 235.42 & 11.82 & 75.95 & 18.34 & 151.37 & 15.86 & 86.98 & 87.83 & 59.48 & 8.19 \\
\hline 167 & 74.65 & 25.37 & 25.92 & 32.85 & 45.78 & 3.54 & 24.15 & 21.55 & 17.11 & 21.22 \\
\hline 174 & 148.27 & 61.59 & 4.63 & 41.50 & 15.78 & 62.97 & 34.45 & 34.42 & 32.94 & 52.54 \\
\hline 177 & 24.60 & 15.52 & 87.95 & 89.54 & 141.71 & 91.87 & 64.94 & 67.83 & 58.23 & 81.12 \\
\hline 156 & 18.13 & 54.17 & 52.22 & 7.17 & 92.25 & 62.14 & 48.15 & 45.24 & 36.35 & 43.88 \\
\hline 157 & 49.64 & 2.25 & 15.82 & 22.92 & 29.53 & 2.14 & 16.59 & 15.53 & 11.49 & 15.17 \\
\hline 180 & 687.49 & 415.98 & 366.21 & 338.80 & 623.93 & 371.16 & 264.75 & 26.61 & 238.34 & 328.46 \\
\hline 169 & n.d. & n.d. & n.d. & n.d. & n.d. & n.d. & n.d. & n.d. & n.d. & n.d. \\
\hline 170 & 433.46 & 242.87 & 23.14 & 28.81 & 351.30 & 222.84 & 163.25 & 159.11 & 143.18 & 183.44 \\
\hline 199 & 64.32 & 47.91 & 43.54 & n.d. & n.d. & n.d. & n.d. & 26.14 & 22.67 & 34.43 \\
\hline 203 & 61.49 & 43.56 & 5.60 & 29.49 & 6.45 & 33.85 & 22.55 & 26.62 & 23.91 & 48.99 \\
\hline 189 & 14.26 & 8.67 & n.d. & 6.30 & 9.89 & 5.97 & 4.47 & 5.76 & n.d. & 6.17 \\
\hline 195 & 27.67 & 19.59 & 21.19 & 13.79 & 29.52 & 11.36 & 11.24 & 1.84 & 1.46 & 12.36 \\
\hline 194 & 57.61 & 46.76 & 41.24 & 3.24 & 66.68 & 31.43 & 23.15 & 24.76 & 25.89 & 34.11 \\
\hline 206 & 14.92 & 14.45 & 15.55 & 8.18 & 16.87 & 8.56 & 7.40 & 5.27 & 8.16 & 9.85 \\
\hline 209 & 15.73 & 14.87 & 16.38 & 7.26 & 15.57 & 6.63 & 4.74 & 4.34 & 5.94 & 9.59 \\
\hline$\sum$ PCBs & 14745 & 6128 & 4777 & 5931 & 9689 & 6154 & 4281 & 4418 & 3351 & 4826 \\
\hline
\end{tabular}


Planilha 11 - Concentrações individuais dos congêneres de PCBs (ng.g $^{-1}$ lipídios) nas toninhas (P. blainvillei) machos filhotes do estado de São Paulo.

\begin{tabular}{|c|c|c|c|c|c|c|c|c|c|}
\hline \multirow[b]{2}{*}{ PCBs } & \multicolumn{9}{|c|}{ (ng.g ${ }^{-1}$ lipídios) } \\
\hline & BP 46 & BP 59 & BP 66 & BP 70 & BP 88 & BP 94 & BP 107 & BP 112 & BP 116 \\
\hline 8 & 0.64 & 2.94 & n.d. & 0.38 & 9.22 & 8.98 & 4.29 & n.d. & n.d. \\
\hline 18 & n.d. & 1.89 & n.d. & 1.98 & 8.63 & 6.36 & 13.60 & 12.17 & 6.37 \\
\hline 31 & 3.57 & 1.92 & 1.20 & 0.39 & 2.46 & 2.69 & 5.26 & 6.54 & 4.49 \\
\hline 28 & 1.72 & 5.24 & 4.68 & 7.44 & 9.50 & 11.57 & 16.28 & 27.48 & 14.47 \\
\hline 33 & n.d. & 1.53 & n.d. & 1.59 & 2.92 & 2.16 & 3.71 & 6.22 & n.d. \\
\hline 52 & 14.29 & 124.19 & 115.69 & 42.54 & 19.61 & 93.46 & 28.69 & 48.93 & 2.98 \\
\hline 49 & 13.49 & 56.78 & 48.34 & 18.23 & 16.11 & 43.63 & 15.17 & 29.37 & 93.15 \\
\hline 44 & n.d. & 5.50 & 5.91 & 4.29 & 3.61 & 8.46 & 6.63 & 6.76 & 8.74 \\
\hline 74 & 4.11 & 38.75 & 36.42 & 14.26 & 6.58 & 29.85 & 9.28 & 14.73 & 56.22 \\
\hline 70 & 3.85 & 4.97 & 5.15 & 5.48 & 5.77 & 6.87 & 5.29 & 6.44 & 7.88 \\
\hline 66 & 11.22 & 4.99 & 38.42 & 18.50 & 13.89 & 39.30 & 14.96 & 27.76 & 61.46 \\
\hline 95 & 23.72 & 141.28 & 96.84 & 4.32 & 26.62 & 96.54 & 33.26 & 58.39 & 22.32 \\
\hline $56 / 50$ & n.d. & 2.36 & 1.58 & 4.89 & 2.21 & 3.42 & 4.38 & 3.48 & 5.89 \\
\hline 101 & 7.73 & 58.22 & 467.49 & 173.95 & 88.27 & 36.48 & 123.52 & 191.67 & 712.61 \\
\hline 99 & 64.30 & 576.14 & 41.89 & 154.49 & 82.70 & 323.30 & 17.99 & 167.37 & 632.97 \\
\hline 97 & 9.92 & 52.69 & 36.46 & 11.88 & 11.77 & 35.88 & 11.58 & 2.21 & 63.14 \\
\hline 81 & n.d. & 8.32 & n.d. & 1.77 & 2.44 & 3.40 & 4.33 & 5.46 & 6.18 \\
\hline 87 & 1.38 & 45.15 & 33.57 & 12.17 & 11.96 & 34.53 & 12.69 & 2.72 & 54.72 \\
\hline 77 & n.d. & n.d. & n.d. & n.d. & n.d. & n.d. & n.d. & n.d. & n.d. \\
\hline 110 & 28.59 & 77.34 & 57.30 & 21.33 & 29.34 & 71.59 & 25.52 & 47.86 & 98.69 \\
\hline 151 & 2.30 & 11.98 & 8.00 & 38.74 & 28.88 & 7.35 & 31.61 & 53.87 & 129.79 \\
\hline 123 & 2.85 & n.d. & 18.72 & n.d. & n.d. & n.d. & n.d. & n.d. & n.d. \\
\hline 149 & 71.76 & 513.67 & 277.13 & 15.43 & 78.15 & 27.29 & 99.25 & 155.33 & 518.35 \\
\hline 118 & 58.65 & 596.99 & 528.28 & 191.82 & 76.35 & 381.27 & 128.47 & 174.83 & 651.85 \\
\hline 114 & n.d. & n.d. & n.d. & n.d. & n.d. & n.d. & n.d. & n.d. & 12.49 \\
\hline 153 & 187.93 & 156.42 & 115.79 & 516.55 & 237.65 & 951.85 & 372.74 & 532.75 & 1376.40 \\
\hline 132 & 18.94 & 226.93 & 115.44 & 85.42 & 57.44 & 218.70 & 73.17 & 116.27 & 293.29 \\
\hline 105 & 16.99 & 12.94 & 111.57 & 43.16 & 22.44 & 9.98 & 33.26 & 41.68 & 152.25 \\
\hline 141 & n.d. & 58.55 & 45.37 & n.d. & n.d. & 42.86 & 21.11 & 33.97 & 74.25 \\
\hline 138 & 152.76 & 142.22 & 147.44 & 467.12 & 225.88 & 876.32 & 362.18 & 478.60 & 1418.87 \\
\hline 158 & 12.15 & 89.96 & 86.39 & 33.78 & 15.84 & 89.74 & 29.52 & 36.39 & 12.41 \\
\hline 126 & 3.28 & 24.98 & 18.25 & 9.75 & 4.14 & 15.59 & 7.14 & n.d. & 21.79 \\
\hline 187 & 53.59 & 439.67 & 317.27 & 17.75 & 81.37 & 256.65 & 122.54 & 163.29 & 381.83 \\
\hline 183 & 17.92 & 14.87 & 17.56 & 5.49 & 26.64 & 94.12 & 45.47 & 49.88 & 129.23 \\
\hline 128 & 19.61 & 138.68 & 132.38 & 6.52 & 33.38 & 12.39 & 42.15 & 57.75 & 152.68 \\
\hline 167 & 6.17 & 44.84 & 33.92 & 16.97 & 7.77 & 26.12 & 12.93 & 16.32 & 44.55 \\
\hline 174 & 11.28 & 89.58 & 47.46 & 24.67 & 14.18 & 48.74 & 2.55 & 31.33 & 81.88 \\
\hline 177 & 17.18 & 149.67 & 97.56 & 52.45 & 27.75 & 82.42 & 38.82 & 51.97 & 134.25 \\
\hline 156 & 8.97 & 84.34 & 38.17 & 38.56 & 14.77 & 62.52 & 26.91 & 33.66 & 93.82 \\
\hline 157 & 3.36 & 31.66 & 25.92 & 12.71 & 4.89 & 18.57 & 9.66 & 1.50 & 3.37 \\
\hline 180 & 57.89 & 527.14 & 425.74 & 216.71 & 96.36 & 339.77 & 167.29 & 21.75 & 471.39 \\
\hline 169 & n.d. & n.d. & n.d. & n.d. & n.d. & n.d. & n.d. & n.d. & n.d. \\
\hline 170 & 34.17 & 326.94 & 247.83 & 125.95 & 56.22 & 25.56 & 97.95 & 122.14 & 294.42 \\
\hline 199 & n.d. & 54.65 & 39.96 & n.d. & n.d. & 32.74 & n.d. & n.d. & 4.53 \\
\hline 203 & 7.96 & 46.16 & 52.37 & 24.79 & n.d. & 32.98 & 38.16 & 35.83 & 42.72 \\
\hline 189 & n.d. & 7.72 & 6.46 & 5.18 & n.d. & 4.73 & n.d. & 4.74 & 8.96 \\
\hline 195 & n.d. & 22.37 & 18.46 & 1.95 & 3.74 & 13.83 & 7.16 & 11.13 & 16.65 \\
\hline 194 & n.d. & 51.39 & 47.83 & 29.65 & 8.54 & 29.98 & 15.77 & 24.64 & 37.00 \\
\hline 206 & n.d. & 12.54 & 13.62 & 9.57 & 2.68 & 8.54 & 3.54 & 7.93 & 8.86 \\
\hline 209 & n.d. & 1.58 & 13.82 & 7.79 & 2.45 & 5.70 & 3.59 & 5.43 & 4.67 \\
\hline$\sum$ PCBs & 1043 & 8660 & 6495 & 2834 & 1480 & 5551 & 2290 & 3160 & 8971 \\
\hline
\end{tabular}


Planilha 12 - Concentrações individuais dos congêneres de PCBs (ng.g ${ }^{-1}$ lipídios) nas toninhas (P. blainvillei) fêmeas adultas do estado de São Paulo.

\begin{tabular}{|c|c|c|c|c|c|c|c|c|c|c|c|}
\hline \multirow[b]{2}{*}{ PCBs } & \multicolumn{11}{|c|}{ (ng. $g^{-1}$ lipídios) } \\
\hline & $\mathrm{BP} 16$ & BP 43 & BP 44 & $\mathrm{BP} 48$ & BP 50 & $\mathrm{BP} 62$ & BP 93 & BP 132 & BP 137 & BP 152 & BP 153 \\
\hline 8 & 1.63 & 0.98 & 1.42 & 6.57 & 3.83 & 21.70 & 2.47 & 9.25 & 7.20 & 36.75 & 12.25 \\
\hline 18 & 4.45 & 2.36 & 3.33 & n.d. & 6.97 & n.d. & n.d. & 6.14 & n.d. & 1.52 & n.d. \\
\hline 31 & 1.30 & 0.77 & 0.22 & 2.15 & 8.22 & 32.33 & 1.17 & 5.74 & 0.69 & 5.45 & 1.19 \\
\hline 28 & 6.93 & 3.45 & 2.45 & 1.19 & 18.65 & 39.23 & 4.27 & 22.24 & 1.42 & 9.67 & 4.85 \\
\hline 33 & n.d. & 1.52 & 0.79 & n.d. & n.d. & 7.98 & n.d. & 12.47 & n.d. & 5.62 & n.d. \\
\hline 52 & 78.96 & 32.74 & 34.42 & 24.15 & 144.52 & 3.66 & 51.69 & 37.78 & 1.56 & 11.15 & 15.42 \\
\hline 49 & 25.42 & 16.54 & 2.48 & 14.99 & 76.65 & 2.14 & 3.15 & 2.78 & 1.22 & 5.97 & 7.17 \\
\hline 44 & 4.71 & 2.26 & 3.73 & 4.50 & 7.62 & n.d. & 3.65 & 15.41 & n.d. & 0.71 & 1.18 \\
\hline 74 & 3.78 & 12.15 & 12.15 & 1.79 & 42.80 & 2.43 & 16.77 & 12.46 & 0.98 & 4.35 & 7.56 \\
\hline 70 & 3.29 & 2.48 & 4.00 & 4.25 & 7.43 & 0.37 & 3.84 & 12.54 & 0.63 & 1.85 & 1.39 \\
\hline 66 & 26.88 & 17.51 & 18.56 & 13.88 & 52.69 & 3.92 & 23.86 & 14.96 & 0.86 & 6.36 & 7.56 \\
\hline 95 & 82.55 & 34.93 & 35.64 & 3.18 & 172.17 & 5.87 & 65.38 & 33.60 & 1.55 & 14.42 & 17.83 \\
\hline $56 / 50$ & 2.12 & 1.93 & 2.15 & 2.77 & 4.16 & n.d. & n.d. & 7.14 & n.d. & 0.57 & 0.91 \\
\hline 101 & 352.24 & 137.33 & 143.11 & 112.39 & 566.49 & 17.16 & 235.35 & 118.54 & 7.49 & 82.94 & 19.49 \\
\hline 99 & 33.44 & 121.62 & 124.39 & 95.17 & 524.99 & 13.14 & 237.58 & 1.77 & 7.43 & 88.55 & 114.25 \\
\hline 97 & 3.56 & 12.56 & 13.85 & 14.36 & 61.99 & n.d. & 23.47 & 15.69 & 1.67 & 7.67 & 7.85 \\
\hline 81 & n.d. & 1.53 & n.d. & n.d. & 3.28 & 28.87 & 4.53 & n.d. & 5.34 & 14.22 & 4.40 \\
\hline 87 & 32.19 & 11.84 & 18.90 & 14.31 & 47.33 & 3.24 & 16.48 & 17.23 & 1.96 & 6.96 & 1.86 \\
\hline 77 & n.d. & n.d. & 0.99 & n.d. & n.d. & n.d. & n.d. & n.d. & n.d. & n.d. & n.d. \\
\hline 110 & 36.18 & 22.76 & 32.80 & 32.87 & 97.44 & 2.56 & 38.93 & 23.86 & 2.25 & 9.68 & 11.29 \\
\hline 151 & 56.96 & 28.27 & 33.62 & 3.70 & 113.59 & 4.84 & 62.87 & 33.43 & 3.34 & 26.67 & 3.54 \\
\hline 123 & 9.84 & 8.68 & 14.64 & 8.68 & 44.54 & 2.76 & n.d. & 8.25 & n.d. & n.d. & 6.37 \\
\hline 149 & 241.96 & 92.20 & 99.29 & 115.39 & 514.90 & 16.55 & 21.42 & 143.59 & 7.98 & 15.28 & 121.27 \\
\hline 118 & 42.47 & 151.26 & 158.17 & 111.18 & 542.00 & 15.19 & 218.24 & 113.30 & 8.59 & 96.25 & 123.59 \\
\hline 114 & n.d. & n.d. & n.d. & n.d. & n.d. & n.d. & n.d. & n.d. & n.d. & n.d. & n.d. \\
\hline 153 & 112.15 & 441.87 & 422.79 & 488.46 & 161.89 & 125.67 & 664.72 & 539.38 & 52.45 & 569.22 & 558.98 \\
\hline 132 & 11.32 & 42.26 & 53.31 & 47.90 & 146.11 & 9.85 & 137.38 & 62.13 & 6.77 & 14.81 & 83.58 \\
\hline 105 & 172.59 & 37.93 & 43.93 & 25.67 & 113.33 & 6.33 & 48.90 & 27.99 & 3.14 & 18.32 & 25.15 \\
\hline 141 & 37.94 & 18.93 & n.d. & n.d. & n.d. & n.d. & n.d. & n.d. & n.d. & 17.96 & n.d. \\
\hline 138 & 866.44 & 338.91 & 344.22 & 366.76 & 1251.29 & 72.86 & 69.77 & 466.68 & 44.48 & 433.41 & 499.23 \\
\hline 158 & 78.83 & 29.36 & 28.18 & 29.12 & 13.22 & 5.60 & 38.42 & 29.92 & 2.85 & 34.54 & 33.88 \\
\hline 126 & 15.55 & 6.39 & 5.93 & 7.58 & 19.70 & 3.58 & 13.82 & 11.54 & n.d. & 11.32 & 11.27 \\
\hline 187 & 338.68 & 121.60 & 119.63 & 186.38 & 464.76 & 63.88 & 255.81 & 21.42 & 3.56 & 243.59 & 246.59 \\
\hline 183 & 122.31 & 41.44 & 4.85 & 76.61 & 154.31 & 23.67 & 89.42 & 62.39 & 1.14 & 79.74 & 8.47 \\
\hline 128 & 87.95 & 4.65 & 42.60 & 39.65 & 124.12 & 1.64 & 75.75 & 48.14 & 5.44 & 38.19 & 46.26 \\
\hline 167 & 33.48 & 11.25 & 12.80 & 14.94 & 41.28 & 1.89 & 18.46 & 15.16 & 2.94 & 16.43 & 17.38 \\
\hline 174 & 5.84 & 17.84 & 17.67 & 31.32 & 92.69 & 4.56 & 37.77 & 35.95 & 3.32 & 29.32 & 32.33 \\
\hline 177 & 19.82 & 38.28 & 34.33 & 48.99 & 145.68 & 14.33 & 8.23 & 56.42 & 6.91 & 63.31 & 69.83 \\
\hline 156 & 77.53 & 27.92 & 24.63 & 29.14 & 84.23 & 6.57 & 38.30 & 27.94 & 3.99 & 33.77 & 38.45 \\
\hline 157 & 24.14 & 9.34 & 9.89 & 11.56 & 29.12 & 2.91 & 14.13 & 11.88 & 1.85 & 12.86 & 13.12 \\
\hline 180 & 457.80 & 157.46 & 152.79 & 284.85 & 559.72 & 99.28 & 316.98 & 256.66 & 49.49 & 354.36 & 354.34 \\
\hline 169 & n.d. & n.d. & n.d. & n.d. & n.d. & n.d. & n.d. & n.d. & n.d. & n.d. & 1.22 \\
\hline 170 & 247.16 & 93.23 & 84.59 & 148.47 & 318.79 & 47.46 & 181.98 & 134.42 & 23.84 & 192.54 & 188.53 \\
\hline 199 & 6.00 & 28.20 & n.d. & 46.74 & 77.00 & n.d. & 38.44 & n.d. & n.d. & 39.14 & 45.26 \\
\hline 203 & 63.47 & 17.30 & 19.91 & 55.98 & 68.35 & 21.52 & 4.85 & 26.64 & n.d. & 45.53 & 35.15 \\
\hline 189 & 1.70 & n.d. & n.d. & n.d. & 9.58 & n.d. & 6.26 & 8.76 & n.d. & 7.73 & 6.27 \\
\hline 195 & 25.71 & 7.55 & 8.70 & 19.95 & 27.12 & 7.91 & 13.57 & 12.75 & 3.82 & 16.30 & 15.11 \\
\hline 194 & 5.17 & 15.30 & 18.79 & 42.95 & 58.45 & 22.89 & 4.93 & 36.23 & 1.78 & 45.73 & 35.52 \\
\hline 206 & 18.80 & 6.63 & 6.44 & 14.79 & 2.68 & 9.54 & 12.99 & 8.53 & 3.57 & 12.98 & 8.14 \\
\hline 209 & 18.84 & 6.12 & 6.21 & 21.24 & 22.12 & 13.73 & 12.47 & 6.17 & 2.13 & 9.78 & 6.77 \\
\hline$\sum$ PCBs & 5932 & 2272 & 2276 & 2687 & 8594 & 797 & 4025 & 2809 & 326 & 2971 & 3068 \\
\hline
\end{tabular}


Planilha 13 - Concentrações individuais dos congêneres de PCBs (ng.g ${ }^{-1}$ lipídios) nas toninhas ( $P$. blainvillei) fêmeas subadultas do estado de São Paulo.

\begin{tabular}{|c|c|c|c|c|c|c|c|c|}
\hline \multirow[b]{2}{*}{ PCBs } & \multicolumn{8}{|c|}{ (ng.g ${ }^{-1}$ lipídios) } \\
\hline & BP 83 & BP 90 & BP 101 & BP 102 & BP 109 & BP 113 & BP 124 & BP 126 \\
\hline 8 & 3.36 & 1.94 & 3.39 & 3.22 & 3.53 & 3.67 & n.d. & n.d. \\
\hline 18 & 3.92 & 3.17 & 5.63 & 3.25 & 3.18 & 1.28 & 4.33 & 1.55 \\
\hline 31 & n.d. & 0.26 & 3.57 & 2.64 & 0.80 & 1.37 & 2.85 & 1.14 \\
\hline 28 & 7.38 & 5.98 & 1.29 & 6.70 & 7.14 & 1.27 & 14.43 & 5.98 \\
\hline 33 & 1.38 & n.d. & 2.92 & n.d. & n.d. & 1.91 & 2.79 & 1.63 \\
\hline 52 & 93.31 & 35.54 & 614.72 & 14.32 & 45.32 & 44.00 & 17.56 & 34.30 \\
\hline 49 & 44.73 & 26.72 & 21.74 & 51.20 & 25.32 & 27.50 & 59.78 & 23.89 \\
\hline 44 & 7.23 & 4.23 & 18.88 & 4.34 & 5.51 & 3.94 & 9.83 & 3.63 \\
\hline 74 & 28.21 & 1.36 & 173.96 & 43.53 & 13.98 & 14.76 & 3.48 & 11.42 \\
\hline 70 & 7.23 & 4.30 & 12.13 & 3.78 & 4.79 & 2.29 & 7.20 & 4.94 \\
\hline 66 & 38.75 & 22.52 & 17.86 & 36.27 & 23.55 & 19.26 & 47.19 & 21.79 \\
\hline 95 & 1.44 & 52.55 & 522.50 & 135.17 & 52.66 & 54.28 & 151.34 & 45.48 \\
\hline $56 / 50$ & 3.30 & 2.26 & 6.55 & 3.47 & 3.14 & 2.67 & 4.12 & 2.18 \\
\hline 101 & 374.39 & 188.55 & 1867.68 & 581.24 & 18.63 & 194.71 & 486.92 & 173.68 \\
\hline 99 & 323.94 & 18.59 & 1496.37 & 468.32 & 143.65 & 196.95 & 44.80 & 173.64 \\
\hline 97 & 39.46 & 2.29 & 147.45 & 52.93 & 21.31 & 2.66 & 5.13 & 17.95 \\
\hline 81 & 2.27 & n.d. & 5.72 & 4.32 & 1.63 & 1.89 & 7.90 & 3.18 \\
\hline 87 & 37.80 & 21.69 & 133.67 & 51.87 & 22.33 & 16.39 & 41.79 & 16.62 \\
\hline 77 & 1.21 & n.d. & n.d. & n.d. & 1.29 & n.d. & n.d. & n.d. \\
\hline 110 & 75.71 & 46.38 & 2.92 & 78.31 & 48.88 & 3.53 & 96.65 & 35.52 \\
\hline 151 & 76.64 & 54.51 & 256.80 & 83.36 & 46.94 & 43.38 & 116.51 & 5.70 \\
\hline 123 & n.d. & n.d. & n.d. & n.d. & n.d. & n.d. & n.d. & n.d. \\
\hline 149 & 296.55 & 173.35 & 144.76 & 48.92 & 134.74 & 164.46 & 474.95 & 153.37 \\
\hline 118 & 365.19 & 167.52 & 1966.48 & 617.62 & 159.54 & 186.63 & 423.20 & 154.69 \\
\hline 114 & n.d. & n.d. & n.d. & n.d. & n.d. & n.d. & n.d. & n.d. \\
\hline 153 & 974.43 & 547.47 & 3625.96 & 1145.63 & 476.34 & 545.14 & 139.23 & 591.22 \\
\hline 132 & 17.40 & 122.18 & 642.27 & 28.83 & 54.78 & 8.88 & 328.52 & 128.86 \\
\hline 105 & 81.56 & 42.78 & 331.48 & 13.86 & 4.47 & 41.67 & 92.20 & 4.63 \\
\hline 141 & 48.22 & 31.33 & 163.79 & 53.99 & 32.12 & n.d. & 67.51 & 3.33 \\
\hline 138 & 94.85 & 498.25 & 35.28 & 1155.79 & 434.93 & 459.32 & 12.53 & 51.75 \\
\hline 158 & 77.46 & 34.13 & 37.32 & 96.73 & 3.60 & 37.44 & 84.88 & 35.90 \\
\hline 126 & 13.67 & 9.69 & 45.42 & 14.81 & 6.68 & 7.97 & 21.28 & 1.34 \\
\hline 187 & 262.16 & 186.55 & 853.57 & 271.14 & 143.65 & 14.27 & 359.75 & 27.65 \\
\hline 183 & 95.89 & 53.93 & 292.36 & 93.34 & 52.98 & 46.14 & n.d. & 64.93 \\
\hline 128 & 97.34 & 58.64 & 339.54 & 16.64 & 51.85 & 52.62 & 126.36 & 58.93 \\
\hline 167 & 26.48 & 12.72 & 98.93 & 34.22 & 14.92 & 12.92 & 35.80 & 15.43 \\
\hline 174 & 49.16 & 34.98 & 196.87 & 59.35 & 22.95 & 25.64 & 82.74 & 32.44 \\
\hline 177 & 79.89 & 6.46 & 3.69 & 89.36 & 37.57 & 44.24 & 119.97 & 59.92 \\
\hline 156 & 57.49 & 29.77 & 234.29 & 71.59 & 3.41 & 26.57 & 78.96 & 31.99 \\
\hline 157 & 19.23 & 11.52 & 67.23 & 24.89 & 9.89 & 9.58 & 23.45 & 12.14 \\
\hline 180 & 34.70 & 22.15 & 164.55 & 341.14 & 23.76 & 171.17 & 455.23 & 257.25 \\
\hline 169 & n.d. & n.d. & n.d. & n.d. & n.d. & n.d. & n.d. & n.d. \\
\hline 170 & 22.96 & 127.55 & 638.69 & 219.96 & 115.20 & 14.89 & 259.63 & 148.68 \\
\hline 199 & 29.63 & 25.53 & 79.39 & 36.44 & 22.33 & n.d. & 61.77 & 32.17 \\
\hline 203 & 31.54 & 2.95 & 82.74 & 27.47 & 24.83 & 17.82 & 51.40 & 29.86 \\
\hline 189 & 4.82 & 3.82 & 16.76 & 5.25 & 3.94 & 5.35 & 7.12 & 4.95 \\
\hline 195 & 14.18 & 11.37 & 37.57 & 14.97 & 1.42 & 8.63 & 16.42 & 14.67 \\
\hline 194 & 28.97 & 27.97 & 72.33 & 29.76 & 23.20 & 2.79 & 41.28 & 36.82 \\
\hline 206 & 6.29 & 8.16 & 14.74 & 7.49 & 7.80 & 5.17 & 8.79 & 11.66 \\
\hline 209 & 5.76 & 6.97 & 11.40 & 6.82 & 5.98 & 4.29 & 7.84 & 9.26 \\
\hline$\sum$ PCBs & 5553 & 3208 & 22181 & 7098 & 2804 & 2829 & 7418 & 3303 \\
\hline
\end{tabular}


Planilha 14 - Concentrações individuais dos congêneres de PCBs (ng.g ${ }^{-1}$ lipídios) nas toninhas (P. blainvillei) fêmeas filhotes do estado de São Paulo.

\begin{tabular}{|c|c|c|c|c|c|}
\hline \multirow[b]{2}{*}{ PCBs } & \multicolumn{5}{|c|}{ (ng.g ${ }^{-1}$ lipídios) } \\
\hline & BP 45 & BP 89 & BP 100 & BP 108 & BP 146 \\
\hline 8 & 2.33 & 4.53 & n.d. & n.d. & 16.22 \\
\hline 18 & 4.99 & n.d. & 13.22 & 7.27 & 6.23 \\
\hline 31 & 0.65 & 1.47 & 9.95 & 2.95 & 3.16 \\
\hline 28 & 4.37 & 3.94 & 37.67 & 9.99 & 11.26 \\
\hline 33 & 1.79 & 1.65 & n.d. & 3.23 & n.d. \\
\hline 52 & 85.64 & 15.30 & 19.38 & 35.97 & 4.86 \\
\hline 49 & 29.33 & 13.15 & 82.85 & 3.20 & 3.49 \\
\hline 44 & n.d. & 1.77 & 21.26 & 5.13 & 7.91 \\
\hline 74 & 26.13 & 5.27 & 54.22 & 12.53 & 1.33 \\
\hline 70 & 3.80 & 3.96 & 18.28 & 5.63 & 5.55 \\
\hline 66 & 21.88 & 12.49 & 64.21 & 24.35 & 23.31 \\
\hline 95 & 8.60 & 23.96 & 184.62 & 46.25 & 55.62 \\
\hline $56 / 50$ & 2.33 & 1.82 & 1.63 & 3.96 & 2.21 \\
\hline 101 & 294.37 & 8.85 & 524.71 & 176.68 & 151.55 \\
\hline 99 & 233.80 & 79.53 & 387.42 & 193.24 & 138.80 \\
\hline 97 & 22.86 & 9.54 & 56.27 & 16.98 & 2.37 \\
\hline 81 & 1.46 & 2.78 & 7.65 & 7.32 & 7.17 \\
\hline 87 & 23.95 & 1.57 & 69.78 & 21.35 & 19.47 \\
\hline 77 & n.d. & n.d. & n.d. & n.d. & n.d. \\
\hline 110 & 38.23 & 24.82 & 137.56 & 4.76 & 46.65 \\
\hline 151 & 38.79 & 25.75 & 124.14 & 54.33 & 41.74 \\
\hline 123 & 14.97 & n.d. & n.d. & n.d. & n.d. \\
\hline 149 & 164.69 & 79.54 & 491.26 & 165.40 & 144.65 \\
\hline 118 & 295.94 & 65.24 & 523.40 & 174.45 & 111.16 \\
\hline 114 & n.d. & n.d. & n.d. & n.d. & n.d. \\
\hline 153 & 51.76 & 289.73 & 144.48 & 639.14 & 362.24 \\
\hline 132 & 56.29 & 43.55 & 192.91 & 156.31 & 146.68 \\
\hline 105 & 64.51 & 18.18 & 116.72 & 47.91 & 31.69 \\
\hline 141 & n.d. & n.d. & 89.86 & n.d. & n.d. \\
\hline 138 & 454.57 & 222.93 & 1271.54 & 562.69 & 356.17 \\
\hline 158 & 42.93 & 15.52 & n.d. & 36.55 & 28.58 \\
\hline 126 & 6.36 & 4.60 & 2.84 & 11.48 & 7.65 \\
\hline 187 & 111.42 & 94.95 & 398.19 & 242.47 & 116.40 \\
\hline 183 & 36.19 & 28.82 & 146.54 & 78.77 & 4.56 \\
\hline 128 & 45.79 & 3.89 & 12.16 & 65.52 & 38.54 \\
\hline 167 & 12.31 & 6.96 & 42.74 & 18.46 & 1.72 \\
\hline 174 & 21.31 & 16.44 & 89.42 & 33.54 & 27.47 \\
\hline 177 & 4.95 & 3.86 & 127.28 & 64.92 & 4.58 \\
\hline 156 & 27.87 & 12.60 & 81.87 & 35.18 & 21.38 \\
\hline 157 & 8.67 & 6.73 & 26.45 & 15.57 & 7.63 \\
\hline 180 & 122.80 & 15.83 & 533.27 & 293.94 & 14.97 \\
\hline 169 & n.d. & n.d. & 1.54 & n.d. & n.d. \\
\hline 170 & 78.66 & 63.96 & 316.15 & 168.42 & 85.13 \\
\hline 199 & 13.20 & n.d. & n.d. & n.d. & 23.99 \\
\hline 203 & 11.86 & n.d. & 68.23 & 48.24 & n.d. \\
\hline 189 & n.d. & 2.42 & 7.83 & n.d. & 3.98 \\
\hline 195 & 6.85 & 6.36 & 21.41 & 17.54 & 6.76 \\
\hline 194 & 8.39 & 11.12 & 47.27 & 42.19 & 14.84 \\
\hline 206 & 3.90 & 3.36 & 12.24 & 15.97 & 5.39 \\
\hline 209 & 4.86 & 3.49 & 8.68 & 13.18 & 3.60 \\
\hline$\sum$ PCBs & 3080 & 1482 & 8152 & 3644 & 2412 \\
\hline
\end{tabular}


ANEXO 2: CROMATOGRAMAS 


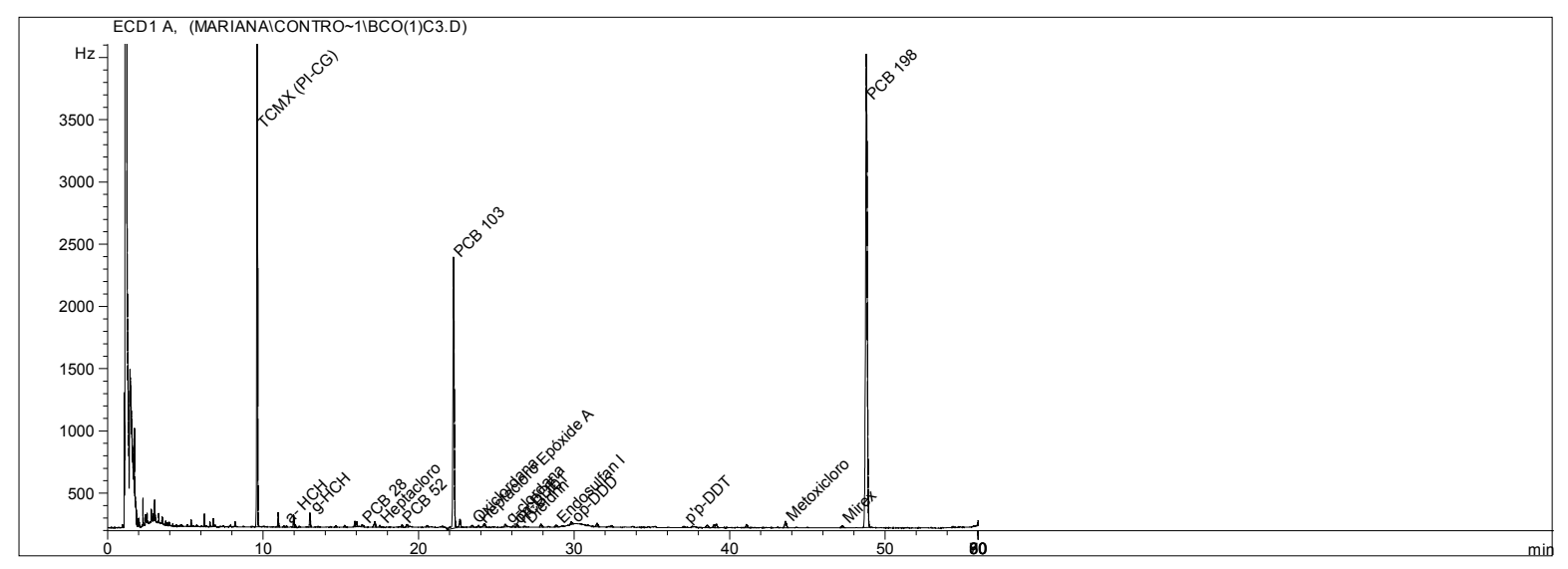

Cromatograma 1. Branco do Controle obtido no GC-ECD.

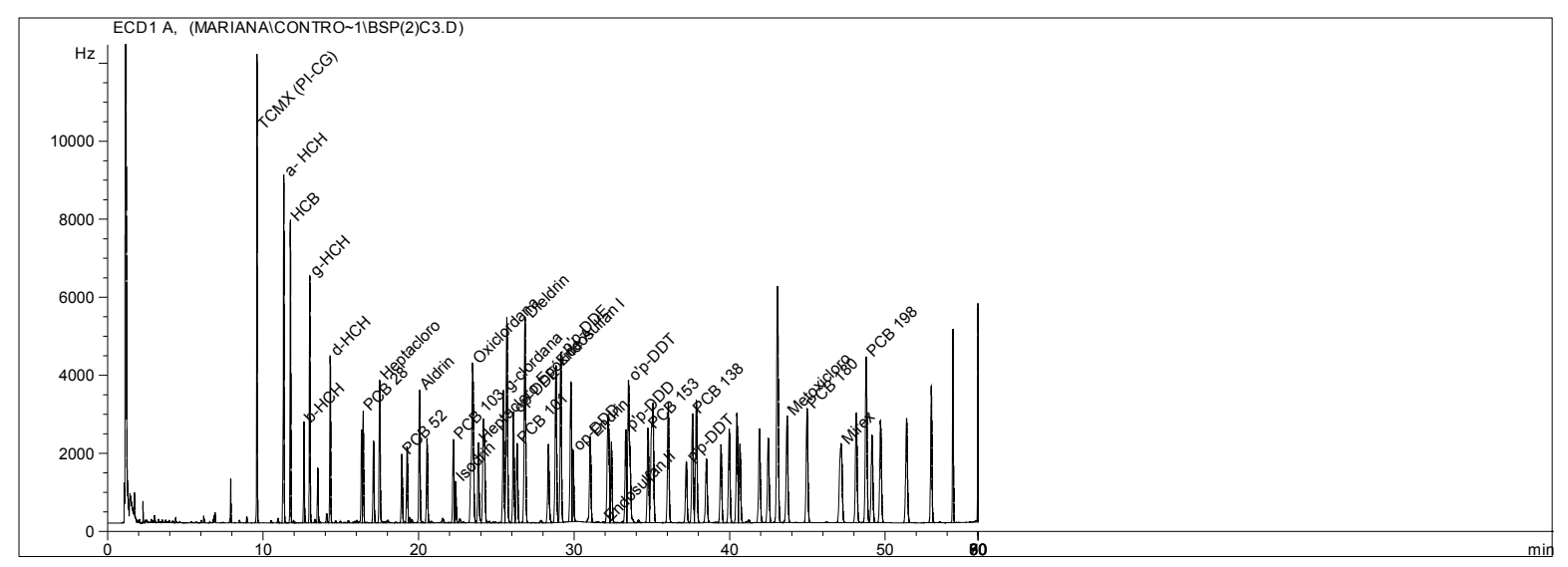

Cromatograma 2. Branco fortificado do Controle obtido no GC-ECD.



Cromatograma 3. Filhote macho da Baixada Santista (BP 66). 